\title{
Role of the microtubulin-associated molecule tau in inflammatory-mediated axonal damage
}

\author{
Dissertation \\ zur Erlangung des Doktorgrades \\ der Mathematisch-Naturwissenschaftlichen Fakultäten \\ der Georg-August-Universität zu Göttingen
}

\author{
Vorgelegt von \\ Philipp Gorlovoy \\ Aus Protvino, Russland
}

Göttingen, 2006 
D7
Referent:
Prof. Dr. Ralf Heinrich
Koreferent:
Prof. Dr. Erwin Neher

Tag der mündlichen Prüfung: 17. Januar 2007 


\section{Table of Contents}

Abbreviations _ 5

Introduction — 7

Neurodegeneration and axonal damage ___ 7

Tau protein ___ 8

Tau phosphorylation __ 10

Tau pathology ___ 11

Technical approach to determine tau interactions ___ 16

Aims of the study _ 19

Material and Methods _ 20

Plasmids construction

Neuronal cultures and transfection __ 20

Neuroblastoma cell line cultures and transfection ___ 21

Immunocytochemistry of primary neurons ___ 21

Immunocytochemistry of TNF receptors I and II____ 22

Immunocytochemistry of total and phosphorylated JNK _ 22

Fluorescence intensity based FRET analysis by photobleaching___ 23

Fluorescence lifetime based FRET analysis by Time-Correlated Single Photon Counting

(TCSPC) _ _ 23

Statistical analysis __ 24

Appendix to Materials and Methods___ 25

Materials ___ 25

Protocols ___ 29

Results__ 38

Expression of designed vectors in primary neurons ___ 38

Intensity based and lifetime based FRET analysis of the fluorescence proteins in neuroblastoma N1E cells ___ 41

Lifetime based FRET analysis of Cerulean in primary neurons ___ 47

FRET between tau-GFP and tubulin-Cy3 in primary neurons transfected with tau-GFP

Phosphorylated JNK in neurites after treatment with TNF- $\alpha$ 59

Lifetime based FRET analysis showed no spontaneous dimerization or polymerization of tau 62

TNF- $\alpha$ induced dimerization / polymerization of tau in neurites 66 
Discussion 70

Why FRET? 70

Cellular model to study tau protein 71

Validation of used cellular model

Mechanism of tau aggregation 73

Role of mediated TNF- $\alpha$ inflammation 73

Involvement of TNF- $\alpha$ in the dimerization / polymerization of tau 74

Pathology of tau and inflammation 75

Summary 77

References 78

Curriculum vitae 86

Acknowledgments 88 


\section{Abbreviations}

AD: alzheimer disease

Cdk5: cyclin-dependent kinase 5

CFP: cyan fluorescent protein

CMV: cytomegalovirus

CNS: central nervous system

ERK: extracellular regulated kinase

FCS: fetal calf serum

FITC: fluoro-isothiocyanate

FLIM: fluorescence lifetime imaging

FRET: förster resonance energy transfer

FTDP-17: frontotemporal dementia with Parkinsonism linked to chromosome 17

GFP: green fluorescent protein

GSK3 $\beta$ : glycogen synthase kinase $3 \beta$

Ig: immunoglobuline

JNK: c-Jun N-terminal kinase

JIP: c-Jun N-terminal kinase interacting protein

MAP: mitogen activated protein

MAPK: mitogen-activated protein kinase

MT: microtubules

$\mathrm{NF}-\kappa \mathrm{B}$ : nuclear factor- $\kappa \mathrm{B}$

NO: nitric oxide

p38: synaptophysin

PBS: phosphate buffered saline

PCR: polymerase chain reaction

PFA: paraformaldehyde

PHF: paired helical filaments

PMT: photomultiplier tubes

PNS: peripheral nervous system

RIP1: receptor interacting protein 1 
SEM: standard error of the mean

TD-FLIM: time-domain fluorescence lifetime imaging microscope

TNF- $\alpha$ : tumor necrosis factor $\alpha$

TNFR1: TNF receptor 1

TRADD: TNF-receptor associated death domain

TRAF2: TNF-receptor associated factor 2

YFP: yellow fluorescent protein 


\section{Introduction}

\section{Neurodegeneration and axonal damage}

Over the past decade investigations revealed a common pathogenic mechanism underlying many neurodegenerative disorders as Alzheimer disease, Parkinson disease and some others. This common mechanism is aggregation and deposition of misfolded proteins leading to progressive central nervous system (CNS) amyloidosis. Thus, highly soluble proteins are gradually converted into insoluble, filamentous polymers that accumulate as deposits in the cytosol nuclei of affected brain cells as well as in the extracellular space (Lee et al. 2001).

In addition to the formation of neurotoxic protein aggregates axonal damage is also a common hallmark of several human CNS diseases. Axons often extend for great distances from their cell bodies of origin, and are therefore susceptible to ischemic or toxic damage in several different vascular territories. Axonal injury involves increased axonal membrane permeability, deleterious intracellular cascades and disturbance of axonal transport and possibly degeneration.

The molecular mechanism of axonal injury in inflammatory brain diseases such as multiple sclerosis (Neumann H., 2003) and synapse loss in neurodegenerative diseases such as Alzheimer's disease (Selcoe et al., 2002) is not known. Several studies observed a close association between the number of activated microglial cells and axonal injury in multiple sclerosis (Bitsch et al., 2000; Peterson et al., 2001), microbial infection (Medana et al., 2002) and brain injury (McGlade-McCulloh et al., 1989). Furthermore, accumulation of $\beta$-amyloid precursor protein (APP), a sign of axonal transport disturbance, is observed in several inflammatory brain diseases including multiple sclerosis (Trapp et al., 1998), microbial infections (Medana et al., 2002; Raja et al., 1997), mechanical injury (Gentleman et al., 1993) and ischemia (Pendlebury, 2000).

There are several indirect mechanisms that can lead to axonal injury. Neuronalglial interactions are important for the maintenance of brain homeostasis and are vital for neuronal survival after brain injury. Death of glia or loss of function of glia, could affect 
the outcome of injured axons (Liu et al., 1999). Glia and invading haematogenous cells may be a source of neurotoxic factors produced in response to infectious agents and / or damage to the neural tissue (Giulian et al., 1993). Cytotoxic T cells (Manning et al., 1987; Medana et al., 2001; reviewed in Neumann et al., 2002), macrophages and microglia have been implicated in the induction of axonal injury (Brueck et al., 1996; Bitsch et al., 2000). Similarly, autoantibodies (Sloviter et al., 1996; Rawes et al., 1997) metalloproteinases (Newman et al., 2001) and other inflammatory mediators, such as tumor necrosis factor and nitric oxide, have also been implicated (Brueck et al., 1996; Giovannoni et al., 1998). Microglial activation is controlled by a positive feedback mechanism - resting microglia can be activated by inflammatory cytokines, which are in turn produced by the microglia themselves - leading to damage of healthy tissue surrounding the site of microglial activation. TNF- $\alpha$ produced by microglia can cause damage during demyelination. Free oxygen radicals released by microglia have a neurotoxic effect in cocultures of neurons and microglia (Thery et al., 1991; Stagi, et al., 2005).

Thus, recognition of the importance of axonal damage has implications both for diagnosis and treatment or prophylaxis of CNS damage in brain diseases.

\section{Tau protein}

The study of sporadic and familial neurodegenerative diseases drive to the conclusion that many of these disorders are characterized by distinct brain lesions that have in common the formation of filamentous deposits of abnormal proteins. Thus, a group of heterogeneous dementias and movement disorders are characterized neuropathologically by prominent intracellular accumulations of abnormal filaments formed by the microtubule-associated protein tau.

Tau localizes predominantly in the cell bodies and axons of neurons. Human tau proteins are encoded by a single gene consisting of 16 exons on chromosome 17, and the CNS isoforms are generated by alternative mRNA splicing of 11 of these exons (Neve et al., 1986, Goedert et al., 1988, Andreadis et al., 1992) (Figure 1). In adult human brain, alternative splicing of exons E2, E3 and E10 generates 6 tau isoforms ranging from 352 to 441 amino acids in length, which differ by the presence of either three (3R-tau) or four 
(4R-tau) carboxy-terminal tandem repeat sequences of either 31 or 32 amino acids (Goedert et al., 1989a,b, Andreadis et al., 1992). In addition, the alternative splicing of tau is developmentally regulated such that only the shortest tau isoform $(3 \mathrm{R} / 0 \mathrm{~N})$ is expressed in fetal brain, whereas all six isoforms appear in the postnatal period of the human brain (Goedert et al., 1989a). In the peripheral nervous system (PNS), there is a high-molecular-weight tau isoform expressing known as "big tau" with an approximate size of $100 \mathrm{kDa}$ (Couchie et al. 1992, Goedert et al. 1992, Nunez et al. 1988).

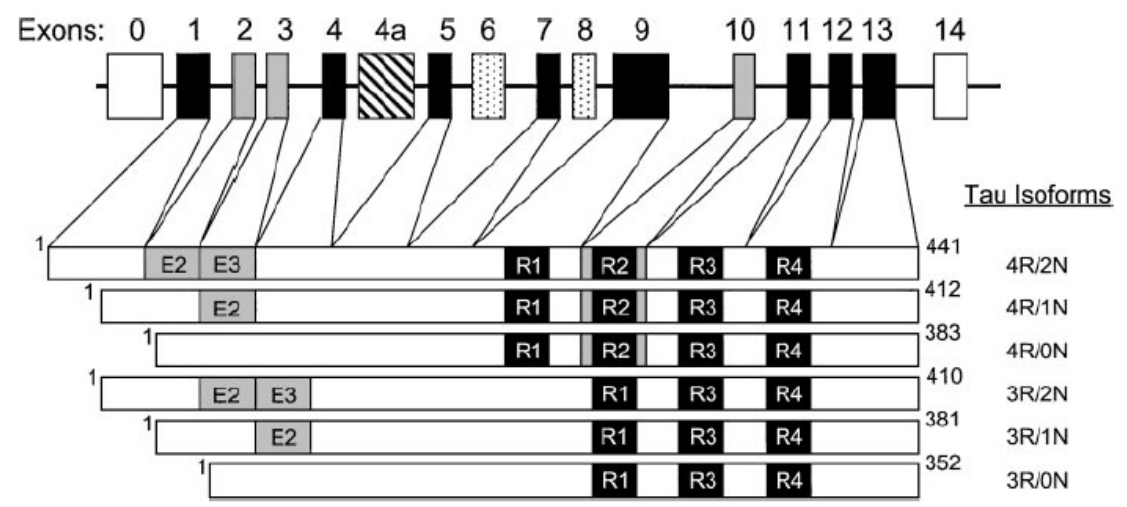

Figure 1. Schematic representation of the human tau gene and the six central nervous system (CNS) tau isoforms generated by alternative mRNA splicing. The human tau gene contains 16 exons, including exon E0, which is part of the promoter. Alternative splicing of E2, E3, and E10 (gray boxes) produces the six tau isoforms. E6 and E8 (stippled boxes) are not transcribed in the human CNS. E4a (striped box), which is also not transcribed in the human CNS, is expressed in the peripheral nervous system, leading to the larger tau isoforms, termed "big tau" (see text). The black bars depict the 18-amino acid microtubule binding repeats and are designated RI to $R 4$. The relative sizes of the exons and introns are not drawn to scale.

Several functions have been attributed to tau: binding to microtubules, stimulation and stabilization of microtubules and the modulation of their dynamics 
(Weingarten et al., 1975, Cleveland et al., 1977, Trinczek et al., 1995). The MT binding domains of tau are localized to the carboxy-terminal half of the molecule within the four MT binding motifs. Sequences flanking the repeats contribute to microtubule binding (Gustke et al., 1994). 4R-tau isoforms are more efficient at promoting MT assembly and have a greater MT binding affinity than do 3R-tau isoforms (Goedert and Jakes 1996, Butner and Kirschner 1991).

Tau is also involved in the establishment of neuronal cell polarity, axon outgrowth and axonal transport (Dawson et al., 2001; Takei et al., 2000). The transport of the vesicles and organelles along the microtubules is supported by motor proteins like kinesin and dynein. Kinesin connects to the cargoes through the association with scaffolding proteins like c-Jun N-terminal kinase interacting proteins (JIP). It was suggested that kinesin and tau compete for the same tubulin binding site.

\section{Tau phosphorylation}

The binding of tau to MT is negatively regulated by phosphorylation. Among the 79 potential serine (Ser) and threonine (Thr) phosphate acceptor residues in the longest tau isoform, 30 have been actually characterized (reviewed in Billingsley \& Kincaid 1997, Buée et al., 2000). These sites are clustered in regions flanking the MT binding repeats. (Drechsel et al. 1992, Bramblett et al. 1993, Yoshida and Ihara1993, Biernat et al. 1993). Embryonic tau is more highly phosphorylated then in adult central nervous system (Kanemaru et al. 1992, Bramblett et al. 1993, Goedert et al. 1993, Watanabe et al. 1993), and the degree of phosphorylation of all the six tau isoforms decreases with age, (Mawal-Dewan et al. 1994).

Little is known about the regulation of tau phosphorylation. A large number of Ser/Thr protein kinases have been suggested as playing a role in regulating tau functions in vivo (reviewed in Billingsley \& Kincaid 1997, Buée et al., 2000). These kinases include mitogen-activated protein kinase (Drewes et al. 1992, Drechsel et al. 1992,

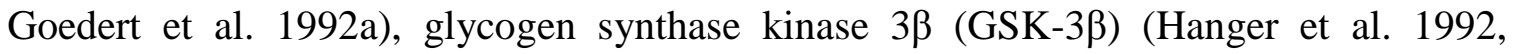
Mandelkow et al. 1992), cyclin-dependent kinase 2 (cdk2) (Baumann et al. 1993), cdk5 (Baumann et al. 1993, Kobayashi et al 1993), cAMP-dependent protein kinase (Litersky and Johnson 1992), Ca2+/calmodulin-dependent protein kinase II (Baudier and Cole 
1987), and MT-affinity regulating kinase (Drewes et al. 1997). In addition, several members of the family of stress-activated protein kinases also phosphorylate tau at multiple sites (Goedert et al. 1997; Reynolds et al. 1997a,b).

Glycogen synthase kinase-3 (GSK-3 $\beta$ ), Ser/Thr kinase highly expressed in the brain, associates with MTs (Mandelkow et al. 1992, Ishiguro et al. 1994, Singh et al., 1995, Takahashi et al. 1995). This kinase might be one of the central regulator in a signaling pathway for neuronal polarity. Signaling pathways act by inhibiting GSK-3 $\beta$ activity. Phosphorylation by GSK-3 $\beta$ inhibits the ability of tau to bind MT and thereby inhibits MT assembly.

Another kinase, - Cdk5 is a Ser/Thr protein kinase highly enriched in neurons and also contributes to the phosphorylation of tau (Baumann et al. 1993, Kobayashi et al. 1993). Sobue et al (2000) demonstrated that tau anchors cdk5 to MTs in a phosphorylation dependent manner. Moreover, cdk5-mediated tau phosphorylation stimulates further phosphorylation of tau by GSK-3 $\beta$ (Yamaguchi et al. 1996, Sengupta et al. 1997). Distribution of both kinases was found in association with pretangle or tangle-bearing neurons in human AD (Patrick 1999, Yamaguchi 1996).

However, the precise contribution of kinases to tau phosphorylation in vivo remains to be defined.

\section{Tau pathology}

\section{Tau and formation of neurofibrillary tangles}

Aggregated tau in form of filaments is a characteristic hallmark of several neurodegenerative diseases including Alzheimer's disease (AD) and frontotemporal dementia with Parkinsonism linked to chromosome 17 (FTDP-17). It is shown that mutations in the tau gene such as the P301L mutation and inherited cases of FTDP-17 indicated a disease-causative role of tau abnormalities in the neurofibrillary degeneration (Hutton et al. 1998; Poorkaj et al. 1998; Spillantini et al. 1998). Until now, 40 different pathogenic tau mutations have been linked to frontotemporal dementia (Cruts and Rademakers, 2006; Alzheimer Disease and Frontotemporal Dementia Mutation Database). All the mutations discovered in tau are dominant, suggesting that the effect of these mutations results in a gain-of-function. Neuropathologically, these mutations 
induced the formation of tau filaments in nerve cells and in glial cells (reviewed in Spillantini et al. 1998a, Crowther and Goedert 2000, Lee et al. 2001, Dermaut et al. 2005). The group of syndromes known as FTDP-17 is autosomal-dominantly inherited neurodegenerative diseases with diverse, but overlapping, clinical and neuropathological features (Foster et al. 1997, Lee et al. 2001, Bird et al. 1997). Subsequently, a number of related neurodegenerative disorders were linked to the same region on chromosome 17 (Wijker et al. 1996, Bird et al. 1997, Foster et al. 1997, Heutink et al. 1997, Lendon et al. 1998) and characterized by marked neuronal loss in affected brain regions, with extensive neuronal and / or glial fibrillary pathology composed of hyperphosphorylated tau protein.

In contrast to familial inherited diseases with tauopathies, sporadic Alzheimer's disease is very common disorder with more than 15 million people affected worldwide. The cause of the sporadic form of Alzheimer's disease is unknown.

Ultrastructurally, the dominant components of neurofibrillary lesions in AD are paired helical filaments (PHFs) and straight filaments. Both PHFs and straight filaments are composed predominantly of abnormally hyperphosphorylated tau proteins (Goedert et al. 1988, Kondo et al. 1988, Kosik et al. 1988, Wischik et al. 1988, Lee et al. 1991). The six soluble tau isoforms observed in normal adult human brain found to be involved in formation of PHFs in Aizheimer disease (Trojanowski and Lee 1994, MorishimaKawashima et al. 1995, Goedert et al. 1995, Hong et al. 1998). The mechanisms underlying PHF formation in neurons are still unclear, but it is possible that hyperphosphorylation disengages tau from MTs, thereby increasing the pool of unbound tau. Numbers of protein kinases and protein phosphatases have been implicated in the dysregulation of tau phosphorylation in the AD brain (Billingsley \& Kincaid 1997, Buée et al. 2000). Unbound tau may be more resistant to degradation and more prone to aggregate than microtubule-bound tau. The detailed molecular mechanism of tau polymerization is not known. The first step in formation of tau polymers is the dimerization of tau (von Bergen et al. 2000). It is believed that the dimerization followed by oligomerization / polymerization of soluble tau, along with conformational changes of the natively unfolded tau, are the initial critical steps in the pathology of neurofibrillary tangle formation (Lee et al. 2001). Studies in this field suggested that only the dimerized 
tau, but not the monomeric tau, shows transition into $\beta$-sheets and serves as a nucleus for tau polymerization (von Bergen et al. 2000).

\section{Tau and involvement of microglia}

Searching the cause leading to the pathology of tau, it was proposed that extracellular factors such as amyloid- $\beta$ aggregates can favor tau polymerization in AD (Hardy and Allsop, 1991). Extracellular aggregates of amyoid- $\beta$ stimulate inflammation and innate brain immunity, particularly microglia in AD. In the Alzheimer disease once microglia activated, an overexpression of reactive oxygen species and cytokines were reported (Behl, 1999). It is not known whether amyloid- $\beta$ favors tau aggregation directly by acting on neurons or indirectly via release of inflammatory cytokines of microglia. In the same time several disorders others than Alzheimer disease were described, which showed abundant, filamentous tau pathology and brain degeneration in the absence of extracellular amiloid- $\beta$ deposition (Lee et al. 2001).

One of the inflammatory cytokines released by microglia is the tumor necrosis factor- $\alpha$ (TNF- $\alpha$ ). It was first isolated by Carswell et al. in 1975 (Carswell et al. 1975). TNF- $\alpha$ plays a key role in a wide of physiological processes, including inflammation, proliferation and programmed cell death. These pleiotropic biological effects of TNF- $\alpha$ result from its ability to initiate different intracellular signaling pathways (Figure 2). Upon binding of TNF- $\alpha$ to TNF receptor 1 (TNF-R1), the signaling molecules TNF-R associated death domain (TRADD), TNF-R associated factor 2 (TRAF2), and receptor interacting protein 1 (RIP1) are recruited to form the so-called complex I. This complex I initiate a signal transduction pathway leading to the activation of the transcription factor $\mathrm{NF}-\kappa \mathrm{B}$. In addition to $\mathrm{NF}-\kappa \mathrm{B}$ activation, TNF- $\alpha$ induced signaling from complex I leads to the activation of different mitogen-activated protein kinase (MAPK) cascades, which ultimately result in the activation of p38 MAPK, extracellular regulated kinase (ERK) and c-Jun N-terminal kinase (JNK) (Wullaert, et al. 2006).

JNK is a member of the mitogen-activated protein (MAP) kinase family. JNKs subfamily consists of 10 different splice variants, which become active after phosphorylation, which leads to further phosphorylation of variety of downstream targets. 
JNKs are rapidly activated within the axons following nerve injury and can be transported on microtubules along the axon via their association with motor proteins of the kinesin family. Several studies shown that crosstalk between TNF-induced NF-кB and JNK pathways are important for determining the biological outcome of TNF stimulation. It is noticed, that transient activation of JNK is associated with cellular survival, whereas prolonged and robust activation of JNK plays an important role in TNF-induced cell death (Wullaert, et al., 2006). Recent studies reported that activated phospho-JNK, as a sign of stress kinase signaling, co-localized with the neurofibrillary tangles in neurites (Mohit et al. 1995; Zhu et al. 2001). 


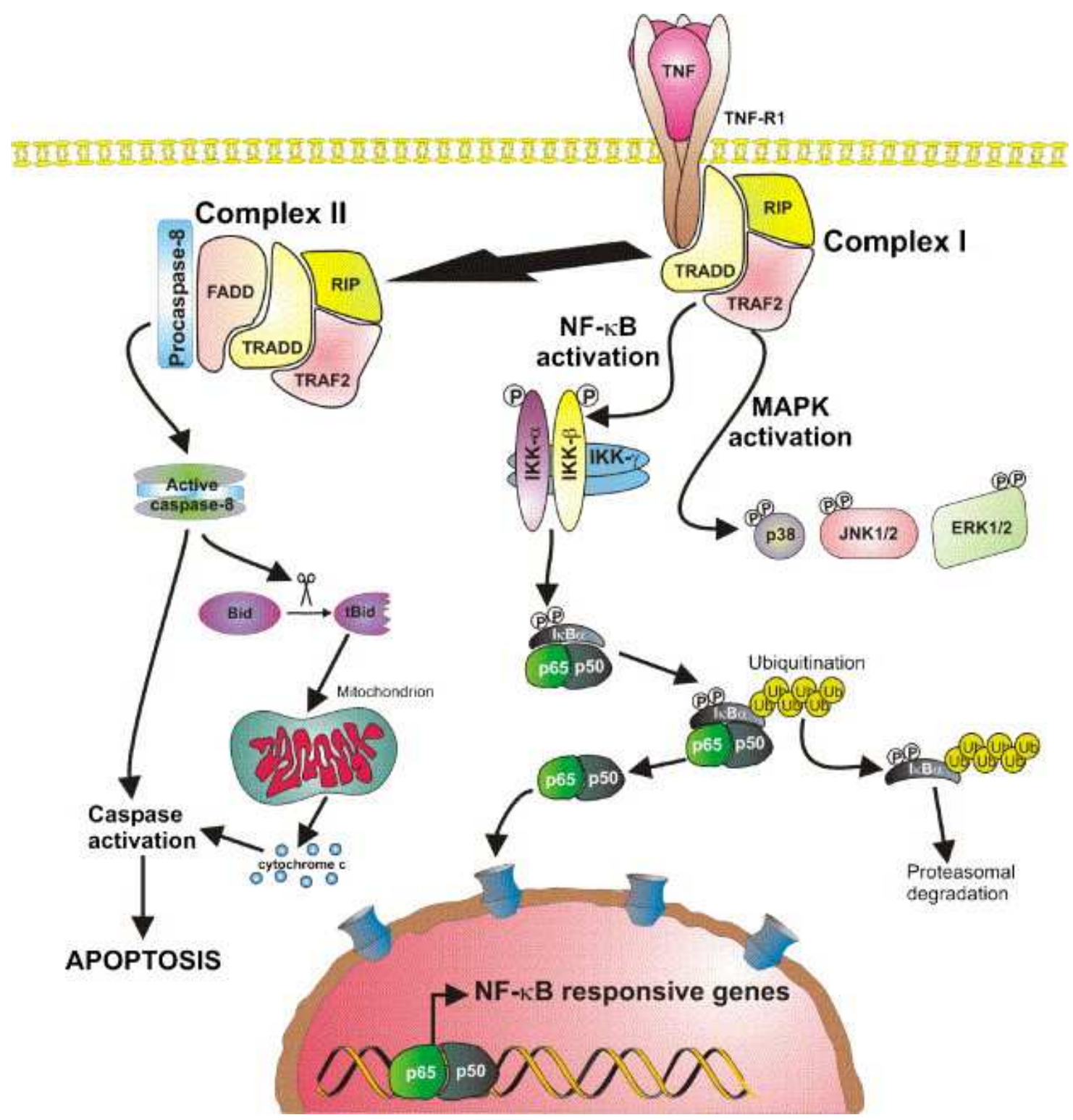

Figure 2. TNF-RI induced signalling pathways. TNF binding to TNF-RI leads to the recruitment of TRADD, TRAF2 and RIP, forming complex I. Signalling from complex I leads to NF- $\kappa B$ activation. In addition, signalling from complex I activate the p38, ERK, and JNK MAP kinases. 


\section{Technical approach to determine tau interactions}

To study tau interactions, Förster resonance energy transfer (FRET) method was used in this present work. FRET, named for Theodor Förster, who, in the 1940s, quantitatively described the phenomenon of energy transfer directly from a fluorophore in the excited state (the donor) to a non-identical acceptor fluorophore (Figure 3A) (Förster, 1948). The efficiency of this energy transfer is mainly dependent on several parameters. The energy transfer rate from the donor to the acceptor decreases with the sixth power of the distance. Therefore it is necessary that the donor and acceptor fluorophores are in close proximity with distances shorter than $10 \mathrm{~nm}$ (Lakowicz, 1999). Further, certain dipole orientations of molecules are required. Finally, the emission spectrum of the donor has to overlap with an excitation spectrum of the acceptor (Figure 3B). The energy transfer itself does not involve any light emission and absorption.

The FRET efficiency indicates the percentage of the excitation photons that contribute to FRET. Energy transfer rate $\mathrm{k}_{\mathrm{T}}$, is described by:

$$
k_{\mathrm{T}}=\frac{1}{\tau_{\mathrm{D}}}\left(\frac{R_{0}}{R}\right)^{6}
$$

where, $R$ - donor-acceptor distance, $\tau_{D}$ - donor fluorescence lifetime in the absence of acceptor, $R_{0}-$ Förster distance at which energy transfer efficiency is $50 \%$.

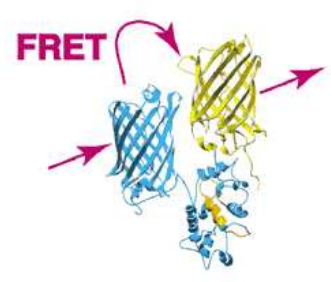

A.

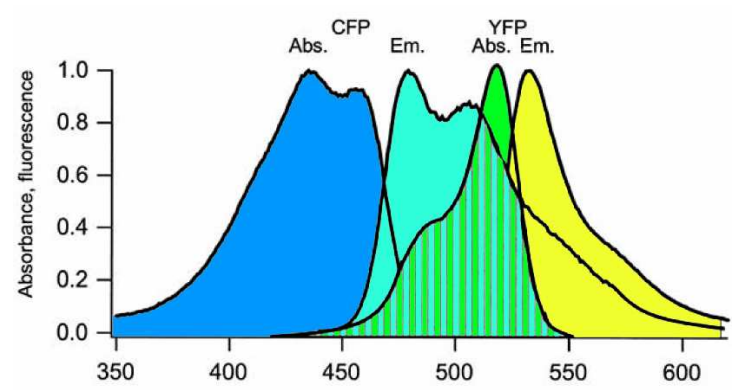

B.

Figure 3. A. Schematic representation of FRET between donor (blue) and acceptor (yellow). B. Absorption and excitation spectra of donor and acceptor molecules. 
FRET can be applied to study interaction between molecules (intermolecular FRET) and conformational changes of molecules (intramolecular FRET) (Figure 4). In both cases molecules of interest have to be fused or bind to the appropriate fluorophores or fluorescence dyes.

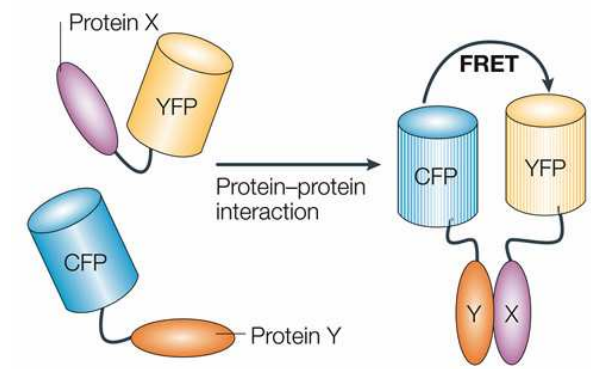

A.

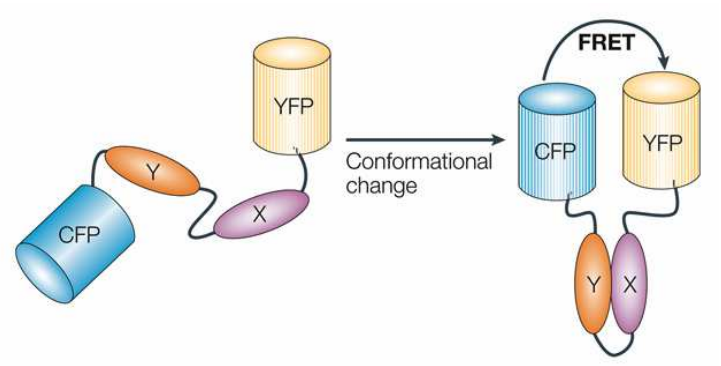

B.

Figure. 4 Schematic representation of intermolecular (A) and intramolecular (B) FRET.

FRET can be detected as a result of several characteristic changes in sample fluorescence. First, the intensity of donor fluorescence is decreased. Quantification of donor fluorescence recovery after acceptor photobleaching is the most direct measure of FRET efficiency. In the photobleaching method, images of donor fluorescence are compared pixel-by-pixel before and after photo-destruction of acceptor with prolonged illumination of the sample at acceptor specific wavelength. If the FRET occurs, the intensity of donor increases after bleaching of the acceptor.

Second, the lifetime of the donor (the time of fluorophore emission measured in picoseconds after brief femtosecond excitation) excited state is decreased. This could be detected using Fluorescence lifetime imaging microscopy (FLIM). The FLIM technique measures the nanosecond duration of the excited state of fluorophores within living cells (Bastiaens and Squire, 1999). An important advantage of these lifetime measurements is 
that they are independent of change in probe concentration, photobleaching and other factors that limit intensity-based steady-state measurements. The fluorescence lifetime of a fluorophore is critically dependent upon the local environment that surrounds the probe. When combined with FRET, this approach can provide direct evidence for the physical interaction between proteins.

In this study, fluorescence lifetime imaging was achieved by time-domain techniques use pulsed excitation and record the fluorescence decay function directly, by time correlated photon counting (Becker W et al. 2001). Equipment and data analysis are described in "Materials and Methods" section. 


\section{Aims of the study}

The exact molecular mechanism of tau aggregation in neurodegenerative disease is not known. Genetic mutations of tau appear to favor the polymerization of tau. Furthermore, it was suggested that extracellular factors such as amyloid- $\beta$ aggregates can stimulate inflammation, which leads to the activation of microglia resulted in increased level of reactive oxygen species and cytokine expression. Tumor necrosis factor alpha (TNF- $\alpha$ ) is one of the cytokines which stimulate inflammation during brain injury. It would be beneficial, than, to understand if TNF- $\alpha$ could be involved in the neurotoxic formation of tau aggregates. To address this question, the main aim of our studies was to determine the effect of TNF- $\alpha$ in dimerization / polymerization of tau.

Therefore, we focused on the following tasks:

- establishment of an adequate cellular model: settle and use of primary hippocampal neurons

- $\quad$ establishment of the novel FRET / FLIM technique to study dimerization / polymerization of tau in cultured hippocampal neurons treated or not with TNF- $\alpha$ 


\section{Material and Methods}

\section{Plasmids construction}

Plasmids expressing GFP (Invitrogen), Cerulean (gift from Dr. Piston, Department of Molecular Physiology and Biophysics, Vanderbilt University Medical Center, Tennessee, USA), Citrine (gift from Dr. Thomas Jovin, Department of Molecular biology, Max Planck Institute for Biophisical Chemistry, Goettingen, Germany) and Cerulean-Citrine were designed based pLenti6/V5-D (Invitrogen) back bone with a cytomegalovirus promoter (CMV). Described genes were obtained from corresponded constructs by PCR using extended primers allowing the product to be inserted into the following vectors. Cerulean and Citrine were cloned between SpeI and XhoI restriction sites. Tau as well as Citrine (for Cerulean-Citrine construct) was cloned between XhoI and ApaI sites. Citrine was directly tagged to Cerulean using an 18 n.a. linker. Human tau (gift from Dr. Götz, Psychiatry, University Zurich) was cloned to the C-terminal of the fluorescent proteins to obtain a fusion protein. Plasmids were purified using EndoFree Maxi Kit (Qiagen, Germany). The sequence of each plasmid was verified by sequencing.

\section{Neuronal cultures and transfection}

Primary neuronal cultures were prepared from hippocampi of C57BL/6 mice embryos (E15) as described previously (Neumann H, et al, 2002). Hippocampi were isolated and dispersed mechanically. Transfection (using $0.5 \mu \mathrm{g}$ plasmid DNA per $1 \times 10^{6}$ cells) or cotransfection (using $0.25 \mu \mathrm{g}$ of each plasmid DNA per $1 \times 10^{6}$ cells) was performed during seeding of the neuronal cells by the Effectene Transfection Kit (Qiagen, Germany). The cells were incubated for 30 minutes with $0.5 \mu \mathrm{g}$ plasmid DNA per $1 \times 10^{6}$ cells, $4 \mu \mathrm{l}$ enhancer, $10 \mu \mathrm{l}$ Effectene and $85 \mu \mathrm{l}$ saline buffer. After transfection, the cells were washed in phosphate buffered saline (PBS) and suspended in BME-based neuronal medium (BME, GibcoBRL, Invitrogen GmbH, Germany) supplemented with 2\% B-27 supplement, (GibcoBRL, Invitrogen $\mathrm{GmbH}$, Germany), 1\% glucose (45\% glucose, Sigma, Germany) and 1\% fetal calf serum (FCS, PAN Biotech GmbH, Germany). Then cells were seeded in 4-well chamber culture dishes (Nunc GmbH\&Co. KG, Germany) with a density of 250000 cells $/ \mathrm{ml}$. The dishes were pretreated with poly-L-ornithin $(0.01$ 
$\mathrm{mg} / \mathrm{ml}$, Sigma, Germany) and laminin (10 $\mu \mathrm{g} / \mathrm{ml}$, Sigma, Germany). After transfection cells were cultured for 3-7 days to obtain morphologically mature neurons. The average transfection efficiency was approximately $0.5 \%$ and the majority of transfected neurons showed plasmid expression on day 3-5.

Neurons were treated with TNF- $\alpha$ (R\&D Systems, Germany) for 1-3 hours, followed by fixation with $0.25 \%$ glutaraldehyde and $4 \%$ paraformaldehyde.

\section{Neuroblastoma cell line cultures and transfection}

Neuroblastoma cell line N1E-115 (gift from Dr. Ponimaskin, Physiology, University Göttingen, Germany) were cultured in BME-based medium (BME, GibcoBRL, Invitrogen $\mathrm{GmbH}$, Germany) supplemented with $10 \%$ fetal calf serum (FCS, PAN Biotech $\mathrm{GmbH}$, Germany), $1 \%$ glucose (45\% glucose, Sigma, Germany), 1\% glutamine and $1 \%$ antibiotic mixture (GibcoBRL) in $75 \mathrm{~cm}^{2}$ dishes (Sarstedt, Germany). Then cells were seeded in 4-well chamber culture dishes (Nunc GmbH\&Co. KG, Germany) with a density of 75000 cells $/ \mathrm{ml}$. On the next day, transfection of cells using Effectene Transfection Kit (Qiagen, Germany), was performed. The transfection mixture, contained $0.5 \mu \mathrm{g}$ plasmid DNA, $4 \mu \mathrm{l}$ enhancer, $10 \mu \mathrm{l}$ Effectene and $85 \mu \mathrm{l}$ buffer, preincubated for 20 minutes, were added directly to the cells. The average transfection efficiency was approximately $30-50 \%$ and the majority of transfected cells showed plasmid expression from day 2. On the day 3-4 cells were fixed with $0.25 \%$ glutaraldehyde and $4 \%$ paraformaldehyde.

\section{Immunocytochemistry of primary neurons}

Primary neurons transfected with GFP-tau cultured for 3-5 days were fixed with $0.25 \%$ glutaraldehyde and $4 \%$ paraformaldehyde followed by treatment with a $0.1 \%$ solution of Triton-X in PBS. After incubation with 1\% BSA in 1x PBS, cells were incubated with mouse anti ß-tubulin antibodies directly conjugate with Cy3 (Sigma). Alternatively, fixed cells were labelled with mouse anti-neurofilament antibodies (Sigma), followed by secondary fluorochrome Cy3-conjugated goat antibody directed against mouse $\operatorname{IgG}$ (1:400, Dianova). Samples were washed with PBS and covered with Mowiol solution and cover glass. 
Primary neurons transfected with GFP cultured for 3-5 days were fixed with $0.25 \%$ glutaraldehyde and $4 \%$ paraformaldehyde followed by treatment with a $0.1 \%$ solution of Triton-X in PBS. After incubation with 1\% BSA in 1x PBS, cells were incubated with mouse anti B-tubulin antibodies directly conjugate with Cy3 (Sigma). Samples were washed with PBS and covered with Mowiol solution and cover glass.

\section{Immunocytochemistry of TNF receptors I and II}

Hippocampal neurons were cultured for 3-5 days, fixed with 4\% paraformaldehyde and then incubated with a rat monoclonal antibody specific for TNFRI or TNFRII (1:200, HyCultBiotech, The Netherlands), followed by FITC conjugated goat secondary antibody against rat $\operatorname{IgG}$ (1:400, Dianova, Germany). After washing, cells were incubated with an axon-specific mouse monoclonal antibody against tau (tau-1, 1:200, PC1C6; Chemicon Int., CA, USA) and Cy3-conjugated goat secondary antibody against mouse $\operatorname{IgG}$ (1:400; Dianova). As a negative control rat $\operatorname{IgG}(1: 200,1 \mu \mathrm{g} / \mathrm{ml}$, Sigma) was applied, followed by FITC-conjugated goat secondary antibody against rat $\operatorname{IgG}$ (1:400, Dianova, Germany). Optical sections along the $\mathrm{z}$-axis were scanned with 40x objective on a confocal laserscanning microscope (Olympus, Germany). For quantification, random fields were selected from neuronal cultures and analyzed under fluorescence microscopy counting the number of axonal processes co-labeled with antibodies directed against tau and TNF receptor I or tau and TNF receptor II.

\section{Immunocytochemistry of total and phosphorylated JNK}

Cultured hippocampal neurons were fixed with $4 \%$ paraformaldehyde, followed by treatment with a $0.1 \%$ solution of Triton-X in PBS and incubation with $1 \%$ BSA in $1 \mathrm{x}$ PBS. For total JNK staining, cells were incubated with rabbit anti-total JNK antibodies (1:100, Cell Signaling Technology, MA, USA), followed by Cy3 conjugated goat anti rabbit IgG (1:400, Dianova). For phosphorylated JNK staining, rabbit anti phosphorylated JNK (1:100, Cell SignalingTechnology), followed by Cy3-conjugated goat anti rabbit $\operatorname{IgG}$ (1:400, Dianova) were used. Subsequently, cells were incubated with mouse monoclonal anti-tau (tau-1, 1:200, PC1C6; Chemicon) and FITC-conjugated goat anti mouse $\operatorname{IgG}$ (1:400; Dianova). As a negative control rabbit IgG (Sigma) was applied, followed by Cy3-conjugated goat anti IgG (1:400, Dianova, Germany). Optical sections 
along the z-axis were scanned using 40x objective with a confocal laser-scanning microscope (Olympus). Neurons were treated for 20 minutes with $20 \mathrm{ng} / \mathrm{ml} \mathrm{TNF}$ as indicated in the text and figures. For quantification, random fields were selected from neuronal cultures either untreated or treated with TNF for 20 minutes and analyzed under fluorescence microscopy counting the number of axonal processes and cell bodies labeled by tau showing expression of phosphorylated JNK. Data of independent experiment were presented as mean +/- SEM.

\section{Fluorescence intensity based FRET analysis by photobleaching}

The theory of FRET was first described by Förster, suggesting how energy could be transferred directly from a fluorophore in the excited state (the donor) to a non-identical acceptor fluorophore. The energy from the donor molecule, without releasing a photon, can be transferred directly to an acceptor, if the emission spectrum of donor overlap the absorbtion spectrum of acceptor (>30\%) and the two fluorophores are within proximity of 1 to $10 \mathrm{~nm}$ to each other. Fluorescence Resonance Energy Transfer (FRET) measurements were applied to investigate molecular interactions at a nanometer scale. In intensity based FRET the bleaching of acceptor (Citrine in Cerulean-Citrine pair) was performed followed by analysis of donor emission. Intensity of donor signal is decreased in presence of the acceptor at a distance less than $10 \mathrm{~nm}$. Thus, after bleaching of the acceptor with a high intensity at acceptor specific wavelength we measured the increase of donor intensity. Experiments were made using a laser scanning microscope (Leica, Olympus, Germany).

\section{Fluorescence lifetime based FRET analysis by Time-Correlated Single Photon Counting (TCSPC)}

Fluorescence resonance energy transfer (FRET) measurements were applied to investigate the proximity at a nanometer scale. Fluorescence lifetime imaging (FLIM) was performed, which relies on the fluorescence lifetime measurement (the time of fluorophore emission measured in picoseconds after brief femtosecond excitation). Lifetime of a donor decreases in the presence of an appropriate FRET acceptor. To record fluorescence lifetime images, time-correlated single photon counting (TCSPC) was used, which has high counting efficiency required to resolve multi-exponential decay analysis 
in scanning microscope (Bacskai et al. 2003). The setup used in this study consisted of a laser scanning microscope (Leica, Bensheim, Germany; Olympus, Germany) equipped with a picosecond Diode lasers (BDL-405 Picosecond Diode Laser, 408nm; BDL-475 Picosecond Diode Laser, $470 \mathrm{~nm}$, Becker\&Hickl $\mathrm{GmbH}$ ) and connected to a TCSPC imaging module (SPC, Becker \& Hickl, Berlin, Germany). An emission filter was placed between the output port of the scanning-head and the time domain-FLIM detector. Sufficient amount of photons (not less than 200 counts) which are required for a reliable mono-exponential decay fit, were collected during 60-120 seconds. Time-resolved fluorescence decays were reconstructed by time correlated single photon counting (TCSPC). Analysis of the data performed using SPCImage software (Becker \& Hickl), which allowed mono-exponential curve fitting of the acquired data on a pixel-by-pixel basis using a weighted least-squares numerical approach. In this case, model, where only significant values of the lifetime (in this case $0.8 \mathrm{~ns}-3.0 \mathrm{~ns}$ ) are taking into consideration, were applied for analysis of the data. Calculation the decay matrix results in a colour coded image which derives the intensity information from the number of photons in each pixel and the colour information from a selected fit parameter which value is coded by a continuous colour scale (running from red to blue). Thus, data are presented as images coded in pseudocolors with lifetime ranges of 0.8 to 1.6 nanoseconds in red (shorter lifetimes indicating FRET) and lifetime ranges of 1.6 to 3.0 nanoseconds in green (long lifetimes indicating no FRET). Furthermore, lifetime values are presented as histograms.

\section{Statistical analysis}

Data of FLIM were analyzed by SPCImage (Becker\&HIckl, GmbH). Statistical analysis was performed using Excel program (Microsoft). Statistical analysis was performed using t-test between the groups. 


\section{Appendix to Materials and Methods}

\section{Materials}

\section{Buffers and solutions}

0.125M Phosphate-Buffered Saline (10xPBS), pH 7.3

\begin{tabular}{|l|c|l|}
\hline Components & concentration & company \\
\hline $\mathrm{NaH}_{2} \mathrm{PO}_{4} \cdot \mathrm{H}_{2} \mathrm{O}$ & $0.007 \mathrm{M}$ & Roth, Germany \\
$\mathrm{Na}_{2} \mathrm{HPO}_{4} \cdot 7 \mathrm{H}_{2} \mathrm{O}$ & $0.034 \mathrm{M}$ & Roth, Germany \\
$\mathrm{NaCl}$ & $0.6 \mathrm{M}$ & Roth, Germany \\
$\mathrm{ddH}_{2} \mathrm{O}$ & up tol liter & Roth, Germany \\
\hline
\end{tabular}

4\% paraformaldehyde (PFA), pH 7.3

\begin{tabular}{|l|c|c|}
\hline Components & amount & company \\
\hline PFA & $20 \mathrm{~g}$ & Sigma, Germany \\
$\mathrm{NaOH}$ & $30 \mathrm{ml}$ & Roth, Germany \\
$\mathrm{PBS}(10 \mathrm{X})$ & $50 \mathrm{ml}$ & \\
$\mathrm{ddH}_{2} \mathrm{O}$ & up to $1 \mathrm{liter}$ & \\
\hline
\end{tabular}

$\underline{\text { TBE Buffer (10x) }}$

\begin{tabular}{|l|c|c|}
\hline Components & concentration & company \\
\hline Tris-Base & $1.78 \mathrm{M}$ & Roth, Germany \\
Boric Acid & $1.78 \mathrm{M}$ & Sigma, Germany \\
EDTA & $0.04 \mathrm{M}$ & Roth, Germany \\
$\mathrm{ddH}_{2} \mathrm{O}$ & to 2 liters & \\
\hline
\end{tabular}

Loading Buffer (6x)

\begin{tabular}{|l|c|c|}
\hline Components & concentration & company \\
\hline EDTA & $0,5 \mathrm{M}$ & Roth, Germany \\
Sucrose & $60 \%$ & Fluke Biochemika, Germany \\
Bromphenol Blue & $0,04 \%$ & Sigma, Germany \\
Xylene Cyanole & $0,04 \%$ & Sigma, Germany \\
Ficol-400 & $2 \%$ & Bio-Rad, Germany \\
\hline
\end{tabular}

$1 \%$ Agarose gel

\begin{tabular}{|l|c|c|}
\hline Components & amount & company \\
\hline Agarose & $0.5 \mathrm{~g}$ & SeaKem,Cambrex, USA \\
Etidium Bromide or & $1.25 \mu \mathrm{l}$ & Roth, Germany \\
Gel Star (when gel extraction) & $4 \mu \mathrm{l}$ & BioWhittaker Molecular \\
& $50 \mathrm{ml}$ & Applications, USA \\
TBE (1X) & & \\
\hline
\end{tabular}


Mowiol

\begin{tabular}{|l|l|l|}
\hline Components & $\begin{array}{l}\text { Amount/ } \\
\text { concentration }\end{array}$ & Company \\
\hline Mowiol 4-88 & $2,4 \mathrm{~g}$ & Kremer, Pigmente \\
Glycerol & $6 \mathrm{~g}$ & Sigma, Germany \\
Tris-Buffer 0,2M pH 8,5 & $12 \mathrm{ml}$ & Roth, Germany \\
1,4-Diazobicyclo-(2.2.2)-octan (DABCO) & $2,5 \%$ & Sigma, Germany \\
Aqua bidest. & $6 \mathrm{ml}$ & \\
& & \\
\hline
\end{tabular}

$\underline{P C R \text { reaction mix }(50 \mu \mathrm{l} \text { sample })}$

\begin{tabular}{|l|c|c|}
\hline Components & amount & company \\
\hline dNTP mix $(10 \mathrm{mM})$ & $1 \mu \mathrm{l}$ & Amersham Bioscience, USA \\
Taq polymerase $(100 \mathrm{U} / 20 \mathrm{ul})$ & $0.5 \mu \mathrm{l}$ & Roche, Germany \\
Forward primer $(10 \mathrm{pmol} / \mathrm{ul})$ & $3 \mu \mathrm{l}$ & MWG, Germany \\
Reverse primer $(10 \mathrm{pmol} / \mathrm{ul})$ & $3 \mu \mathrm{l}$ & MWG, Germany \\
Buffer $(10 \mathrm{X})$ & $5 \mu \mathrm{l}$ & Roche, Germany \\
dd $\mathrm{H}_{2} \mathrm{O}$ & $37.5 \mu \mathrm{l}$ & Roth, Germany \\
\hline
\end{tabular}

\section{Digestion reaction mix (20 $\mu$ l sample)}

\begin{tabular}{|l|c|l|}
\hline Components & concentration & company \\
\hline Enzyme 1 & $0.5 \mu \mathrm{l}$ & Roche, Germany \\
Enzyme 2 & $0.5 \mu \mathrm{l}$ & Roche, Germany \\
Buffer & $2 \mu \mathrm{l}$ & Roche, Germany \\
insert/plasmid & up to $1 \mu \mathrm{g}$ & \\
ddH2O & up to $20 \mu \mathrm{l}$ & \\
\hline
\end{tabular}

\section{Ligation reaction mix (10 $\mu$ l sample)}

\begin{tabular}{|l|c|c|}
\hline Components & concentration & company \\
\hline T4 Ligase & $1 \mu \mathrm{l}$ & Roche, Germany \\
Ligation Buffer & $1 \mu \mathrm{l}$ & Roche, Germany \\
DNA & $8 \mu \mathrm{l}$ & \\
total reaction volume & $10 \mu \mathrm{l}$ & \\
\hline
\end{tabular}




\section{Cell culture media}

\section{Primary neurons cell medium}

\begin{tabular}{|l|c|c|}
\hline Components & concentration & company \\
\hline BME & $1 \%$ & Gibco, Germany \\
FCS & $1 \%$ & PAN, Germany \\
$1 \%$ Glucose & $2 \%$ & Sigma, Germany \\
B-27 supplement & & Gibco, Germany \\
\hline
\end{tabular}

\section{N1E cell line medium}

\begin{tabular}{|l|c|c|}
\hline Components & concentration & company \\
\hline BME & & Gibco, Germany \\
FCS & $10 \%$ & PAN, Germany \\
$1 \%$ L-Glutamate & $1 \%$ & Gibco, Germany \\
$1 \%$ Penisilin/Streptomicin & $1 \%$ & Gibco, Germany \\
$1 \%$ Glucose & $1 \%$ & Sigma, Germany \\
\hline
\end{tabular}

\section{Other reagents}

\begin{tabular}{|l|l|}
\hline Components & Company \\
\hline Ampicillin & Sigma, Gemany \\
LB broth & Fluke Biochemika, Germany \\
LB agar & Fluke Biochemika, Germany \\
DMSO & Sigma, Germany \\
Poly-L-Lysine & Sigma, Germany \\
Poly-L-Ornitine & Sigma, Germany \\
Laminin & Sigma, Germany \\
Ethanol & Roth \\
Trypsin-EDTA $(1 \mathrm{X})$ & Gibco, Germany \\
\hline
\end{tabular}

\section{Cytokines}

\begin{tabular}{|l|l|}
\hline Components & Company \\
\hline TNF- $\alpha, 10 \mu \mathrm{g} / \mathrm{ml}$ & R\&D Systems, Germany \\
\hline
\end{tabular}




\section{Antibodies}

Primary antibodies

\begin{tabular}{|l|l|l|}
\hline Epitope & Produced & Company \\
\hline Tau-1 & mouse & Chemicon Int., CA, USA \\
\hline$\beta$-tubulin-Cy3 & mouse & Sigma, Germany \\
\hline neurofilament & mouse & Sigma, Germany \\
\hline TNFRI & rat & HyCultBiotech, The Netherlands \\
\hline TNFRII & rat & HyCultBiotech, The Netherlands \\
\hline Total JNK & rabbit & Cell Signaling Technology, MA, USA \\
\hline Phospho-JNK & rabbit & Cell Signaling Technology, MA, USA \\
\hline
\end{tabular}

Secondary antibodies

\begin{tabular}{|l|l|l|}
\hline IgG FITC-conjugated & goat & Dianova, Germany \\
\hline IgG Cy3-conjugated & goat & Dianova, Germany \\
\hline
\end{tabular}

\section{Kits}

\begin{tabular}{|l|l|}
\hline Components & Company \\
\hline Miniprep kit & Qiagen, Germany \\
Maxiprep kit & Qiagen, Germany; Invitrogen, Germany \\
Gel extraction kit & Qiagen, Germany \\
Clean up kit & Qiagen, Germany \\
Effectene transfection kit & Qiagen, Germany \\
\hline
\end{tabular}

\section{Consumables}

1. 6 and 24-well culture plates

2. $15 \mathrm{ml}$ tubes

3. $50 \mathrm{ml}$ tubes

4. $5 \mathrm{ml}, 10 \mathrm{ml}, 25 \mathrm{ml}$ pippets

5. chamber slides

6. cryovials

$7.75 \mathrm{~cm}$ and $175 \mathrm{~cm}^{2}$ culture flasks

$8.5 \mathrm{ml}$ polystyrene round-botton tubes

$9.3 \mathrm{~cm}, 10 \mathrm{~cm}$ culture dish

10. bacteria culture $10 \mathrm{ml}$ tube

11. $500 \mu 1,1000 \mu \mathrm{L}$ plastic tube

12. PCR tubes

13. $10 \mathrm{ul}, 100 \mu \mathrm{l}$ and $1000 \mu \mathrm{l}$ tips

14. filters (250 and $500 \mathrm{ml})$
1. Cellstar, VWR International, Germany

2. Cellstar, VWR International, Germany

3. Sarstedt, Germany

4. Sarstedt, Germany

5. Nunc GmbH, Germany

6. VWR International, Germany

7. Sarstedt, Germany

8. BD Falcon, USA

9. Sarstedt, Germnay

10. Sarstedt, Germany

11. Eppendorf, Germnay

12. Biozym Diagnostik, Germany

13. Starlab, Germany

14. Millipore, Germany 


\section{Equipment and software}

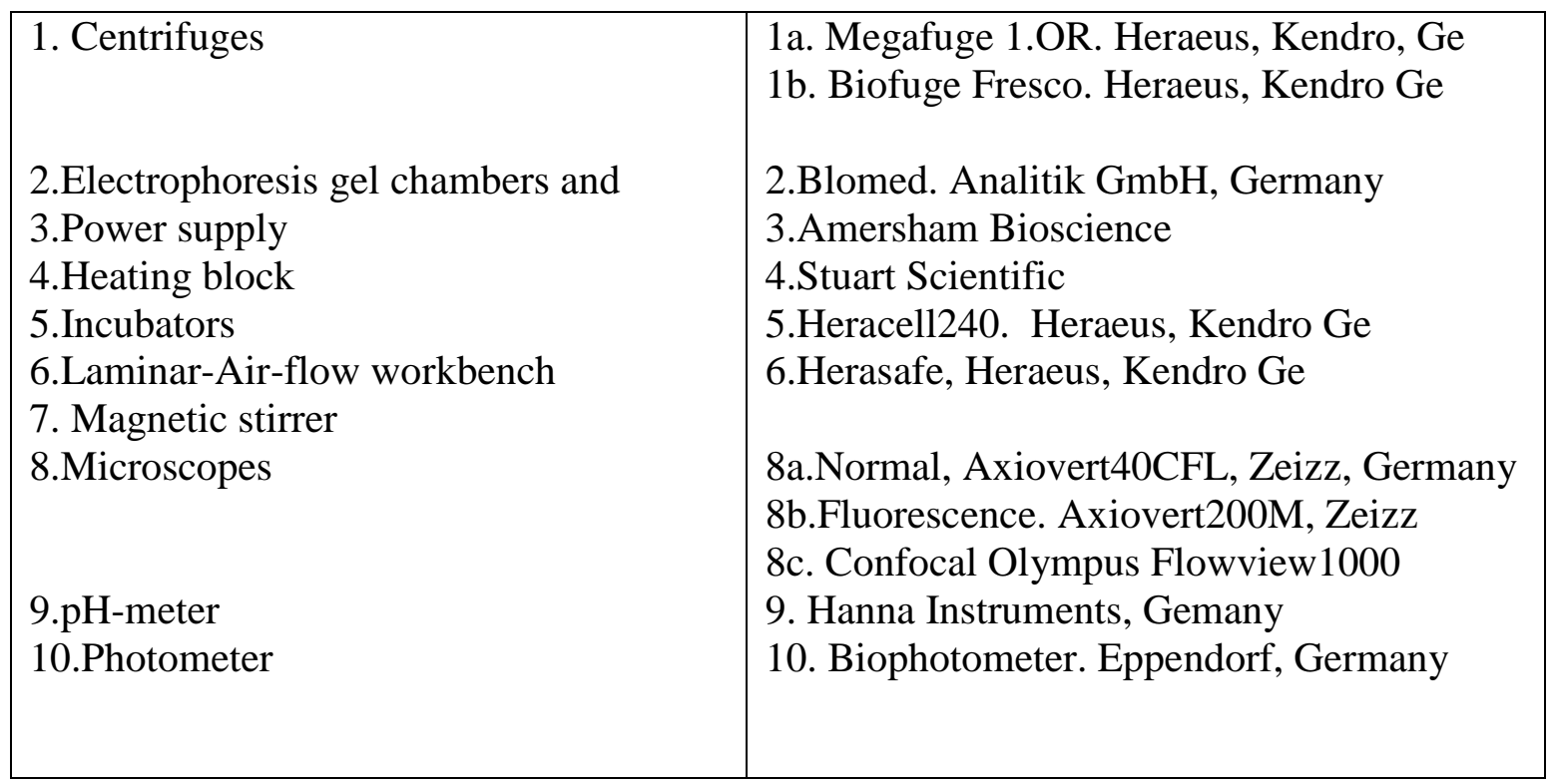

\section{Animals}

C57B16 mice strain.

\section{Protocols}

\section{Polymerase Chain Reaction (PCR)}

Polymerase chain reaction was performed for the amplification of specific cDNAs in order to obtain gene products for insertion into constructs of interest, as well as for the analysis of sequences inserted into such constructs following mini-prep plasmid preparation. In cases where correct sequences were required a polymerase with high proofreading ability was used, Vent Polymerase (New England Bio Labs), whereas in cases of analysis a standard Taq Polymerase was used (Roche). A master mix was prepared containing all required reagents and aliquoted to PCR tubes according to the following protocol: 
- Master mix:

$\begin{array}{lllll} & \mathbf{1} \text { Tube } & \text { 2 Tubes } & \text { 3 Tubes } & \text { 5 Tubes } \\ \mathbf{H 2 O}(\boldsymbol{\mu l}) & 41 & 82 & 123 & 205 \\ \text { dNTPs }(\boldsymbol{\mu l}) & 1 & 2 & 3 & 5 \\ \mathbf{1 0 x} \text { Buffer }(\boldsymbol{\mu l}) & 5 & 10 & 15 & 25 \\ \text { Polymerase }(\boldsymbol{\mu l}) & 0.5 & 1 & 1.5 & 2.5 \\ \text { Total }(\boldsymbol{\mu l}) & 47.5 & 95 & 142.5 & 237.5\end{array}$

- Add $48 \mu$ master mix to each tube.

- Add $1 \mu l$ of appropriate cDNA (nothing for negative control).

- Mix $0.5 \mu \mathrm{l}$ of forward and reverse primers $(100 \mathrm{pmol} / \mathrm{ml})$ per tube for both sample and control and add $1 \mu$ to each tube.

Place tubes into PCR machine and choose required programme (use heated lid!).

Initial denaturation step $-94^{\circ} \mathrm{C} 3 \mathrm{~min}$

Cycle Step 1 - Denaturation $94^{0} \mathrm{C} 1 \mathrm{~min}$

Cycle Step 2 - Annealing 55-60 $60^{\circ} 1 \mathrm{~min}$ (dependent upon primers used)

Cycle Step 3 - Elongation $74^{0} \mathrm{C} 1 \mathrm{~min}$ ( $3 \mathrm{~min}$ for Vent Polymerase)

Final Elongation Step $-74^{0} \mathrm{C} 3 \mathrm{~min}$

PCR products were either stored at $4^{0} \mathrm{C}$ or ran on a $1 \%$ agarose gel for analysis or extraction of the product.

\section{Agarose Gel Analysis and Extraction}

In order to observe PCR products they were run on a $1 \%$ agarose gel. For analysis, ethidium bromide was added to the gel to allow visualization under an U.V. lamp. Where extraction of the product was required, "Gelstar" (BioWhittaker Molecular Applications) was used instead of ethidium bromide to allow visualization without the use of an U.V. lamp and thus preventing the possibility of mutation.

- Weigh 0.5g agarose (Sea Kem LE Agarose Cambrex).

- Add to 50ml 1x TBE Buffer and dissolve using microwave at $850 \mathrm{~W}$.

- Add 1.25 $\mu \mathrm{l}$ Ethidium Bromide $(2.5 \mu \mathrm{l} / 100 \mathrm{ml})$, or $4 \mu \mathrm{l}$ Gelstar, and set in gel apparatus.

- Add a mixture of $3 \mu 1$ loading dye and $6 \mu l$ sample to each well, using a ladder in one to evaluate product size. 
- Connect to power supply and set to $120 \mathrm{~V}, 110 \mathrm{~A}$ for $30 \mathrm{~min}$.

- Visualize DNA under an U.V. lamp.

- For extraction, visualize using Flu-O-Blu lamp (Biozyme), cut out required fragment and extract DNA.

Extraction of DNA from agarose was performed using the QIAquick Gel Extraction Kit (Qiagen) as follows:

- Excise DNA fragment and weigh.

- Add 3xVol buffer QG to 1xVol gel (max 400mg, normally use 450 $\mu \mathrm{l}$ ).

- Leave at $50^{\circ} \mathrm{C}$ for $10 \mathrm{~min}$ (vortex every $3 \mathrm{~min}$ ).

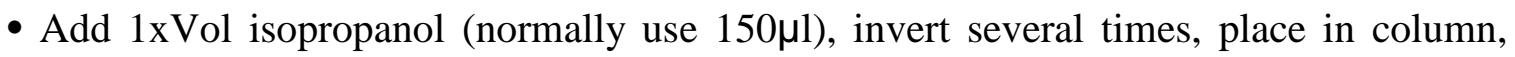
centrifuge 1min, discard flowthrough. (Qiagen column collects fragments within range of $70 \mathrm{bp}-10 \mathrm{~Kb})$.

- Add 500 $4 \mathrm{l}$ QG buffer, centrifuge $1 \mathrm{~min}$, discard flowthrough.

- Add 750 4 l buffer PE, centrifuge 1min, discard flowthrough, repeat centrifugation.

- Place column in clean tube, add $10 \mu \mathrm{EB}$ buffer $/ \mathrm{H}_{2} \mathrm{O}$, leave $1 \mathrm{~min}$, centrifuge $1 \mathrm{~min}$.

\section{$\underline{\text { Restriction Digestion }}$}

Digestion of DNA with restriction enzymes (Roche) was performed in order to analyze a mini prep plasmid preparation. Digestion was performed at $37^{\circ} \mathrm{C}$ for 2 hour using the reaction mix listed below. Digested insert/plasmid DNA was run on a $1 \%$ agarose gel for analysis and extracted when needed for ligation.

$0.5 \mu l$ Enzyme 1

$0.5 \mu l$ Enzyme 2

$2 \mu 1$ Buffer

$17 \mu \mathrm{l}$ insert/plasmid in $\mathrm{H}_{2} \mathrm{O}$ (up to $1 \mu \mathrm{g}$ )

$20 \mu \mathrm{l}$ total reaction volume

\section{$\underline{\text { Ligation }}$}

Ligation of insert into plasmid was performed using T4 DNA Ligase (Roche). Ligation reactions were normally carried out at $15^{\circ} \mathrm{C}$ for minimum 6 hours. The reaction mix used 
was as listed below. Normally a ratio of 1:3 was used for plasmid : DNA incert in a volume of $8 \mu \mathrm{l}$.

$1 \mu 1 \mathrm{~T} 4$ Ligase

$1 \mu l$ Ligation Buffer

$8 \mu l$ DNA

$10 \mu$ l total reaction volume

\section{Transformation}

Chemically competent bacteria (TOP10 Chemically Competent E.Coli, Invitrogen) were transformed with ligated insert-plasmid DNA and expanded according to the following protocol:

- Defrost chemically competent cells on ice $(200 \mu$ l per tube).

- Aliquot $100 \mu \mathrm{l}$ of cells per transformation.

- Add 1-5 $\mu 1$ of ligation mix to $100 \mu \mathrm{l}$ of competent bacteria and leave on ice for $30 \mathrm{~min}$.

- Heat-shock cells at $42^{\circ} \mathrm{C}$ in water bath for $1 \mathrm{~min}$.

- Return cells to ice for $2 \mathrm{~min}$.

- Add $1 \mathrm{ml} \mathrm{LB}$ medium and incubate for $45 \mathrm{~min}$ at $37^{\circ} \mathrm{C}$ (rotatory shaker, 200rpm).

- Centrifuge for $3 \mathrm{~min}$ at 5000rpm and remove excess medium.

Resuspend pellet in $100 \mu 1$ of LB

- Plate onto appropriate selective LB plates and incubate at $37^{0} \mathrm{C}$ overnight.

- Pick colonies and grow in selective LB medium for $10 \mathrm{hr}$ at $37^{\circ} \mathrm{C}$ in shaker.

- Isolate plasmid DNA using mini-prep kit (Qiagen).

- Verify ligation by restriction digest and PCR.

- Prepare high concentrate stock of positive samples using maxi-prep kit (Qiagen).

\section{EndoFree Plasmid Maxi Kit Protocoll}

(EndoFree Plasmid Maxi Kit; Qiagen)

\section{Preparations:}

- transfer 5ml LB medium into culture tube (3 - 5 tubes for each sample)

- add antibiotics (ampicillin: 100 $\mathrm{g}$ ampicillin per 1ml; 
kanamycin: $33 \mu \mathrm{g}$ kanamycin per $1 \mathrm{ml}$ )

- transfer colonies with inoculation loop into tubes

- shake for $8-10 \mathrm{~h}$ at $37^{\circ} \mathrm{C}$ with $250 \mathrm{rpm}$

Method:

- transfer $30 \mu \mathrm{l}$ of the $5 \mathrm{ml}$ shaking culture into $250 \mathrm{ml} \mathrm{LB}$ medium with antibiotics

- shake for about $16 \mathrm{~h}$ at $37^{\circ} \mathrm{C}$ and $250 \mathrm{rpm}$

(- cool down centrifuge at $+4^{\circ} \mathrm{C}$ )

- transfer the $250 \mathrm{ml}$ shaking culture to $4 \mathrm{x} 50 \mathrm{ml}$ tubes

- centrifuge for $15 \mathrm{~min}$ at $8^{\circ} \mathrm{C}$ with 5000rpm

- throw supernatant

- resuspend all pellets in $10 \mathrm{ml}$ of cold buffer P1

- add 10ml of buffer P2 and shake 4 - 6 times

- incubate for $5 \mathrm{~min}$ at RT

- in the meanwhile, screw cap onto QIAFilter Cartridge and put it into a 50ml tube

- after 5min of incubation, add 10ml of cold buffer P3 and shake the lysate carefully $4-6$ times

- pour lysat into the prepared QIAFilter and incubate for 10min at RT

- unscrew caps from filter and inject cell-lysate into the 50ml-tube by using a plugger

- add 2,5ml of ER buffer to the filtered lysate and shake 10 times

- incubate for 30min on ice

- in the meanwhile, equilibrate Qiagen-tip 500 by adding 10ml buffer QBT and allow the column to empty by gravity flow

- after 30 min of incubation, pour lysate into the Qiagen-tip 500 and allow it to enter the resin by gravity flow (throw flow-through)

- wash the Qiagen-tip 500 two times with 30ml buffer QC (throw flow-through)

- elute DNA with $15 \mathrm{ml}$ buffer QN (use a new 50ml tube)

(- break possible: store sample at $4^{\circ} \mathrm{C}$ )

- precipitate DNA by adding $10,5 \mathrm{ml}$ room-temperature isopropanol to the eluted DNA

- mix and centrifuge for $60 \mathrm{~min}$ at $8^{\circ} \mathrm{C}$ with 5000rpm

- throw supernatant 
- wash pellet with $5 \mathrm{ml}$ endotoxin-free, room temperature $70 \%$ ethanol and centrifuge for $15 \mathrm{~min}$ at $8^{\circ} \mathrm{C}$ with 5000rpm

- throw supernatant

- air-dry pellet for 5 - 10 min and dissolve pellet in $100 \mu$ l of endotoxin-free buffer TE

- measure DNA concentration

\section{Neuronal Cell Culture}

Preparations:

- 2 days before culturing the cells:

cover bottom of dishes/chamber slides with $0,01 \%$ PLO in 0,15M Boric Acid

(Poly-L-Ornithine, Sigma-No.: P-3655)

- incubate over night at $37^{\circ} \mathrm{C}$

- aspirate PLO

- wash 3 times with 1xPBS

- cover bottom of dishes/chamber slides with Laminin $(10 \mu \mathrm{g} / \mathrm{ml}$ in aqua bidest.)

- incubate over night (or for at least 4 - 5h) at $37^{\circ} \mathrm{C}$

- aspirate Laminin before using

Method:

- desinfect abdomen of dead mouse with $70 \%$ ethanol

- cut abdomen skin with scissors and forceps without cutting the peritoneum

- cut peritoneum, take out the uterus and transfer it into a $100 \mathrm{~mm}$ dish with sterile PBS (on ice)

- take embryos out of the uterus, cut their heads and transfer the heads into a $60 \mathrm{~mm}$ dish with sterile PBS (on ice)

- transfer one head into a $60 \mathrm{~mm}$ dish with a little bit of PBS

- fix the head with a sharp forceps through the eyes and cut skin and skull between the two brain hemispheres using a micro scissors

- remove skin and skull, take the brain out of the head and transfer the brain to a $60 \mathrm{~mm}$ dish with sterile PBS (on ice); repeat with all heads

- transfer one brain into a $60 \mathrm{~mm}$ dish with a little bit of PBS

- cut the brain between the two hemispheres 
- remove the cerebellum and the brainstem

- remove the meninges using two forceps

- cut hippocampus and transfer it into a tube with $5 \mathrm{ml}$ PBS

- cut cortex and transfer it into a tube with 5ml PBS

- repeat with all the brains

- homogenize tissue in the tubes with 5ml-pipette

- centrifuge for $7 \mathrm{~min}$ at $37^{\circ} \mathrm{C}$ with $2500 \mathrm{rpm}$

- aspirate PBS

- resuspend cells in 1 - 5ml neuronal medium (BME, 1\% FCS, 1\% glucose, $2 \% \mathrm{~B}-27)$

- count cells using a counting chamber

- dilute cells with neuronal medium up to a concentration of $10^{6}$ cells $/ \mathrm{ml}$

- put cells into dish:

dish $\varnothing 30 \mathrm{~mm} \rightarrow \sim 5^{*} 10^{5}$ cells in $2 \mathrm{ml}$

$\operatorname{dish} \varnothing 60 \mathrm{~mm} \rightarrow \sim 10^{6}$ cells in $4 \mathrm{ml}$

4-well-chamber-slide $\rightarrow \sim 20000-50000$ cells in 1ml per well

- incubate cells at $37^{\circ} \mathrm{C}$ and $5 \% \mathrm{CO}_{2}$

(Do not change medium!)

\section{Immunocytochemistry of Cultured Cells}

Materials:

E15-neurons or cell line cells on chamber slides.

Method:

- aspirate medium

- wash once with PBS (RT)

- incubate for 20min with $4 \%$ PFA at room temperature

- aspirate PFA

- wash once with PBS (room temperature)

- incubate for 10 min with $0,1 \%$ Triton-X

- remove chambers from slide

- wash 3 times with PBS (room temperature) 
- drop PBS from slides onto a wipe

- border slide with PAP-Pen

- incubate slide $30 \mathrm{~min}$ with $1 \% \mathrm{BSA}$ in PBS (if longer then at $4^{\circ} \mathrm{C}$ )

- incubate over night with primary antibody at $+4^{\circ} \mathrm{C}$ in a wet box $(500 \mathrm{ml} / \mathrm{slide})$

- wash 3 times 10min with PBS at room temperature (in a cuvette)

- incubate over night with secondary antibody at $+4^{\circ} \mathrm{C}$ in a wet box $(500 \mu \mathrm{l} /$ slide $)$

- wash 3 times 10min with PBS at room temperature (in a cuvette, keeping in the dark)

- drop PBS from slides onto a wipe

- drop 2 drops of Mowiol solution over the slide and put cover slip over it

- dry it over night at $+4^{\circ} \mathrm{C}$

Storage: store dark at $+4^{\circ} \mathrm{C}$

\section{Effectene Transfection of primary neurons with Effectene Transfection Reagent}

- mix in an Eppendorf-Cup $85 \mu \mathrm{l}$ EC-buffer, 0,5 $\mu \mathrm{g}$ of plasmid and $4 \mu \mathrm{l}$ Enhancer (ratio

8:1 Enhancer:DNA),

- vortex for $1 \mathrm{sec}$, incubate for $2-5 \mathrm{~min}$ at room temperature

- add $10 \mu \mathrm{l}$ Effectene, vortex for $10 \mathrm{sec}$, incubate for 5-10 min at room temperature

- prepare $15 \mathrm{ml}$ tubes with $10^{6}$ freshly isolated neurons in $1 \mathrm{ml}$ neuronal-medium

- add $100 \mu 1$ neuronal-medium to transfection mixture, mix with pipette

- add Effectene-reaction-mixture carefully to the cells, shake inverting the tube, carefully

- incubate for $30 \mathrm{~min}$ at $37^{\circ} \mathrm{C}$ and $5 \% \mathrm{CO}_{2}$, without cap

- drop cold PBS onto the mixture up to the top of the tube

- shake tube inverting, carefully

- centrifuge for $5 \mathrm{~min}$ at $+4^{\circ} \mathrm{C}$ and $2000 \mathrm{rpm}$

- aspirate supernatant

- resuspend cells in $4 \mathrm{ml}$ neuronal medium

- seed cells in one 4-well-chamber $(1 \mathrm{ml} /$ well $)$ and incubate at $37^{\circ} \mathrm{C}$ and $5 \% \mathrm{CO}_{2}$

- check transfection efficiency starting from the day 3.

\section{Effectene Transfection of cell line cells with Effectene Transfection Reagent}


- one day before transfection seed cell line cells in chamber slides with density 75000 cells/ml

- on the day of transfection, mix in an Eppendorf-Cup $85 \mu$ EC-buffer, 0,5 $\mu \mathrm{g}$ of plasmid and $4 \mu \mathrm{l}$ Enhancer (ratio 8:1 Enhancer:DNA),

- vortex for $1 \mathrm{sec}$, incubate for $2-5 \mathrm{~min}$ at room temperature

- add $10 \mu \mathrm{l}$ Effectene, vortex for $10 \mathrm{sec}$, incubate for 5-10 min at room temperature

- add $100 \mu 1$ neuronal-medium to transfection mixture, mix with pipette

- add Effectene-reaction-mixture drop by drop carefully to the cells

- check transfection efficiency starting from the day 2. 


\section{Results}

\section{Expression of designed vectors in primary neurons}

Following the aim of the present work to observe the expression of tau and investigate tau protein, we first designed vectors which could express certain fluorescent proteins alone and in fusion with tau, in primary neurons as well as in cell lines. Used constructs are based on the backbone of pLenti6/V5 (Figure 5). This vector allows expression of proteins in different type of cells including primary neuronal cultures. Construct contains CMV (cytomegalovirus) promoter and resistance to Ampicillin.

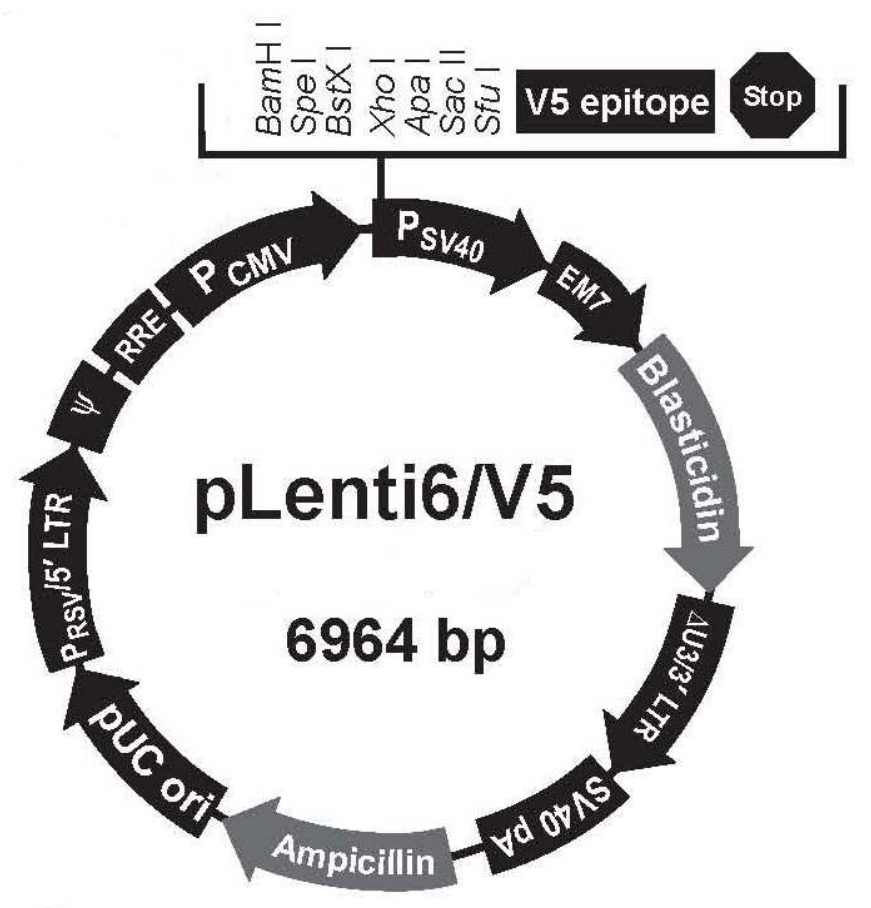

Figure 5. Schematic map of pLenti6/V5 construct. Gene sequences of GFP, Cerulean and Citrine were cloned in the multiple cloning site between SpeI and XhoI restriction sites. Human tau protein (ht441) was cloned between XhoI and ApaI. 
Gene sequences of GFP, Cerulean and Citrine were cloned in the multiple cloning site between SpeI and XhoI restriction sites. Human tau protein (ht441) was cloned between XhoI and ApaI on the C-terminal of the fluorescent molecules in order to prevent the influence on the sites of tau responsible for interaction with tubulin, and dimerization, which are present on the C-terminal site of tau. In order to check the expression of designed plasmids, primary neuronal cultures from hippocampi of C57BL/6 mice embryos (E15) were isolated and dispersed mechanically. Cells were transfected with GFP, Cerulean, Citrine, GFP-tau, (using $0.5 \mu \mathrm{g}$ plasmid DNA per $1 \times 10^{6}$ cells) and cotransfected with Cerulean-tau and Citrine-tau (using $0.25 \mu \mathrm{g}$ of each plasmid DNA per $1 \times 10^{6}$ cells during seeding) using Effectene Transfection Kit. Cells were seeded in BMEbased neuronal medium (BME) supplemented with 2\% B-27 supplement, $1 \%$ glucose and $1 \%$ fetal calf serum in 4-well chamber culture dishes (pre-treated with poly-L-ornithin and laminin) with a density of 250000 cells $/ \mathrm{ml}$. On the day 3-5 when the neurons showed expression of the transfected proteins, cells were fixed and used for further experiments. In parallel N1E cell line cells, used as a test system, were transfected with corresponding plasmids. In this case, cells were first seeded in chamber slides with density 75000 cells $/ \mathrm{ml}$ and transfected using Effectene Transfection Kit, on the next day, followed by fixation on the $2^{\text {nd }}$ day after transfection.

Confocal laser scanning microscopy of transfected neurons demonstrated expression of all the plasmids with distribution all along the neurites in cells (Figure 6). Equal expression of designed constructs was also observed in N1E cells. These results conclude that obtained vectors expressing fluorescent proteins alone as well as in fusion with tau protein can be used for the further approaches in primary neurons as well as in cell line. 

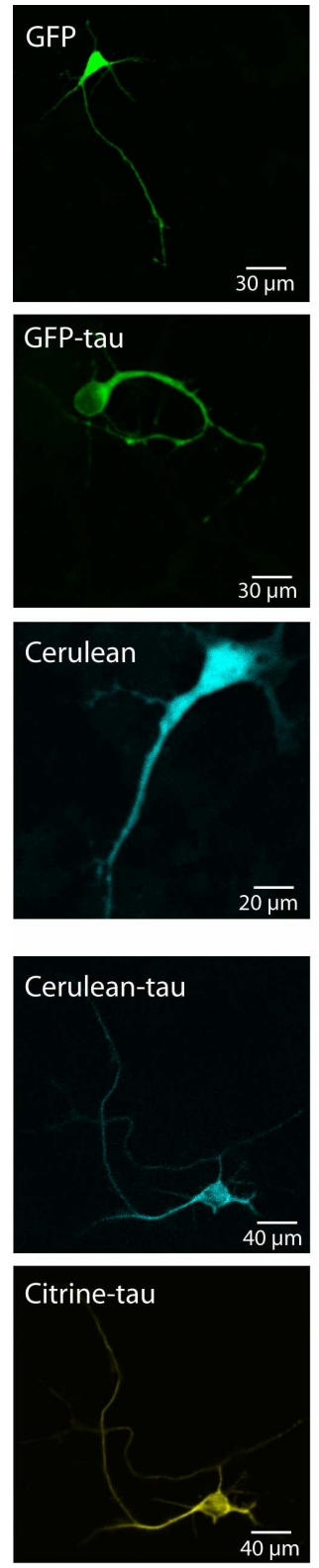

Primary neurons

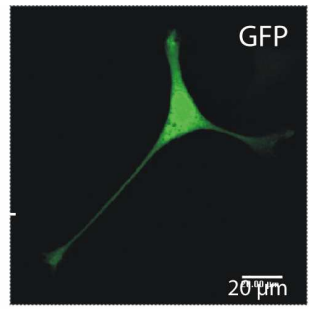

GFP-tau
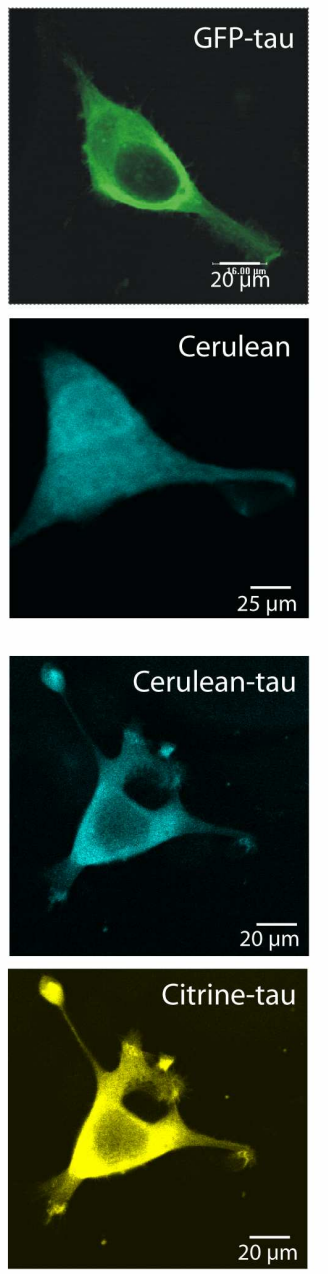

N1E cells

Figure 6. Analysis of a protein models in primary neuronal cultures and N1E cell line. Confocal images of primary neurons 3 days or N1E cells 2 days after transfection with GFP, Cerulean, Citrine, GFP-tau, and cotransfection with Cerulean-tau and Citrine-tau. 


\section{Intensity based and lifetime based FRET analysis of the fluorescence proteins in neuroblastoma N1E cells}

One of the novel methods allows to study the interaction of proteins named Förster resonance energy transfer (FRET). To establish the FRET based method and to test the possible FRET pair of distinct fluorescence dyes, which might be suited for our investigations, neuroblastoma N1E cells were used. N1E cells were chosen because of the higher transfection efficiency of this type of cells, compare to primary neurons, therefore being a better candidate for testing the system. Cells first were cultured in BME-based

medium in $75 \mathrm{~cm}^{2}$ dishes. Then cells were seeded in 4-well chamber culture dishes with a density of 75000 cells/ml, followed by transfection with Cerulean, Citrine and CeruleanCitrine, on the next day. On the day 2 cells showed about $30-50 \%$ expression of the transfected proteins. Cells were fixed and used for FRET experiments.

First, cells expressing Cerulean were analysed using confocal laser scanning microscopy. Scanning using $458 \mathrm{~nm}$ laser showed expression of the fluorescent proteins in the cells (Figure 7A). Fluorescence lifetime images were then obtained from Cerulean using 408 $\mathrm{nm}$ diode laser excitation and time correlated single photon counting (TCSPC). An emission filter for Cerulean detection was placed between the output port of the scanning-head and the time domain fluorescence lifetime imaging detector. Lifetimes from 0.8 to 1.6 nanoseconds were coded in red, representing expected signals from FRET, (Figure 7B). Lifetimes from 1.6 to 3.0 nanoseconds were coded in green, representing the expected lifetime of Cerulean in the absence of acceptor. The lifetime of Cerulean alone showed a normal distribution $2.0+/$ - 0.023 nanoseconds (mean +/- SEM) indicative of a lack of FRET, showed after determination the average of the peak lifetimes collected from several regions of interest in the cells (Figure 8).

Cells, expressing Cerulean-Citrine were scanned by confocal laser scanning microscopy, using $458 \mathrm{~nm}$ laser for Cerulean and $515 \mathrm{~nm}$ laser for Citrine, showed clear expression of the fluorescent dyes in the cells (Figure 9A). For intensity based FRET measurements the bleaching of acceptor (Citrine) in part of the cell was performed followed by analysis of donor emission. 
A

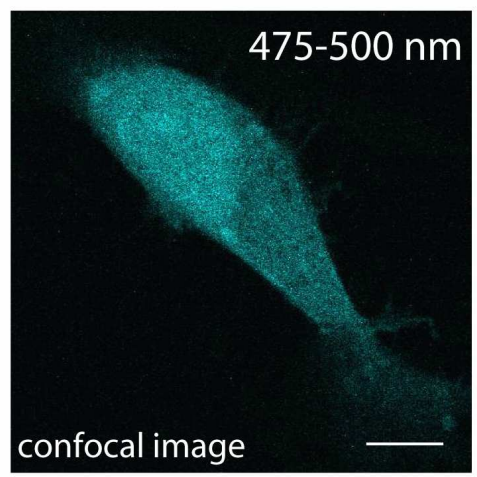

B
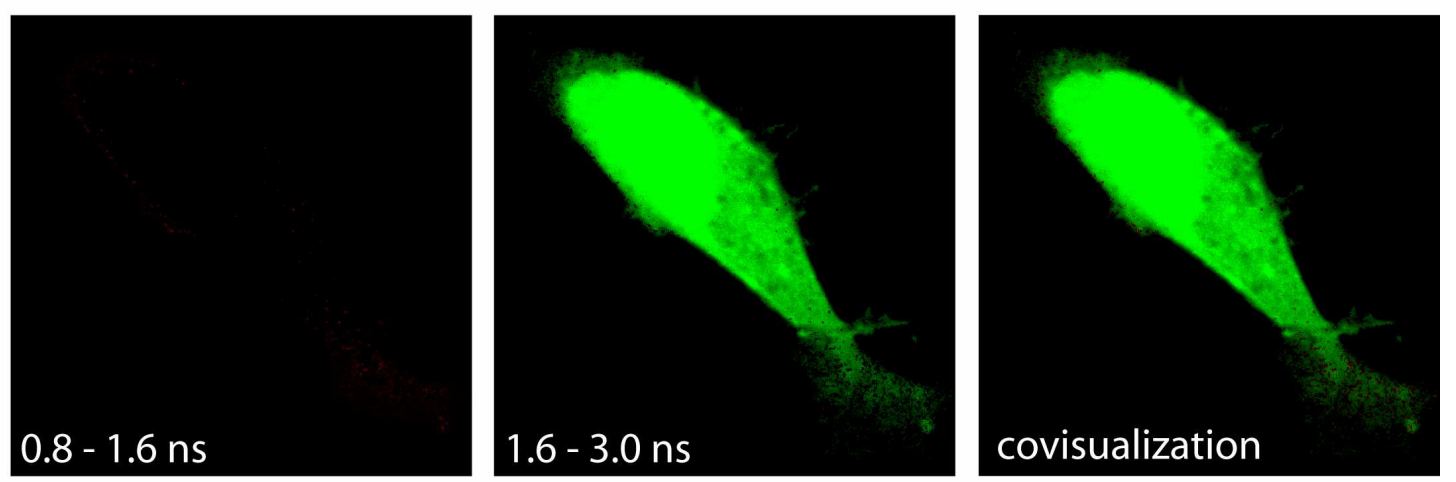

Figure 7. N1E cells 2 days after transfection with Cerulean. A. Confocal analysis showed expression of Cerulean in the cell. B. FLIM analysis of Cerulean in the same cell. Lifetimes are coded in red (0.8 to $1.6 \mathrm{~ns})$ and green (1.6 to $3.0 \mathrm{~ns})$. Scale bar: $20 \mu \mathrm{m}$.

As expected the intensity of the donor in the area where acceptor was bleached is increased compare to the unbleached area (Figure 9A). The same cells were used for fluorescence lifetime-based FRET to measure and compare the lifetime of Cerulean in the bleached and non-bleached area. We expected that in non-bleached area the lifetime distribution will be shifted to shorter lifetimes compared to the bleached areas, where the lifetime should be similar to the lifetime of Cerulean alone. 


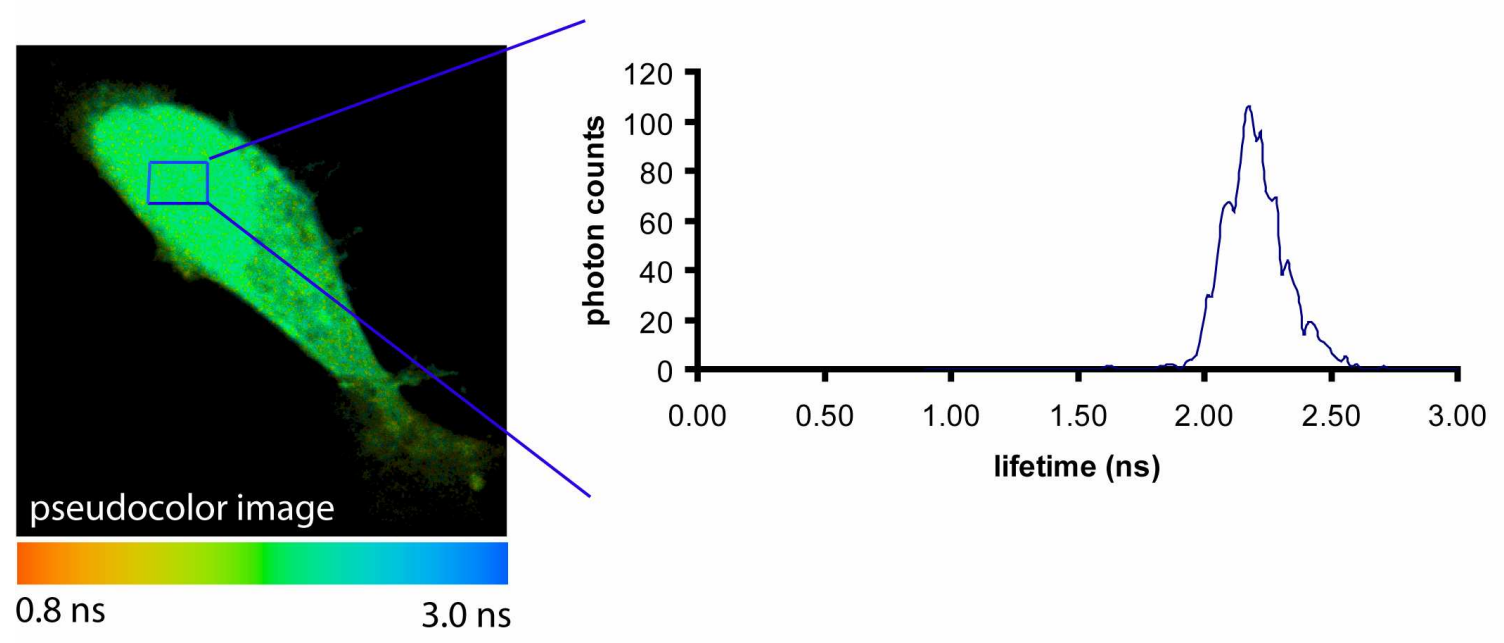

Figure 8. N1E cells 2 days after transfection with Cerulean. Pseudocolor image and distribution of the Cerulean lifetime in the cell expressing Cerulean, from the region of interest shows a normal distribution of Cerulean with a peak between 2.0 and $2.5 \mathrm{~ns}$.

Indeed, the experiment showed shorter lifetimes (less than $1.6 \mathrm{~ns}$ ) of the Cerulean in the non-bleached areas compared to the Citrine bleached areas (Figures 9B, 10A). In detail, the average of the peak lifetimes collected from several regions of interest in the cells, showed lifetime distribution of Cerulean in the bleached area $1.93+/-0.019$ nanoseconds (mean +/- SEM), compare with a nonbleached area with distribution $1.42+/-0.054$ nanoseconds (mean +/- SEM), indicative of FRET (Figure 10B).

Additionally, cells expressing Citrine were analysed. After confocal scanning microscopy, showing distribution of the expressed protein in the cell (Figure. 11A), lifetime analysis was performed. We expected, that no sufficient values of lifetime of Citrine will be obtained, using the emission filter determined for Cerulean. Indeed, analysis of the data showed insufficient values less than $0.8 \mathrm{~ns}$ (Figure 11B, C) demonstrated by, both cell transfected with Citrine and other cells which are not transfected. This result indicates signal obtained from background. 


\section{A}
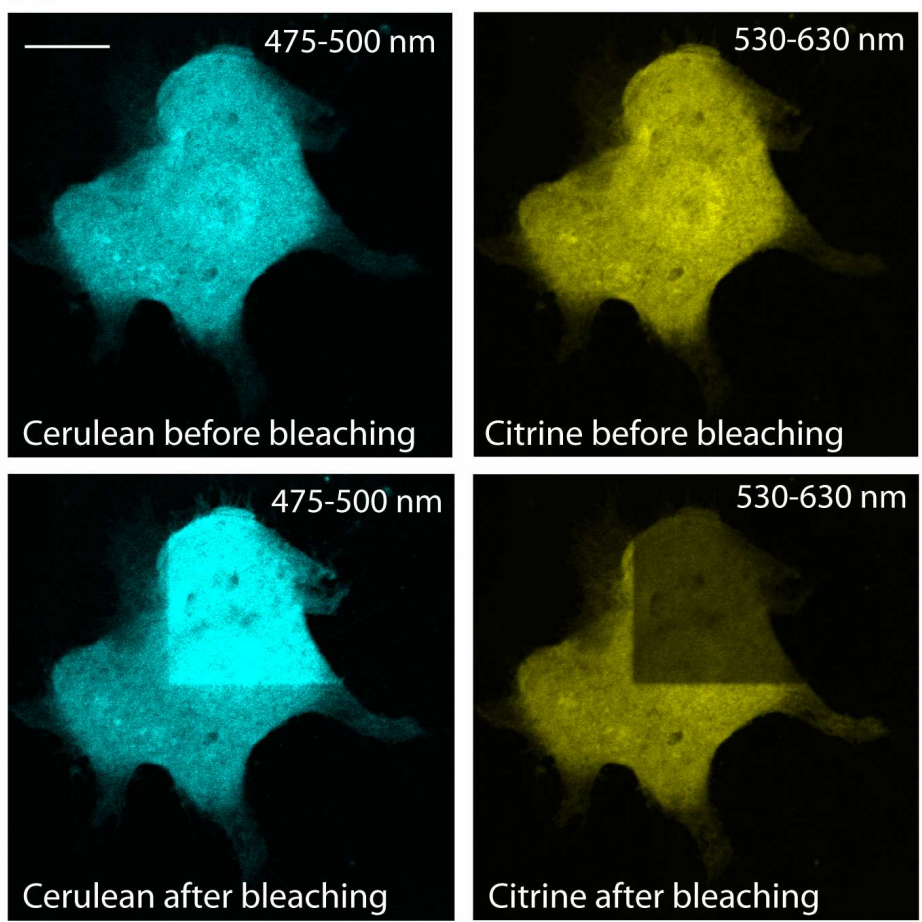

B
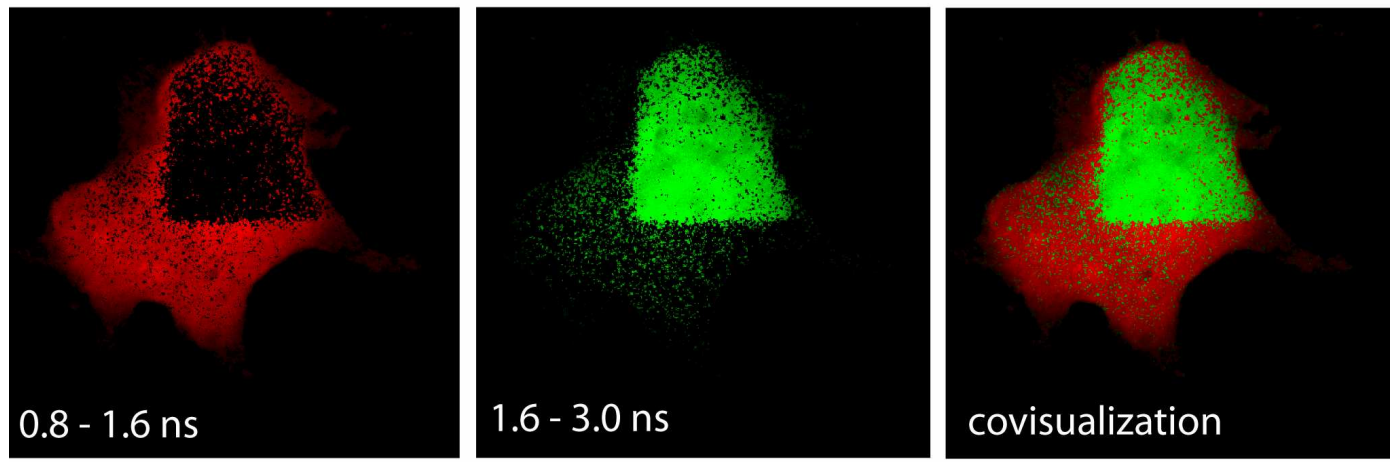

Figure 9. N1E cells 2 days after transfection with Cerulean-Citrine. A. Confocal images of the donor (Cerulean) and acceptor (Citrine) before and after photobleaching of the acceptor using intensity based FRET analysis. After photobleaching of the acceptor an increase of the donor emission by 35-38\% was observed in region of interest. B. FLIM analysis of Cerulean in the same cell. Lifetimes are coded in red (0.8 to $1.6 \mathrm{~ns})$ and green (1.6 to $3.0 \mathrm{~ns}$ ). FLIM analysis shows lifetime distribution before and after photobleaching. Scale bar: $20 \mu m$. 


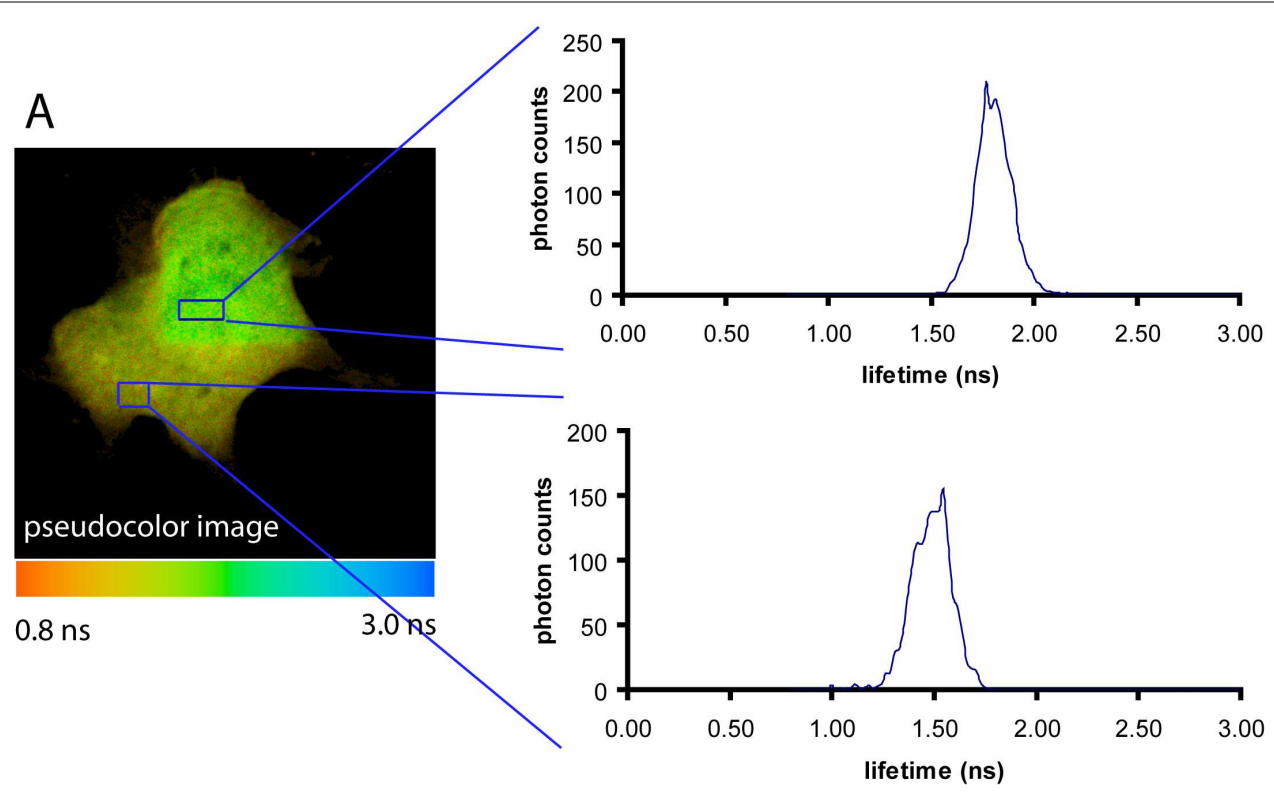

B

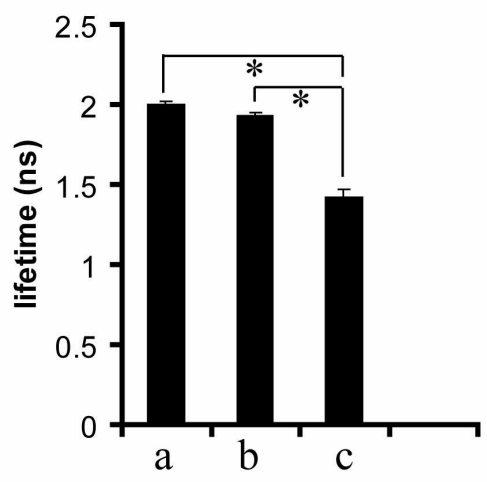

a - Cerulean; b - Cerulean-Citrine; $\mathrm{n}=15$ non-bleached area, $\mathrm{n}=15$
C

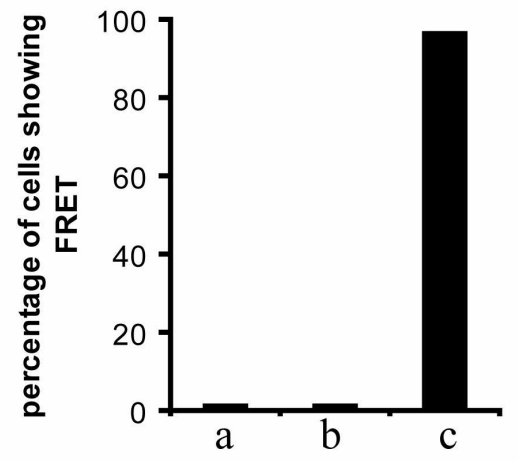

c - Cerulean-Citrine bleached area $\mathrm{n}=15$

Figure 10. NIE cells 2 days after transfection with Cerulean-Citrine. A. Distribution of the Cerulean lifetime in the cell, from the region of interest. B. Analysis of lifetime peak values. Averaged lifetime distribution of three regions of interest in several N1E cells (n), transfected with Cerulean and Cerulean-Citrine. Data are presented as mean +/SEM of independent experiments. For each experimental condition $n>5$; * $p<0.001$ (two-tailed t-student test). C. Analysis of the percentage of cells showing short lifetime as a sign of FRET in NIE cells expressing Cerulean and Cerulean-Citrine. 


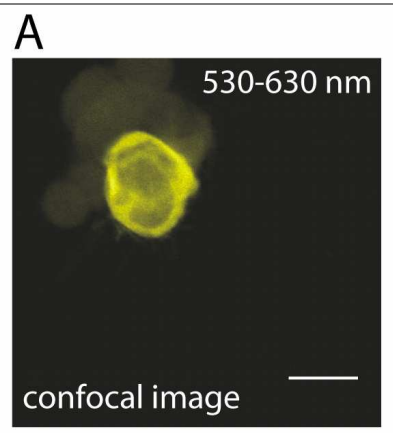

B
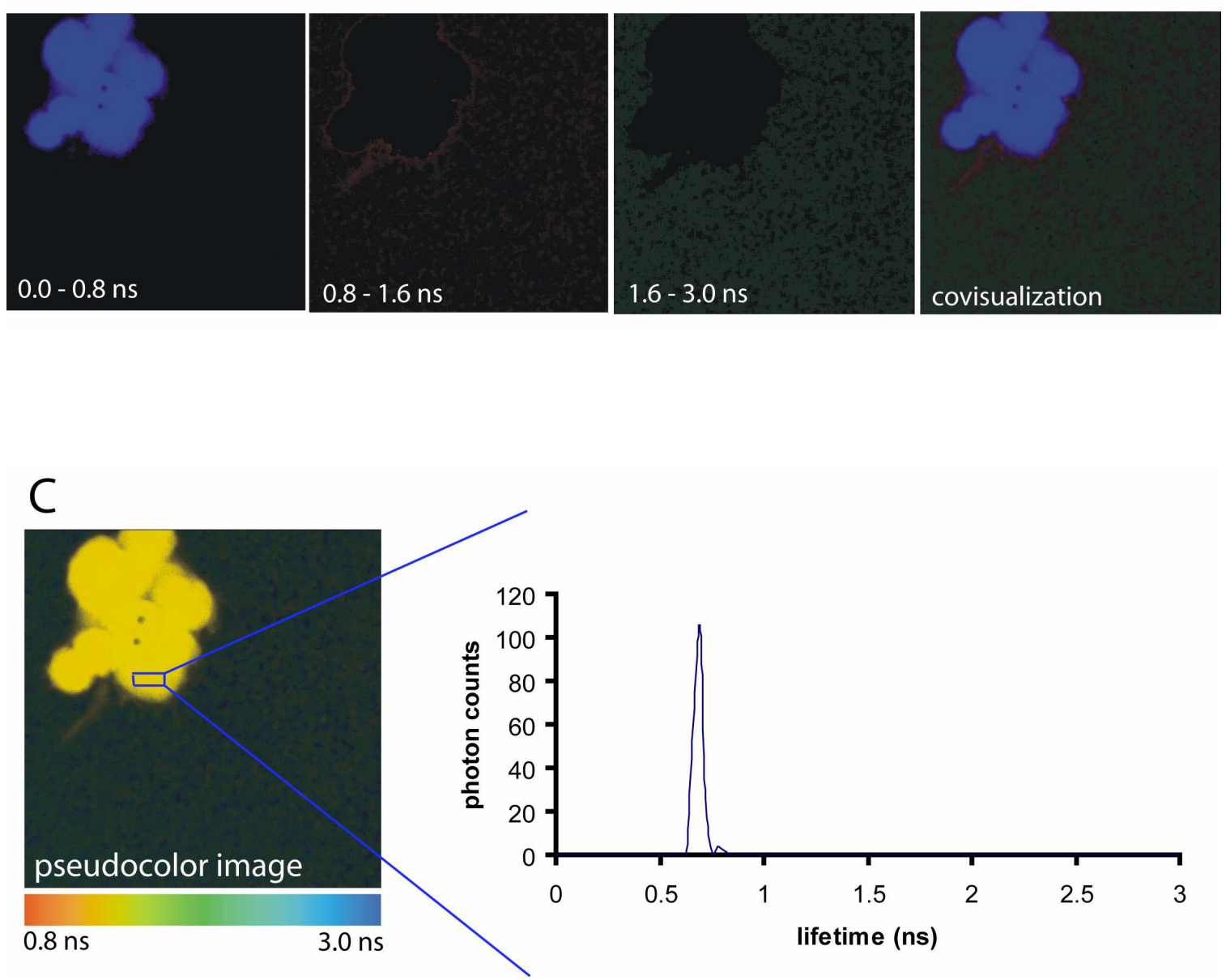

Figure 11. N1E cells 2 days after transfection with Citrine. A. Confocal analysis showed expression of Citrine in the cell. B. FLIM analysis of Citrine in the same cell. Lifetimes are coded in blue (0.0 to $0.8 \mathrm{~ns})$, red (0.8 to $1.6 \mathrm{~ns})$ and green (1.6 to $3.0 \mathrm{~ns})$. $\boldsymbol{C}$. Pseudocolor image and distribution of the Cerulean lifetime of the same cell, from the region of interest, showed lifetime peak in the area less than $0.8 \mathrm{~ns}$. Scale bar: $30 \mu \mathrm{m}$. 


\section{Lifetime based FRET analysis of Cerulean in primary neurons}

To confirm results in primary neurons we transfected primary neuronal cultures from hippocampi of C57BL6 mice embryos (E15), with Cerulean and Cerulean-Citrine. Confocal scanning analysis showed clear distribution of the expressed proteins in the cell bodies and along the neurites (Figures 12A, 14A).

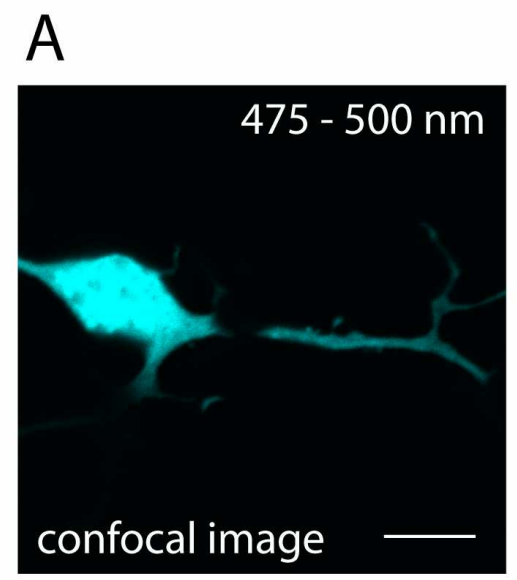

B
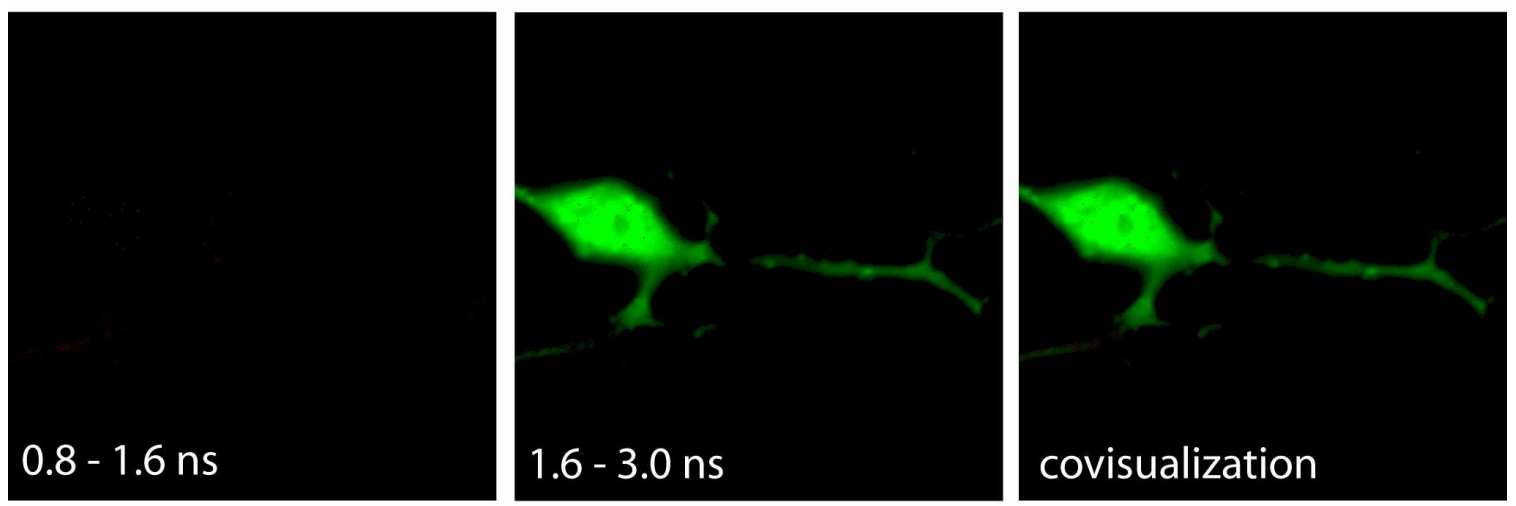

Figure 12. Primary neurons 4 days after transfection with Cerulean. A. Confocal analysis showed expression of Cerulean along the cell. B. FLIM analysis of Cerulean in the same cell. Lifetimes are coded in red (0.8 to $1.6 \mathrm{~ns})$ and green (1.6 to $3.0 \mathrm{~ns})$. Scale bar: $10 \mu \mathrm{m}$. 
FLIM measurements of cells expressing Cerulean showed lifetime distribution of Cerulean alone in primary neurons $2.1+/-0.017$ nanoseconds (mean +/- SEM) in the cell body and $1.99+/-0.032$ nanoseconds (mean +/- SEM) in the neuritis (Figure 12B, 13).

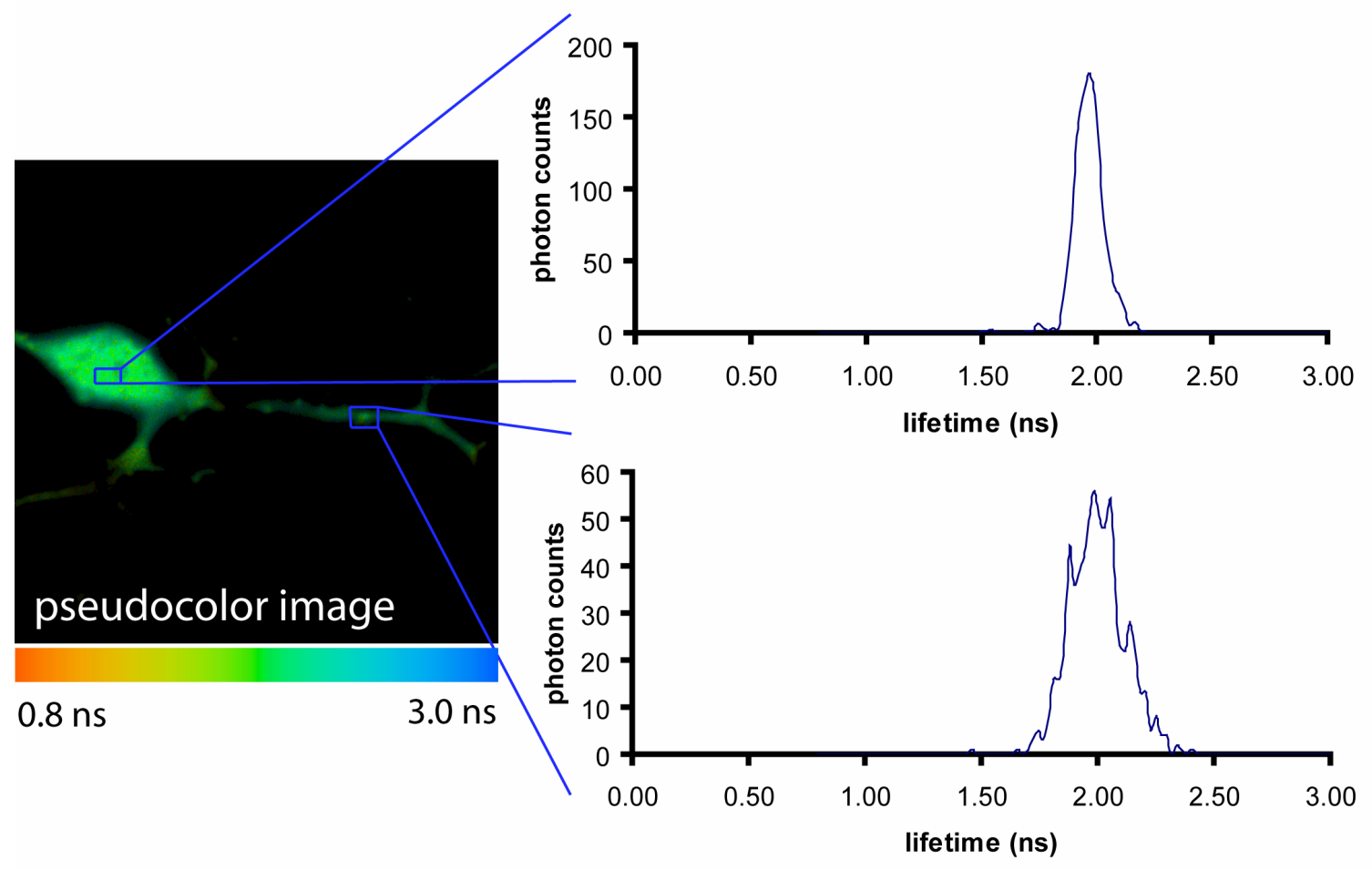

Figure 13. Primary neurons 4 days after transfection with Cerulean. Pseudocolor image and distribution of the Cerulean lifetime in the cell, from the region of interest, showed that both in the cell body and in the neurites the lifetime for Cerulean is about 2.0 ns.

In the same time, primary neurons transfected with Cerulean-Citrine construct showed lifetime distribution $1.39+/-0.051$ nanoseconds (mean +/- SEM) in the cell body and $1.38+/-0.049$ nanoseconds (mean +/- SEM) in neurites (Figure 14B, 15A, B). 


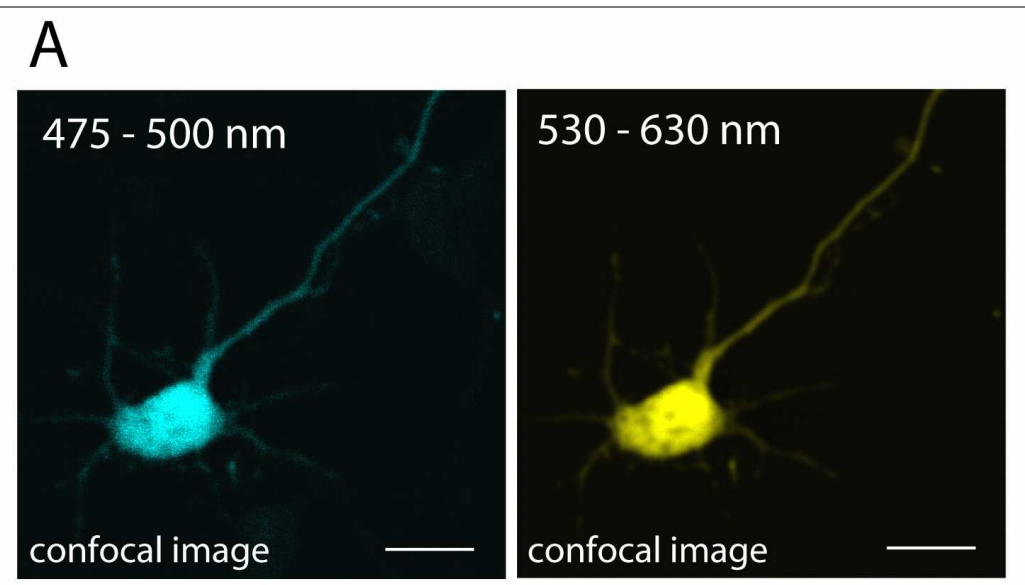

B
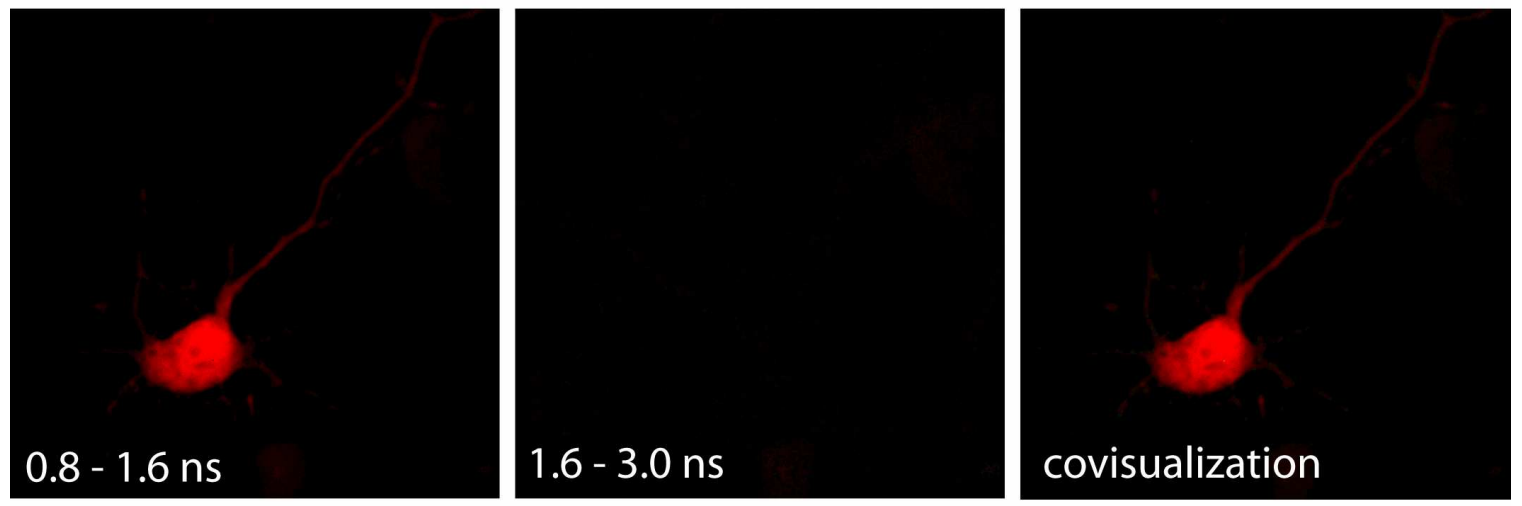

Figure 14. Primary neurons 4 days after transfection with Cerulean-Citrine.

A. Confocal images of the donor (Cerulean) and acceptor (Citrine) showed expression of Cerulean and Citrine all along the cell. B. FLIM analysis of Cerulean in the same cell. Lifetimes are coded in red (0.8 to $1.6 \mathrm{~ns})$ and green (1.6 to $3.0 \mathrm{~ns})$. Scale bar: $10 \mu \mathrm{m}$.

Calculation of percentage of cells having FRET showed that $97 \%$ of cells expressing Cerulean-Citrine demonstrate shift in the lifetime (Figure 15C). These results showed that FRET occurred between Cerulean and Citrine molecules, which can be measured by FLIM, and that Cerulean-Citrine as a proper FRET pair can be used in the further studies of protein interactions. 


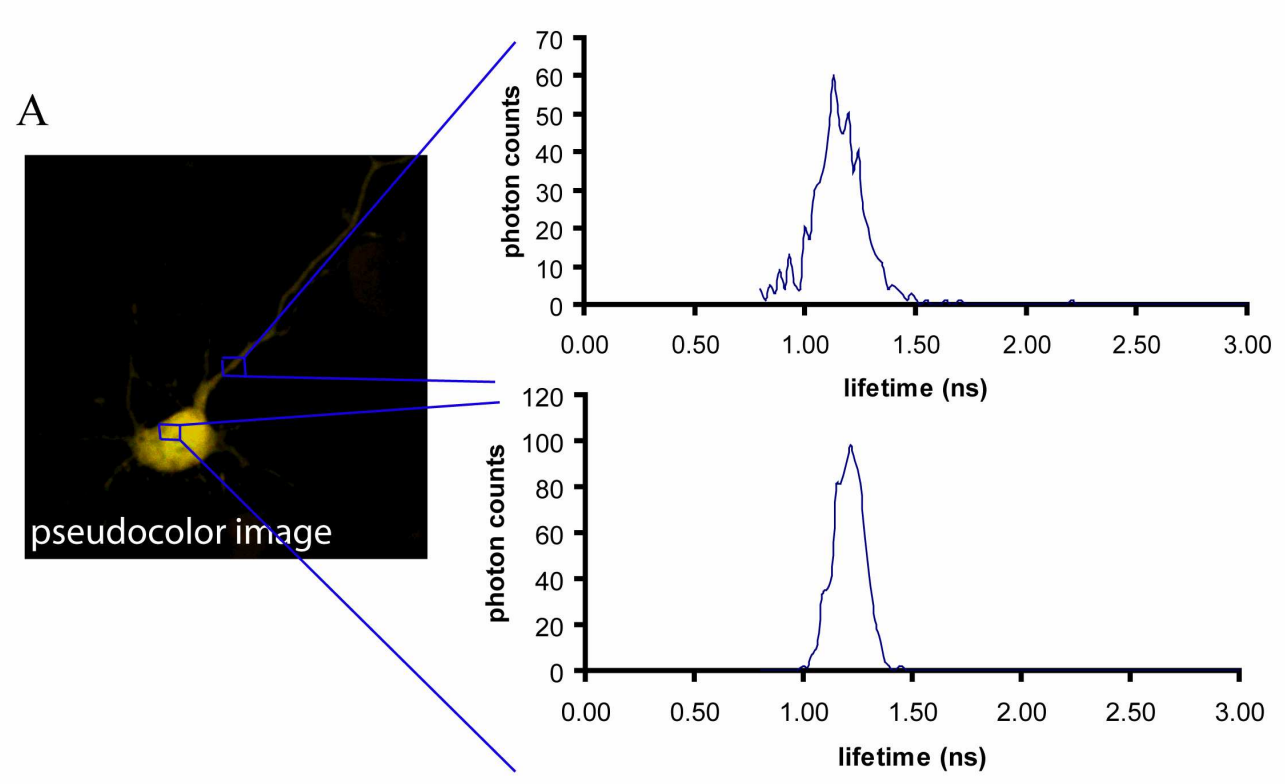

B

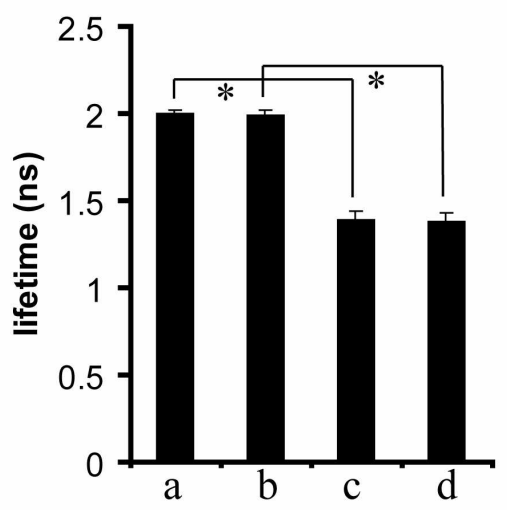

C

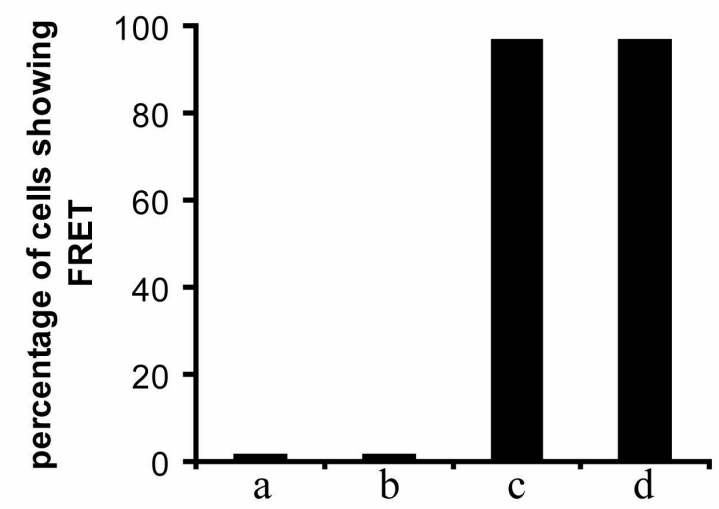

a - Cerulean; b - Cerulean; cell body axon

c - Cerulean-Citrine cell body $\mathrm{n}=8$ axon $\mathrm{n}=10$ $\mathrm{n}=10$ $\mathrm{n}=8$

Figure 15. Primary neurons 4 days after transfection with Cerulean-Citrine.

A. Distribution of the Cerulean lifetime in the cell from the regions of interest. $\boldsymbol{B}$. Analysis of lifetime peak values. Averaged lifetime distribution of three regions of interest in several primary neurons, transfected with Cerulean and Cerulean-Citrine. Data are presented as mean +/- SEM of independent experiments. For each experimental condition $n>5$; * $p<0.001$ (two-tailed t-student test). C. Analysis of the percentage of cells showing short lifetime as a sign of FRET in primary neurons expressing CeruleanCitrine. 


\section{FRET between tau-GFP and tubulin-Cy3 in primary neurons transfected with tau- GFP}

To study the expression of human tau in primary neurons we first determine whether overexpressed GFP-tau interacts with its physiological binding partner tubulin. We transfected hippocampal primary neurons with human tau gene tagged at its $\mathrm{N}$-terminal with green fluorescent protein (GFP), as well as with GFP alone, followed by fixation of cells on the 3-5 day after transfection. Using confocal scanning microscopy GFP-tau and GFP visualized in the cell body and neurites (Figures 16A, 22A). No change in differentiation or any toxicity was observed in the GFP-tau transfected neurons compared to GFP transfected neurons after 3-5 days of transfection.

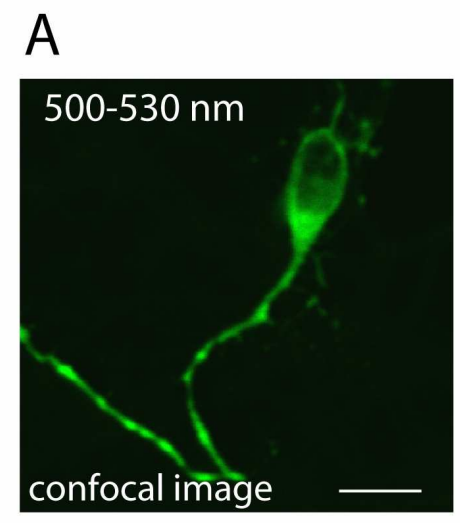

B

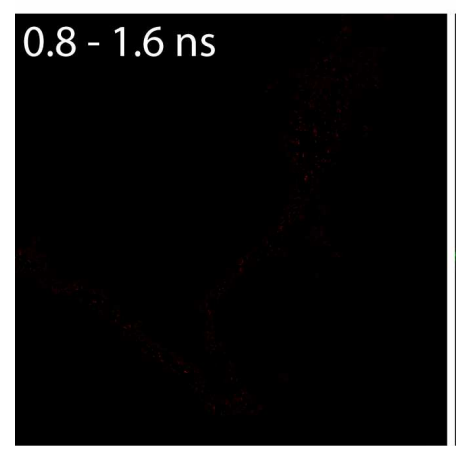

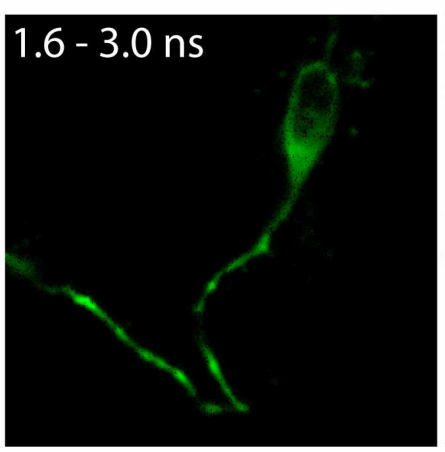

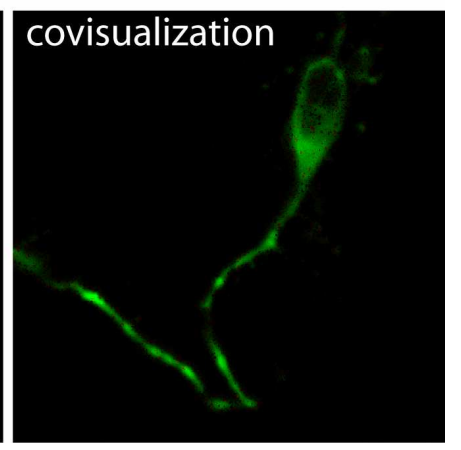

Figure 16. Primary neurons 4 days after transfection with the GFP-tau plasmid.

A. Classic confocal analysis of GFP demonstrates distribution of GFP-tau along the cell. B. FLIM analysis of GFP in the same cell. Lifetimes are coded in red (0.8 to $1.6 \mathrm{~ns})$ and green (1.6 to $3.0 \mathrm{~ns}$ ). Scale bar: $10 \mu \mathrm{m}$. 
Next, neurons, transfected with GFP-tau were labeled with a Cy3-conjugated monoclonal antibody directed against ß-tubulin (Figure 18A). As a negative control antibodies directed against neurofilament marked by Cy3 were applied (Figure 20A). Furthermore, neurons expressing GFP were immunostained with Cy3-conjugated antibodies directed against B-tubulin (Figure 22A).

Lifetime based FRET analysis showed a shift of the lifetime distribution and detection of lifetimes lower than $1.6 \mathrm{~ns}$ indicating FRET in 55 percent (Figures 18B, 19A, B, C) of analyzed neurons transfected with GFP-tau labeled with Cy3-tubulin antibody with a more pronounced FRET in neurites compared to cell bodies. In detail distribution of lifetime of GFP consists of 1.97 +/- 0.058 nanoseconds (mean +/- SEM) in the cell bodies and $1.55+/-0.026$ nanoseconds (mean +/- SEM) in the neurites. In nonlabeled cells expressing GFP-tau, lifetime detected in the range 1.6 - $3.0 \mathrm{~ns}$ (Figures 16B, 17) with distribution 1.97 +/- 0.017 nanoseconds (mean +/- SEM) in the cell body and $1.98+/$ 0.030 nanoseconds (mean $+/$ - SEM) in the neurites.

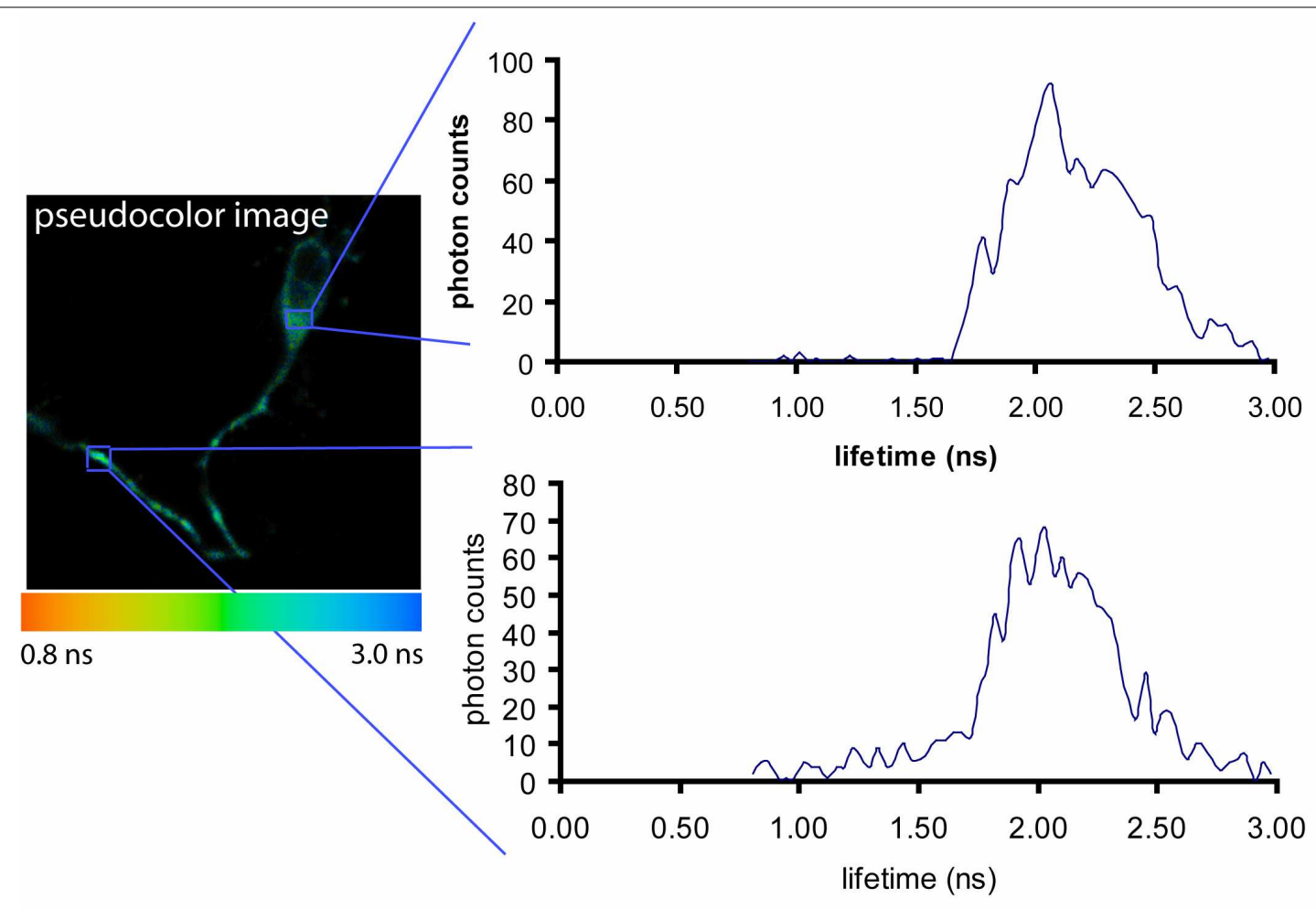

Figure 17. Primary neurons 4 days after transfection with GFP-tau plasmid. Pseudocolor image and distribution of the GFP lifetime from the region of interest in the cell, showed distribution of lifetime of GFP with a peak about 2.0 ns. 
A
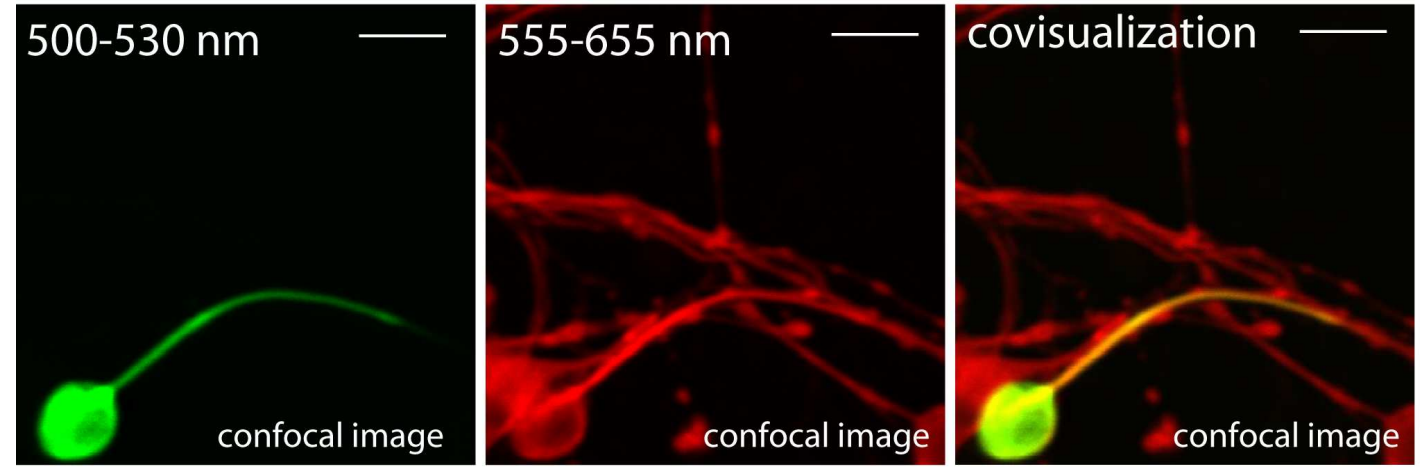

B
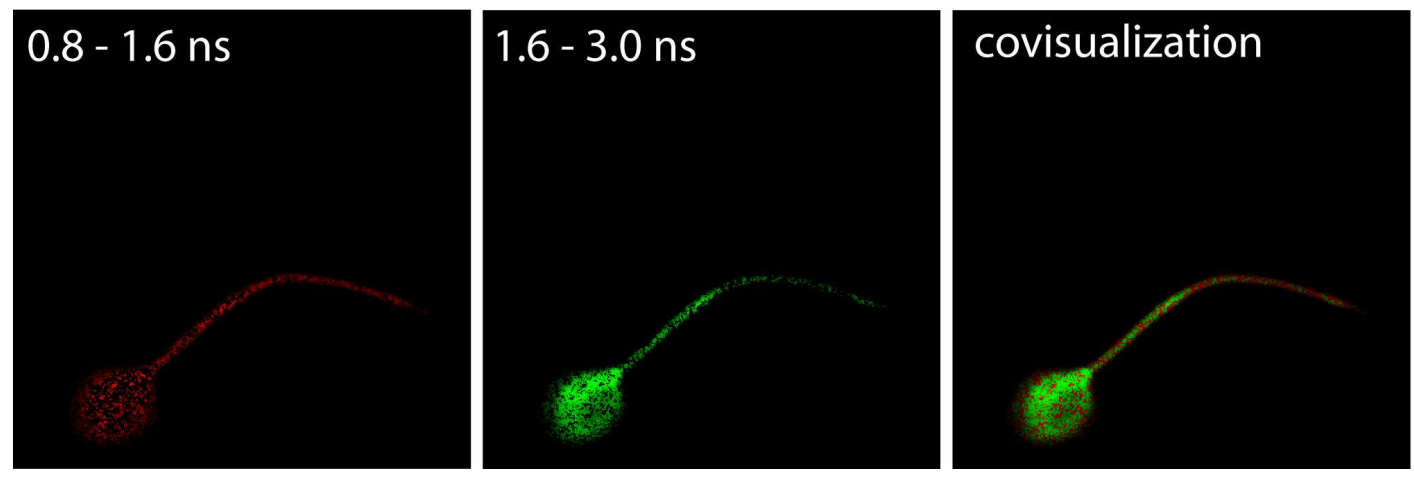

Figure 18. Primary neurons 4 days after transfection with GFP-tau and labeled with monoclonal anti- $\beta$-tubulin-Cy3 antibodies. A. Classic confocal analysis of GFP and Cy3 demonstrates colocalisation of GFP-tau and Cy3-tubulin. B. FLIM analysis of GFP in the same cell. Lifetimes are coded in red (0.8 to $1.6 \mathrm{~ns})$ and green (1.6 to $3.0 \mathrm{~ns})$. Scale bar: $15 \mu m$. 

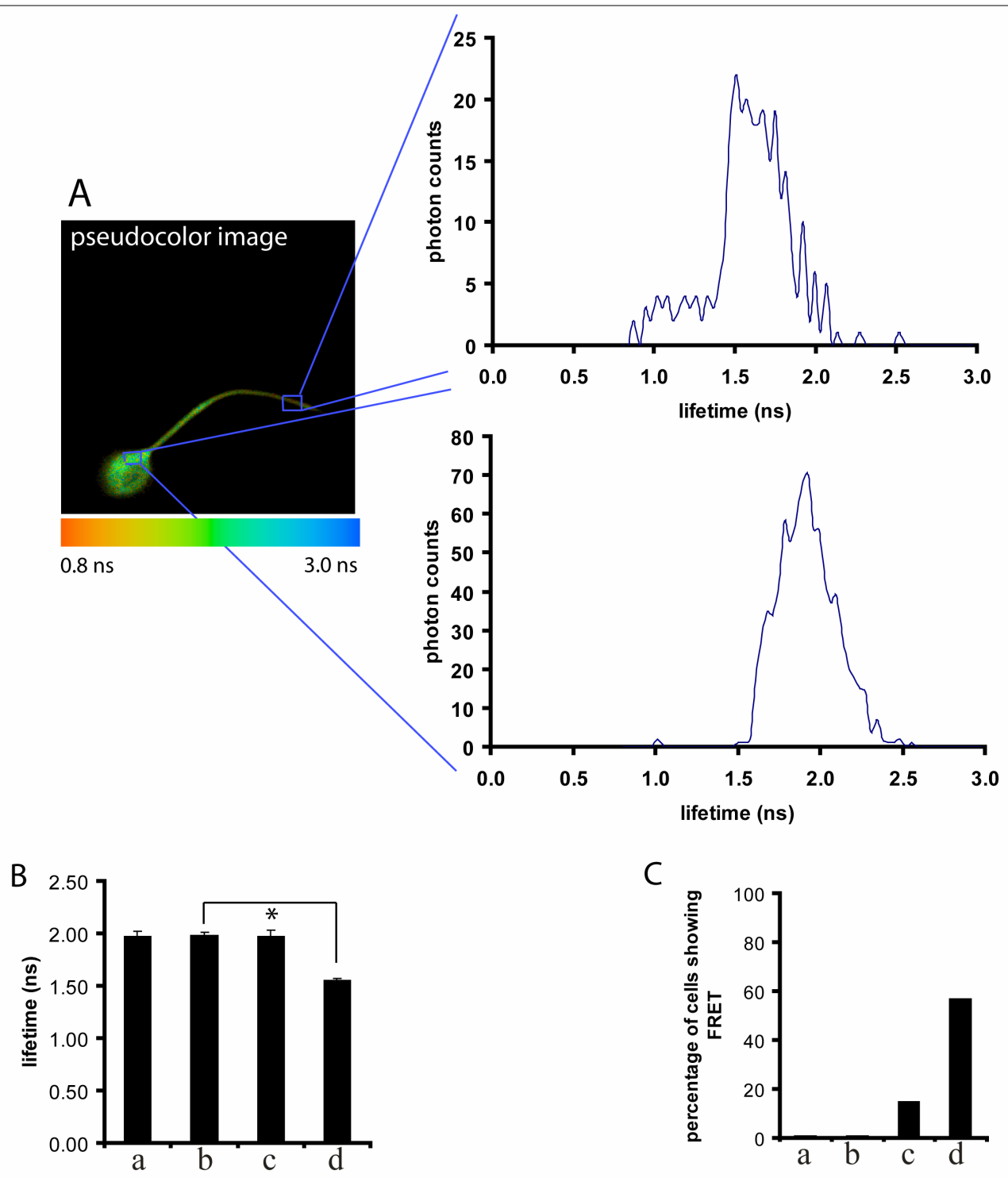

C

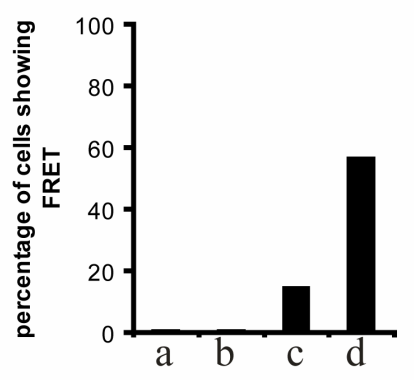

a - GFP-tau; b - GFP-tau; c - GFP-tau + B-tubulin-Cy3; d - GFP-tau + B-tubulin-Cy3 cell body axon cell body axon $\begin{array}{llll}\mathrm{n}=10 & \mathrm{n}=10 & \mathrm{n}=8 & \mathrm{n}=8\end{array}$

Figure 19. Primary neurons 4 days after transfection with GFP-tau and labeled with monoclonal anti-ß3-tubulin-Cy3 antibodies. A. Distribution of the GFP lifetime in the region of interest of the cell. B. Analysis of lifetime peak values. Averaged lifetime distribution of three regions of interest in several primary neurons (n), transfected with GFP-tau alone or labeled with $\beta$-tubulin-Cy3. Data are presented as mean +/- SEM of independent experiments. For each experimental condition $n>5$; * $p<0.001$ (two-tailed $t$ student test). C. Analysis of the percentage of cells showing short lifetime as a sign of FRET in primary neurons expressing GFP-tau and labeled with $\beta$-tubulin-Cy3. 
As a negative control we transfected primary neurons with GFP-tau, followed by labeling with Cy3-neurofilament; as well as, neurons were transfected with GFP followed by labeling with B-tubulin-Cy3. No shift in the lifetime was detected in neurons transfected with GFP-tau and labeled with Cy3-neurofilament antibodies (Figures 20B, 21A, B). Distribution of lifetime of GFP in this case was $1.96+/-0.075$ nanoseconds (mean +/SEM) in the cell body and $1.97+/-0.041$ nanoseconds (mean +/- SEM) in the neurites. Furthermore, lifetime of GFP were not altered in neurons transfected with GFP alone and immunolabeled with Cy3-tubulin antibodies (Figures 22B, 23A, B) showing distribution of $2.01+/-0.022$ nanoseconds (mean +/- SEM) in the cell body and $1.98+/-0.047$ nanoseconds (mean +/- SEM) in neurites.
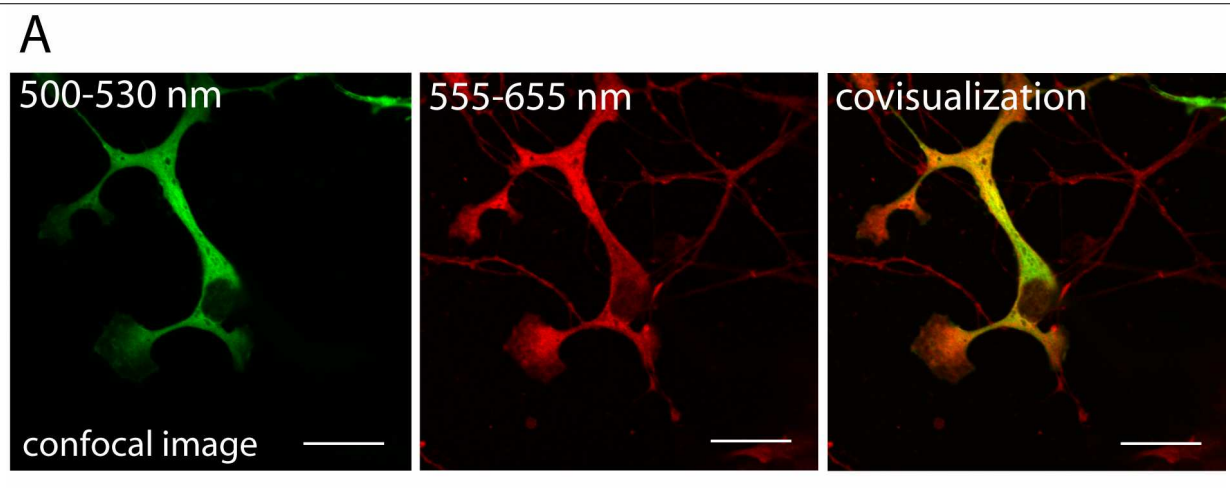

B
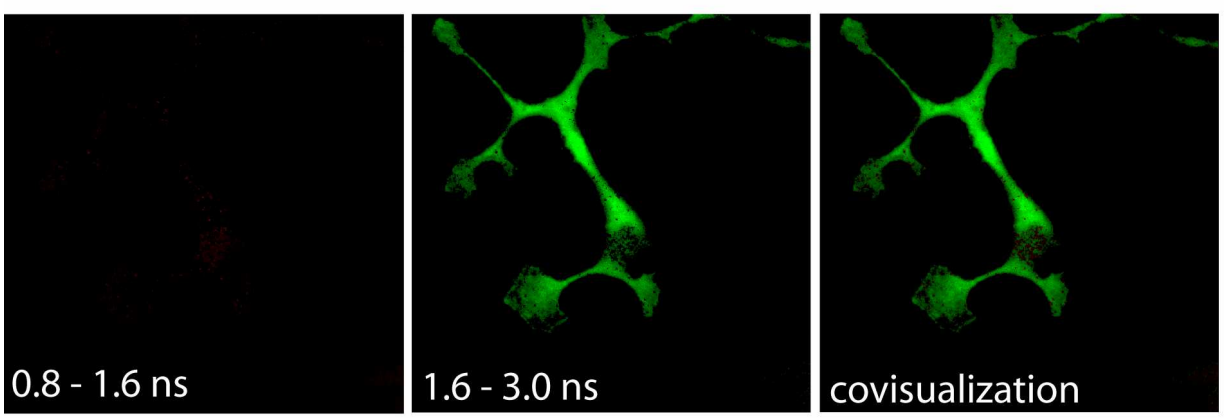

Figure 20. Primary neurons 4 days after transfection with the GFP-tau plasmid and labeled with monoclonal anti-neurofilament antibodies, followed by Cy3-marked antibodies. A. Classic confocal analysis of GFP and Cy3 demonstrates distribution of GFP-tau and Cy3-neurofilament in the cell. B. FLIM analysis of GFP in the same cell. Lifetimes are coded in red (0.8 to $1.6 \mathrm{~ns})$ and green (1.6 to $3.0 \mathrm{~ns})$. Scale bar: $20 \mu \mathrm{m}$. 


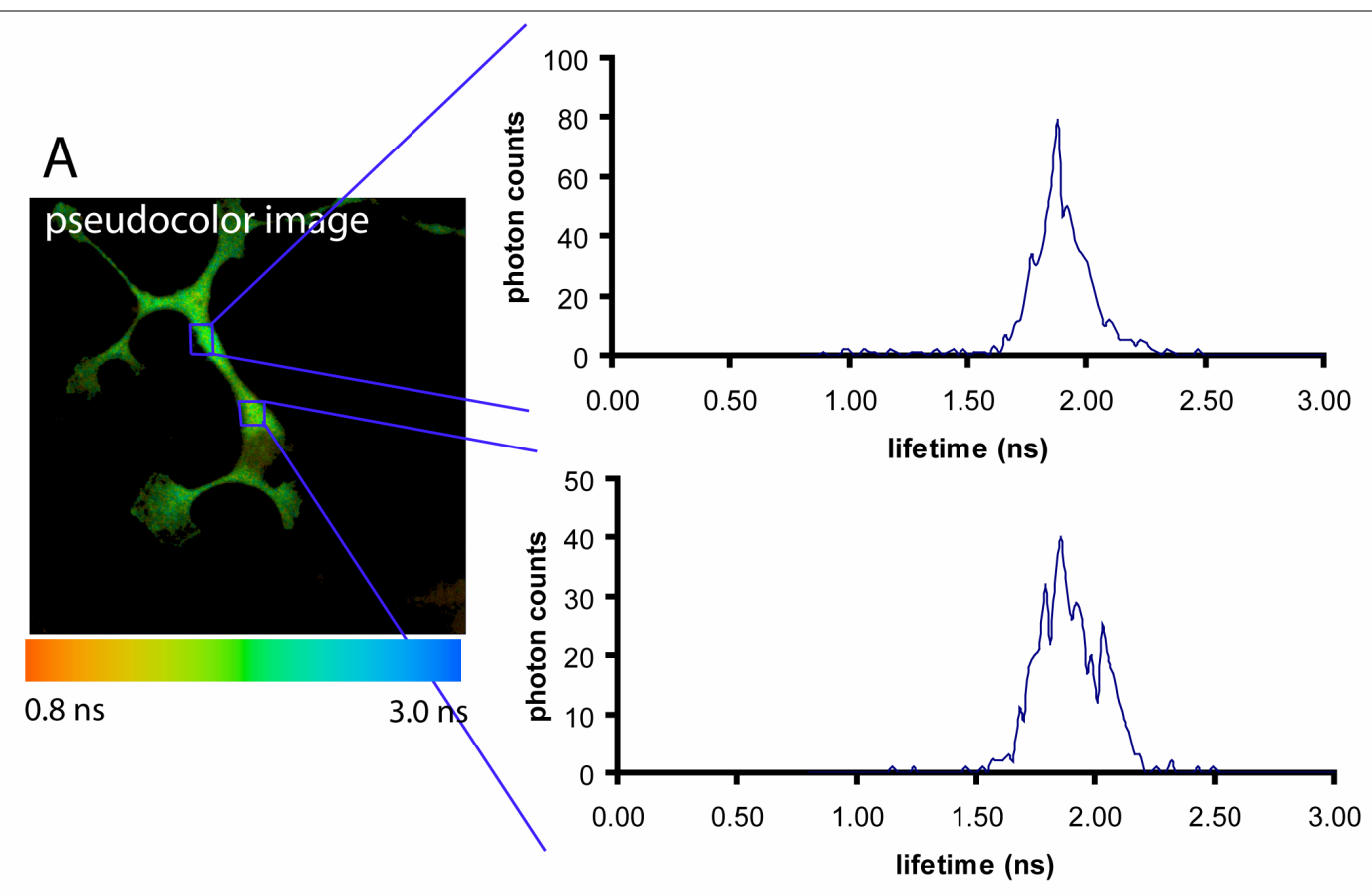

B

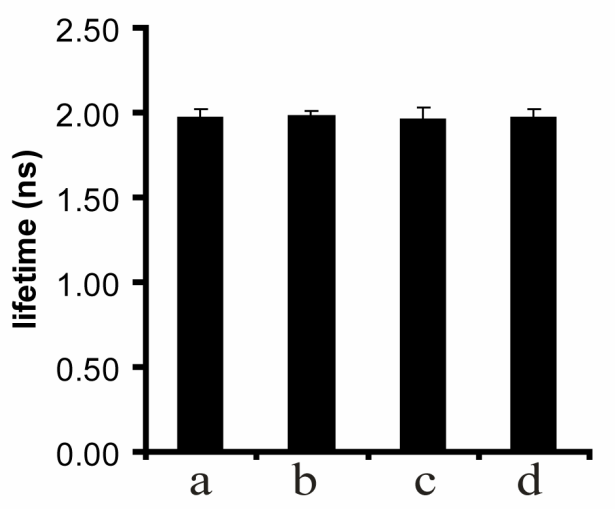

a - GFP-tau cell body, $\mathrm{n}=10$

b - GFP-tau axon, $\mathrm{n}=10$

c - GFP-tau + neurofilament-Cy3 cell body, $\mathrm{n}=8$

$\mathrm{d}$ - GFP-tau + neurofilament-Cy3 axon, $\mathrm{n}=8$

Figure 21. Primary neurons 4 days after transfection with the GFP-tau plasmid and labeled with monoclonal anti-neurofilament antibodies, followed by Cy3-marked antibodies. A. Distribution of the GFP lifetime from the region of interest in the cell. $\boldsymbol{B}$. Analysis of lifetime peak values. Averaged lifetime distribution in three regions of interest in several primary neurons (n), transfected with GFP-tau alone or labeled with antineurofilament-Cy3. Data are presented as mean +/- SEM of independent experiments. For each experimental condition $n>5$. 
A
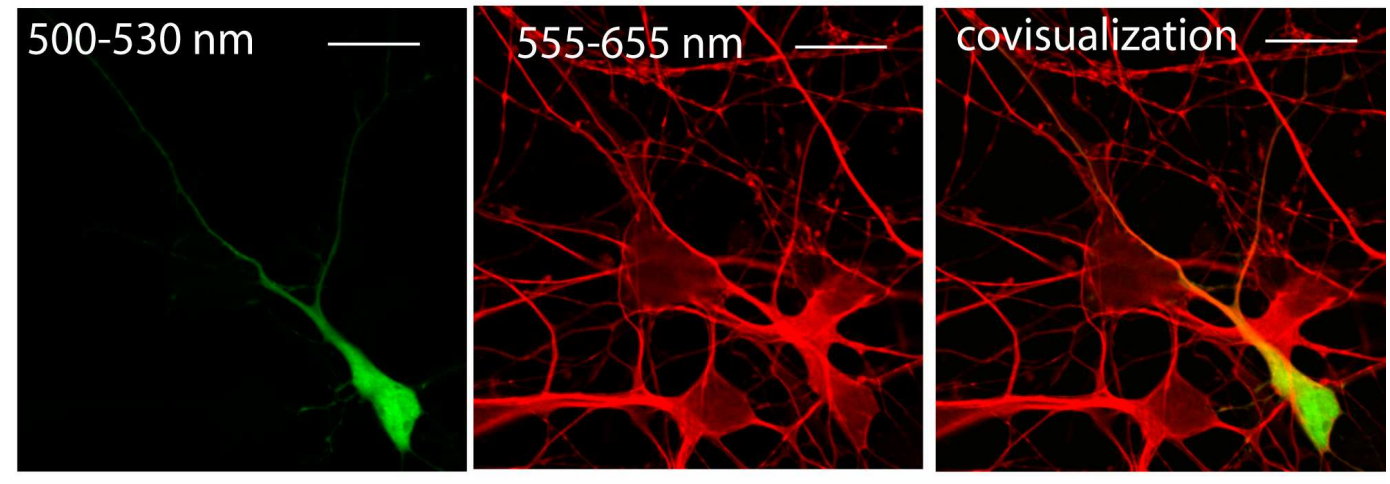

B
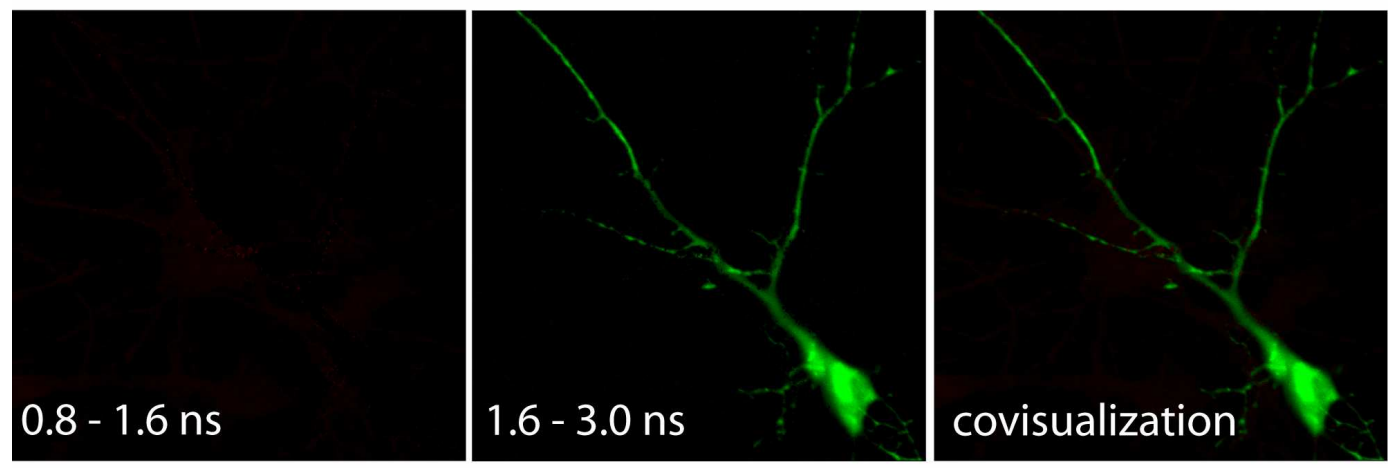

Figure 22. Primary neurons 4 days after transfection with the GFP plasmid and labeled with monoclonal anti-ß-tubulin-Cy3 antibodies. A. Classic confocal analysis of GFP and Cy3 demonstrates distribution of GFP and $\beta$-tubulin-Cy3 in the cell. B. FLIM analysis of GFP in the same cell. Lifetimes are coded in red (0.8 to $1.6 \mathrm{~ns})$ and green (1.6 to $3.0 \mathrm{~ns})$. Scale bar: $20 \mu \mathrm{m}$. 


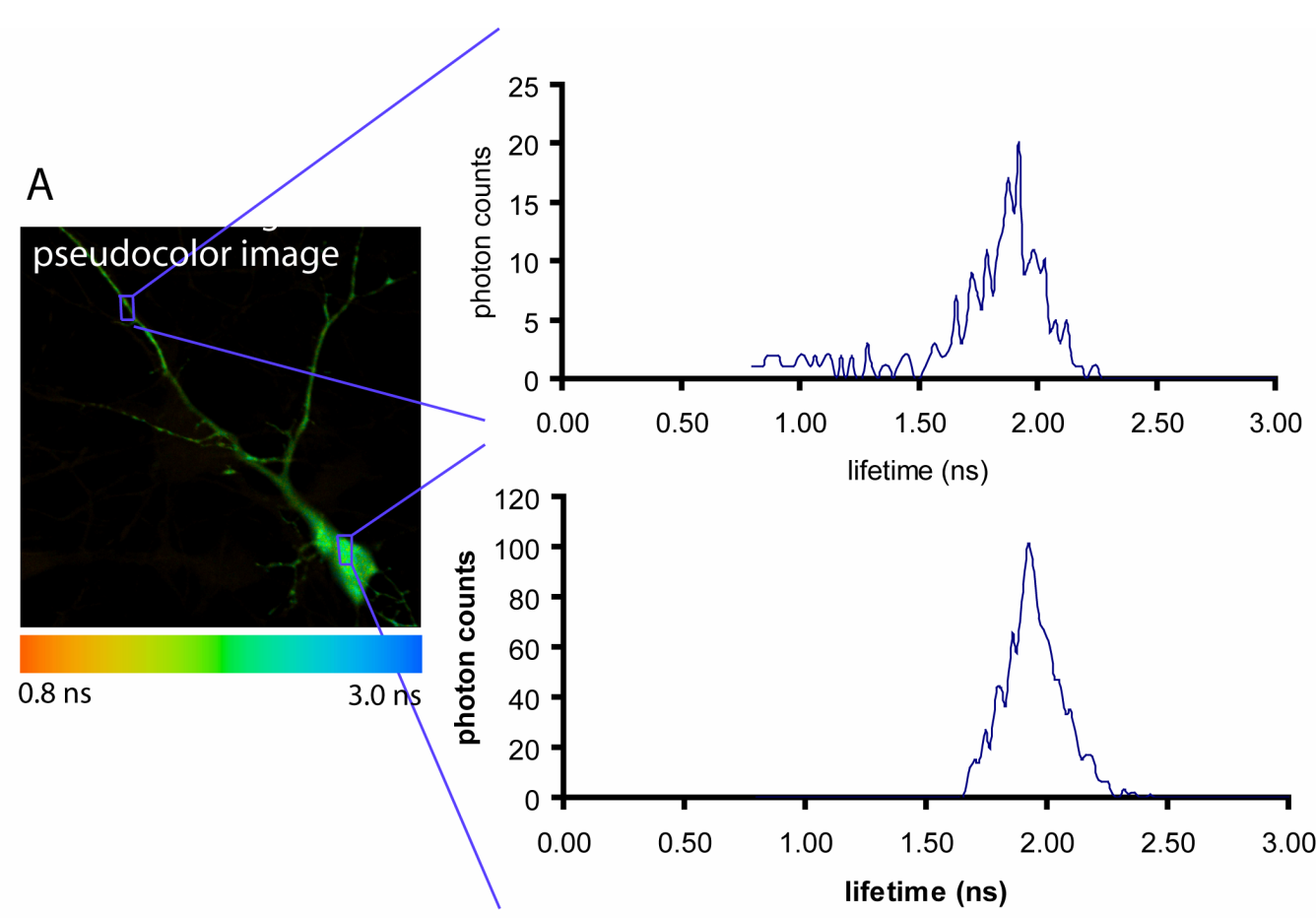

B

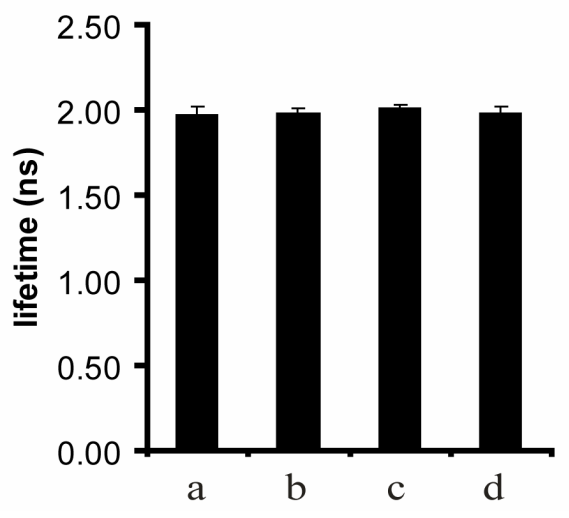

a - GFP cell body, $n=10$

$\mathrm{b}$ - GFP axon, $\mathrm{n}=10$

c - GFP + anti- $\beta$-tubulin-Cy3 cell body, $\mathrm{n}=8$

$\mathrm{d}$ - GFP + anti-ß-tubulin-Cy3 axon, $\mathrm{n}=8$

Figure 23. Primary neurons 4 days after transfection with the GFP plasmid and labeled with monoclonal anti- $\beta$-tubulin-Cy3 antibodies. A. Distribution of the GFP lifetime from the region of interest in the cell. $\boldsymbol{B}$. Analysis of lifetime peak values. Averaged lifetime distribution in three regions of interest in several primary neurons (n), transfected with

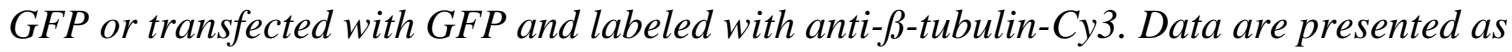
mean +/- SEM of independent experiments. For each experimental condition $n>5$. 
In summary, these results indicate that overexpressed tau protein can interact with tubulin in primary neuron cultures, resulted in shift of the GFP lifetime towards the lower values.

\section{Phosphorylated JNK in neurites after treatment with TNF- $\alpha$}

Phosphorylation of JNK is the result of the inflammatory cytokine TNF- $\alpha$ signaling in most cell types. Recently our group observed an increase of phosphorylated JNK in axons after stimulation with microglial-derived nitric oxide (Stagi et al. 2006). Therefore, on the next step we want to analyze if TNF- $\alpha$ could also induce the stimulation of JNK. Cultured hippocampal neurons were labeled with antibodies to TNF receptor I or II, followed by FITC-conjugated secondary antibody staining. Double-labeling was performed by monoclonal mouse antibodies directed against the axonal marker protein tau, followed by Cy3-conjugated goat secondary antibody. Analysis by confocal microscopy demonstrated that neurites identified by tau immunolabelling showed immunostaining for TNF receptors I and II (Figure 24). In detail, $82.0 \%+/-7.2 \%$ (mean +/- SEM) of tau positive neurites were labeled with antibodies against TNF receptor I and $88.1 \%+/-1.3 \%$ (mean +/- SEM) of tau positive neurites were labeled with antibodies directed against TNF receptor II.

Then, cultured hippocampal neurons were treated with TNF- $\alpha$ (20 ng/ml) for 20 minutes and JNK was analyzed by immunocytochemistry with specific antibodies directed against total JNK and phosphorylated JNK, followed by Cy3 conjugated secondary antibodies. Subsequently, cells were incubated with mouse monoclonal anti tau. Expression of total JNK was detected in all neurons and neurites, while the expression of the phosphorylated JNK indicating JNK activity was more restricted. In untreated neurons, phosphorylated JNK was not detected in neurites (Figure 25A and B). After treatment of neurons with 20 $\mathrm{ng} / \mathrm{ml}$ TNF- $\alpha$ for 20 minutes, strong immunolabeling of almost all neurites by phosphorylated JNK was detected. Quantification of tau positive neurites showed that after TNF- $\alpha$ treatment the majority (84 \% +/- 13\%; mean +/- SEM) expressed phosphorylated JNK, while in untreated neurons a minority of tau positive neurites (11\% +/- 7\%; mean +/- SEM) showed immunolabelling for phosphorylated JNK (Figure 25).

Obtained results showed that TNF- $\alpha$ applied to primary neuronal cultures can activate phosphorylation of JNK stress kinase. 


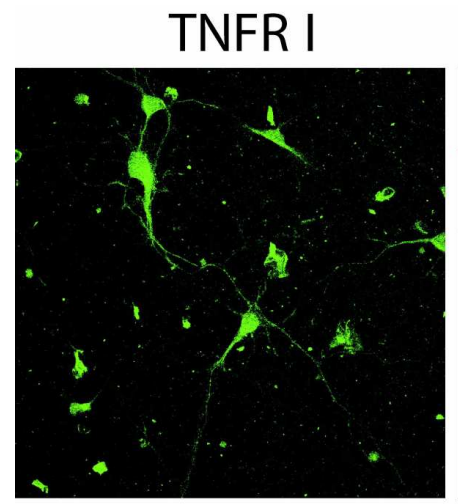

TNFR II

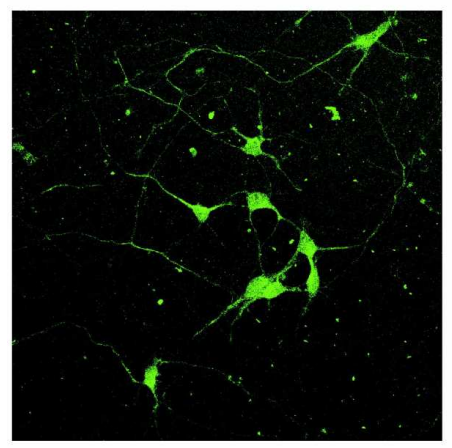

Control

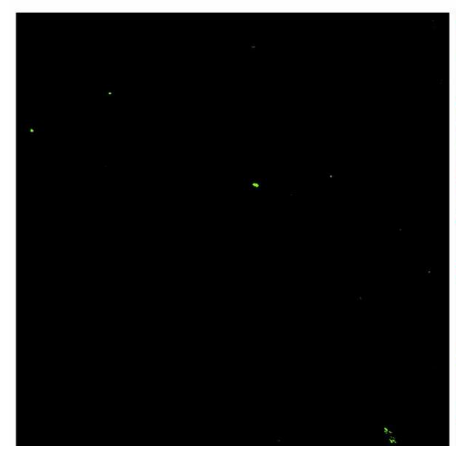

Tau

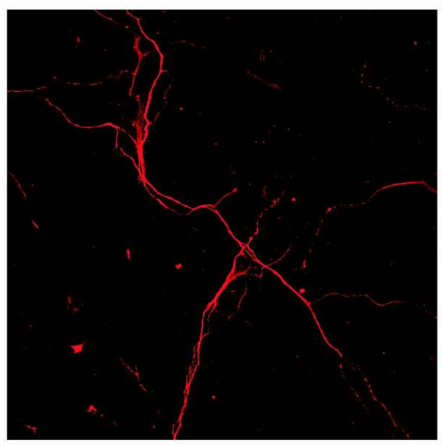

Tau

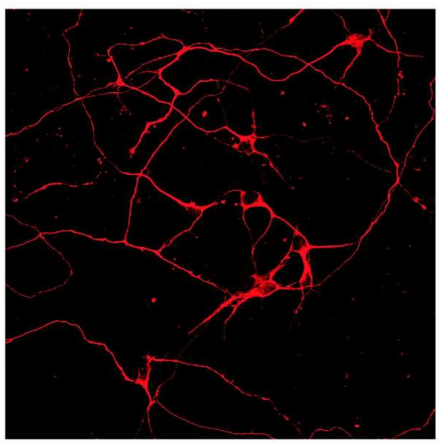

Tau

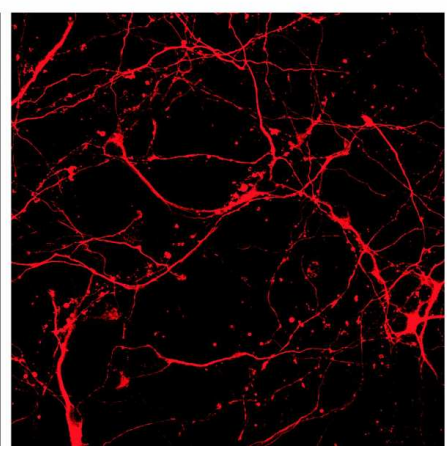

Covisualization

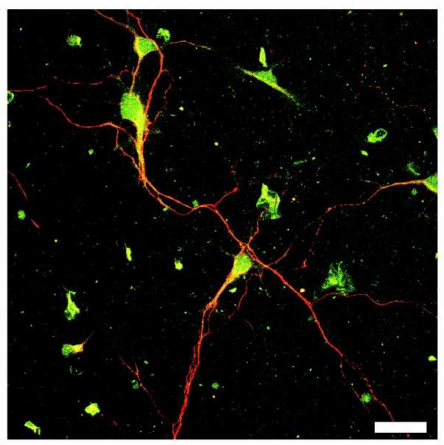

Covisualization

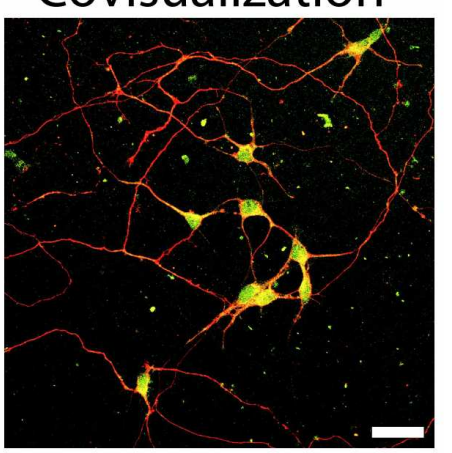

\section{Covisualization}

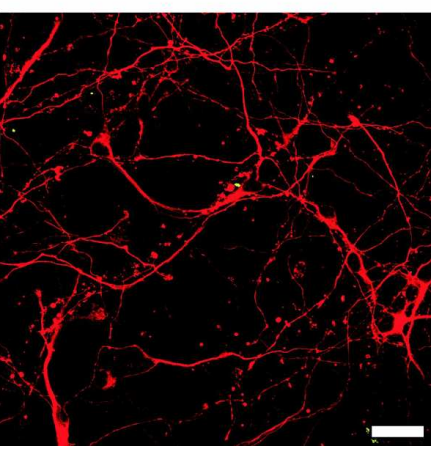

Figure 24. Immunodetection of TNF receptor I and TNF receptor II in neurites. Cultured hippocampal neurons were immunolabeled with specific antibodies directed against TNF receptor I (TNFR I), TNF receptor II (TNFR II) or control antibodies (Control) and then colabelled with antibodies directed against tau (Tau). Constitutive expression of TNF receptor I and TNF receptor II was detected in the majority of tau positive neurites. Scale bars: $30 \mu \mathrm{m}$. 

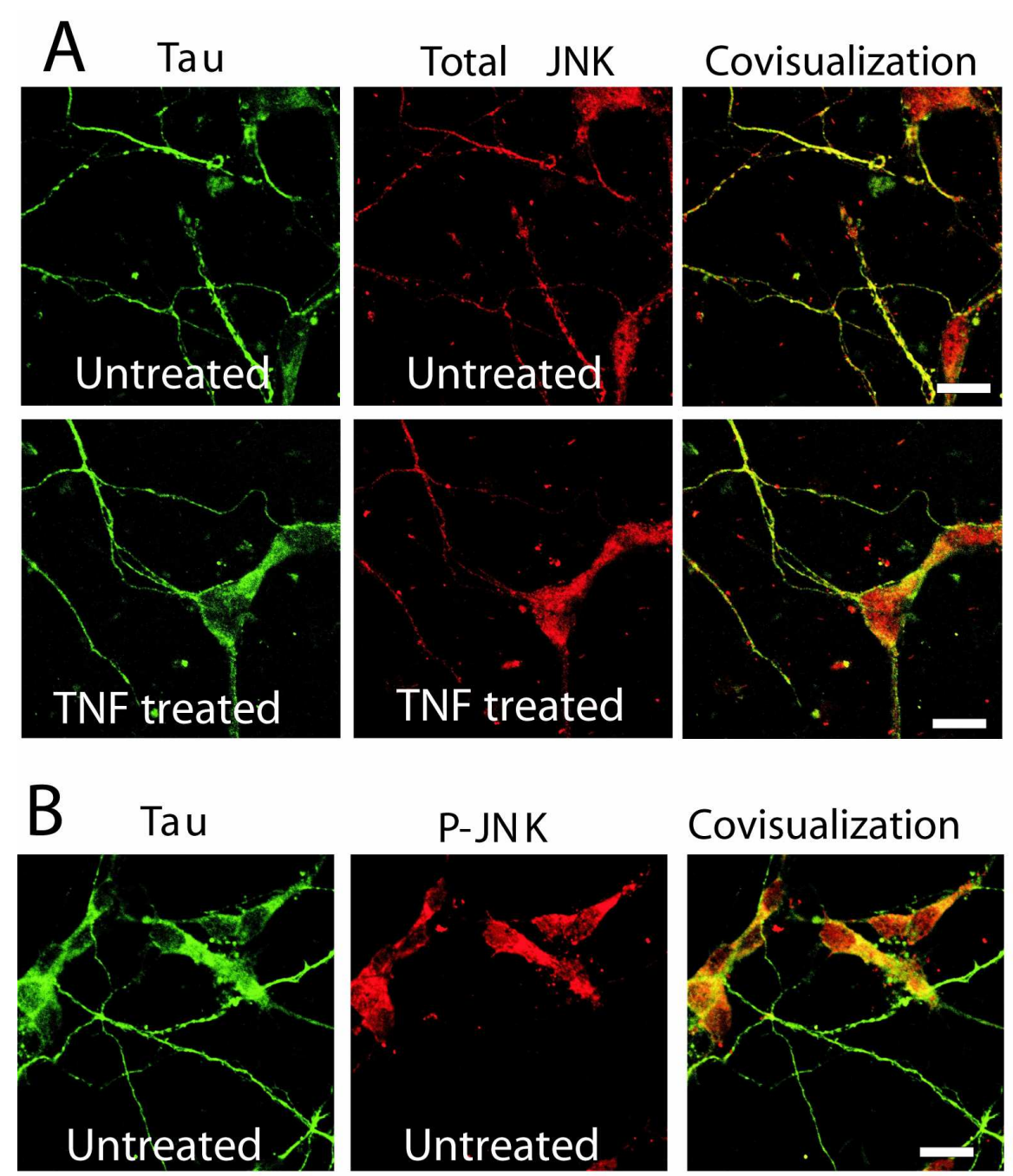

\section{Covisualization}
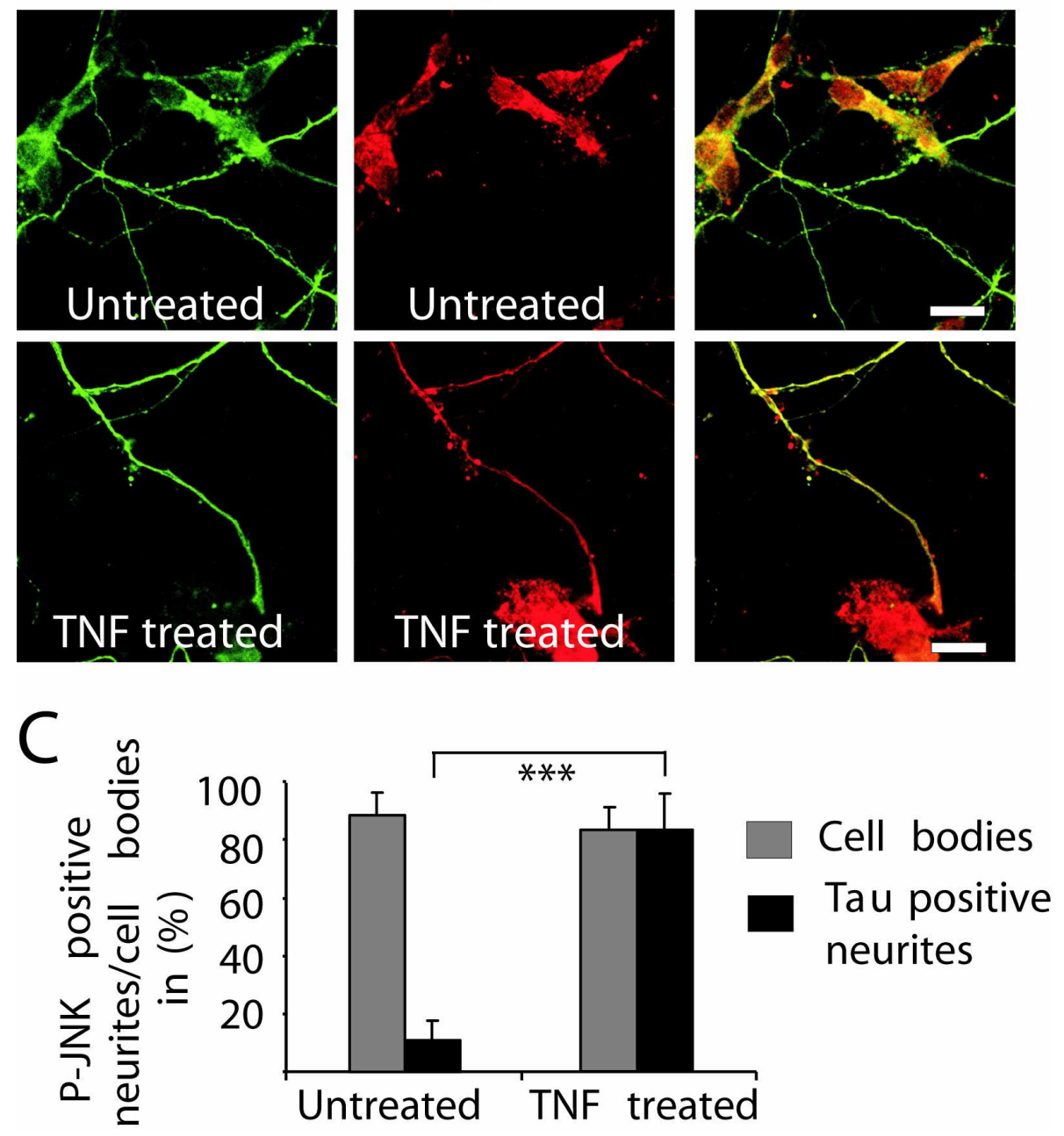
Figure 25. Immunodetection of phosphorylated JNK in neurites after TNF- $\alpha$ treatment.

A. Cultured hippocampal neurons either untreated or treated with TNF- $\alpha(20 \mathrm{ng} / \mathrm{ml}$ for 20 minutes) were immunolabelled with specific antibodies directed against JNK (Total $J N K)$ and colabelled with antibodies directed against tau (Tau). Expression of JNK was detected in cell bodies and neurites without TNF- $\alpha$ treatment. Scale bars: $20 \mu \mathrm{m}$.

B. Cultured hippocampal neurons either untreated or treated with TNF- $\alpha$ were immunolabelled with specific antibodies directed against phosphorylated JNK (PJNK) and colabelled with antibodies directed against tau (Tau). Treatment of neurons with TNF- $\alpha$ for 20 minutes resulted in strong labelling of phosphorylated JNK in cell bodies and tau positive neurites. Scale bars: $20 \mu \mathrm{m}$.

C. Number of processes and cell bodies identified by colabelling with antibodies directed against tau showing expression of phosphorylated JNK. Neurons were either untreated or treated with TNF- $\alpha$ for 20 minutes. Data are presented as mean +/- SEM. For each experimental condition $n=25 ; * * * p<0.001$ (two-tailed Mann-Whitney U test).

\section{Lifetime based FRET analysis showed no spontaneous dimerization or polymerization of tau}

We showed that TNF- $\alpha$ could activate one of the stress kinases JNK, which expected to be involved as well in the pathology of tau. Therefore we rise the question if TNF- $\alpha$ can have any effect on tau particularly on dimerization / polymerization of tau. First, primary neurons from hippocampi were transfected with Cerulean-tau as well as cotransfected with Cerulean-tau and Citrine-tau. Cells were fixed after 3-5 days and confocal microscope scanning followed by lifetime analysis was performed (Figures 26, 27, 28, 29).

FLIM analysis showed that neurons expressed normal tau after cotransfection did not show any FRET, neither in cell bodies nor in the neurites (Figures 26B, 27A, B). In detail, the lifetime distribution of the Cerulean in cells cotransfected with Cerulean-tau and Citrine-tau was $1.90+/-0.054$ nanoseconds (mean +/- SEM) in cell bodies and 1.98 
+/- 0.043 nanoseconds (mean +/- SEM) in neurites (Figure 27A, B). That is very similar to the cells transfected with Cerulean-tau only (Figures 28B, 29) where distribution of lifetime of Cerulean in cell bodies was $2.03+/-0.066$ nanoseconds (mean +/- SEM) and in neurites $2.05+/-0.079$ nanoseconds (mean +/- SEM). These results indicate that there is no spontaneous dimerization or polymerization of tau in cotransfected primary neurons.

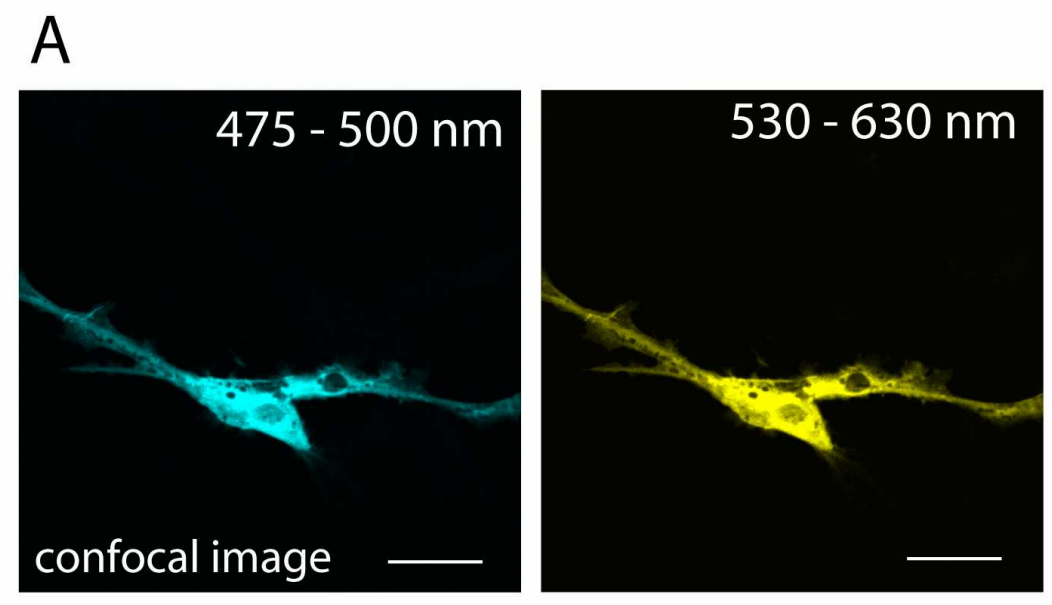

B
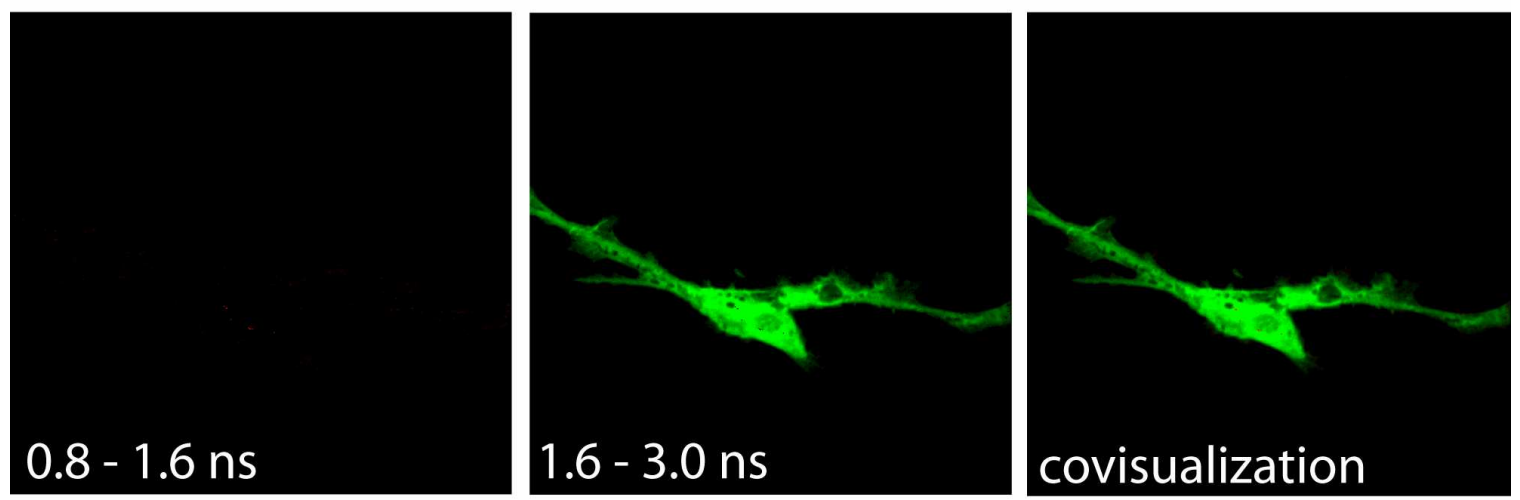

Figure 26. Primary neurons 4 days after cotransfection with Cerulean-tau and Citrinetau. A. Confocal analysis showed expression of Cerulean-tau and Citrine-tau along the cell. B. FLIM analysis of Cerulean in the same cell. Lifetimes are coded in red (0.8 to 1.6 ns) and green (1.6 to $3.0 \mathrm{~ns})$. Scale bar: $15 \mu \mathrm{m}$. 


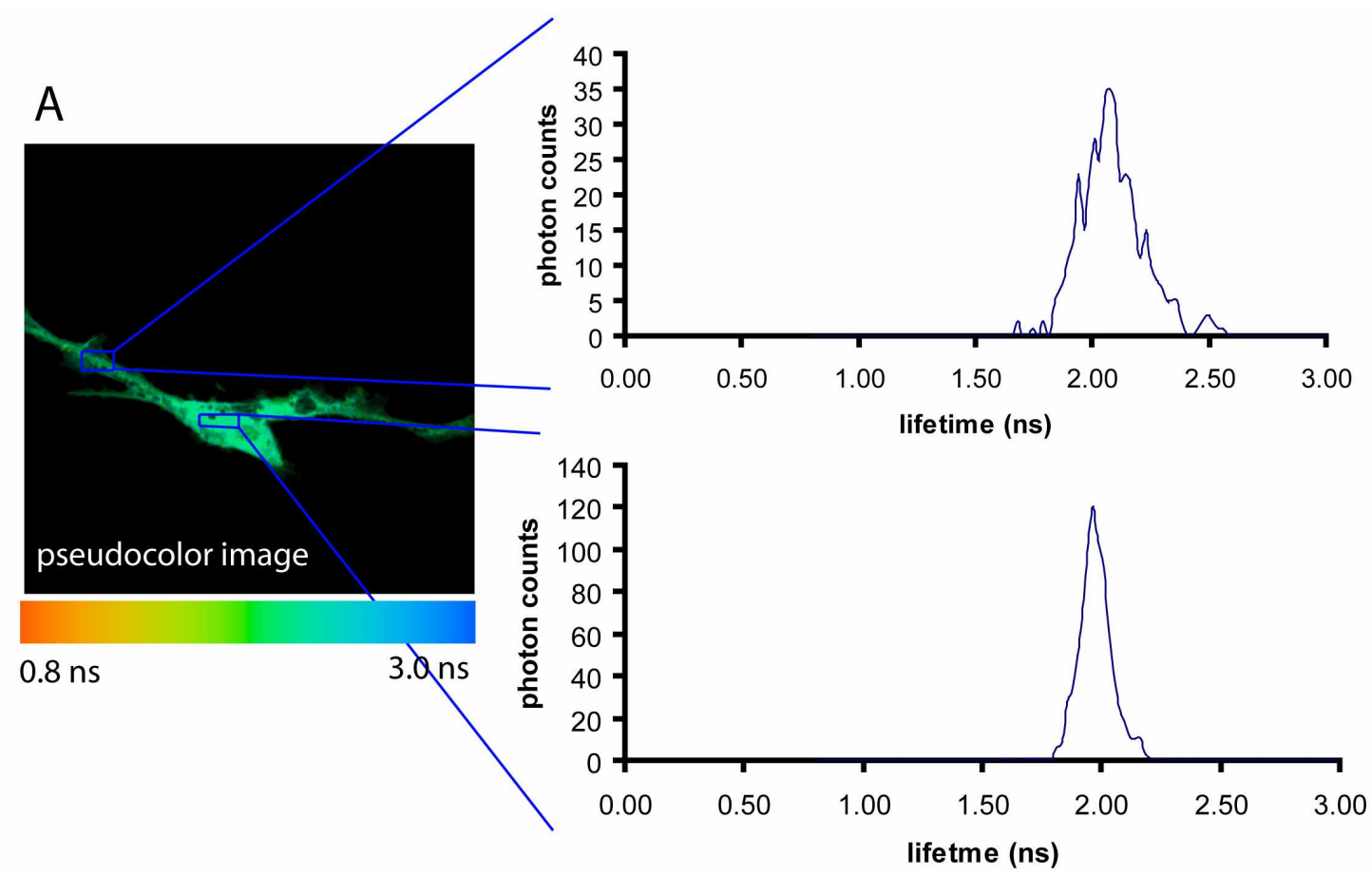

B

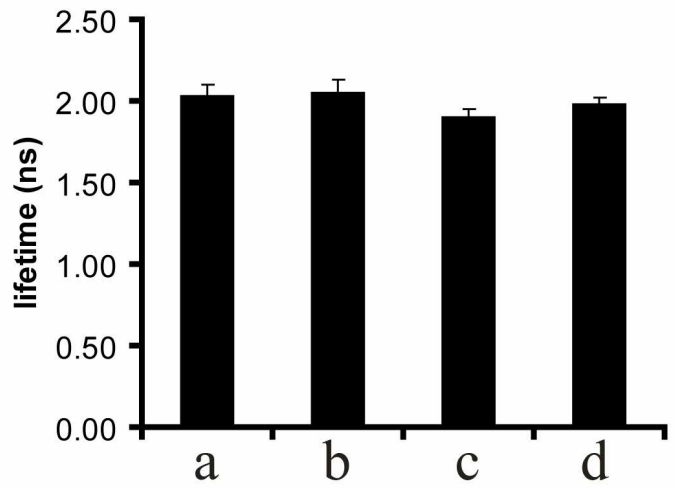

a - Cerulean-tau cell body, $n=10$

$\mathrm{b}$ - Cerulean-tau axon, $\mathrm{n}=10$

c - Cerulean-tau + Citrine-tau cell body, $\mathrm{n}=10$

$\mathrm{d}$ - Cerulean-tau + Citrine-tau axon, $\mathrm{n}=10$

Figure 27. Primary neurons 4 days after cotransfection with Cerulean-tau and Citrinetau $\boldsymbol{A}$. Distribution of the Cerulean lifetime in the cell from the regions of interest. $\boldsymbol{B}$. Analysis of lifetime peak values. Averaged lifetime distribution of three regions of interest in several primary neurons (n), transfected with Cerulean-tau and cotransfected with Cerulean-tau and Citrine-tau. Data are presented as mean +/- SEM of independent experiments. For each experimental condition $n>5$. 
A

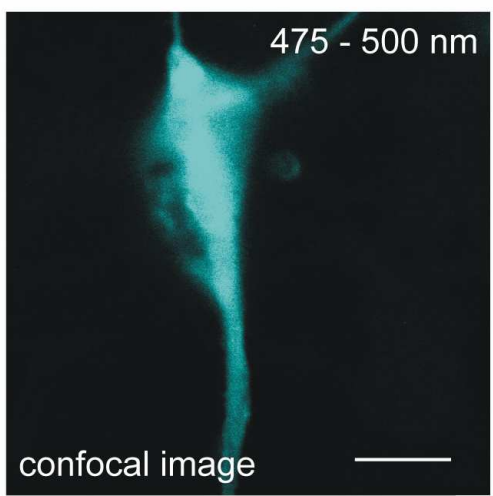

B
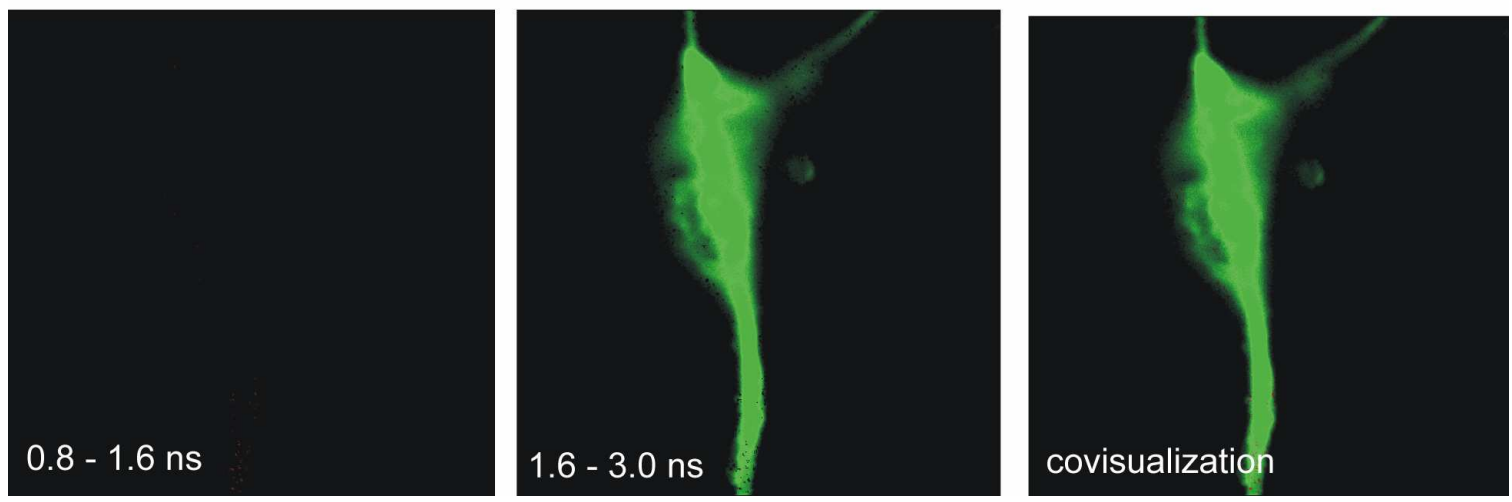

Figure 28. Primary neurons 4 days after transfection with Cerulean-tau. A. Confocal analysis showed expression of Cerulean-tau along the cell. B. FLIM analysis of Cerulean in the same cell. Lifetimes are coded in red (0.8 to $1.6 \mathrm{~ns})$ and green (1.6 to $3.0 \mathrm{~ns})$. Scale bar: $15 \mu m$ 


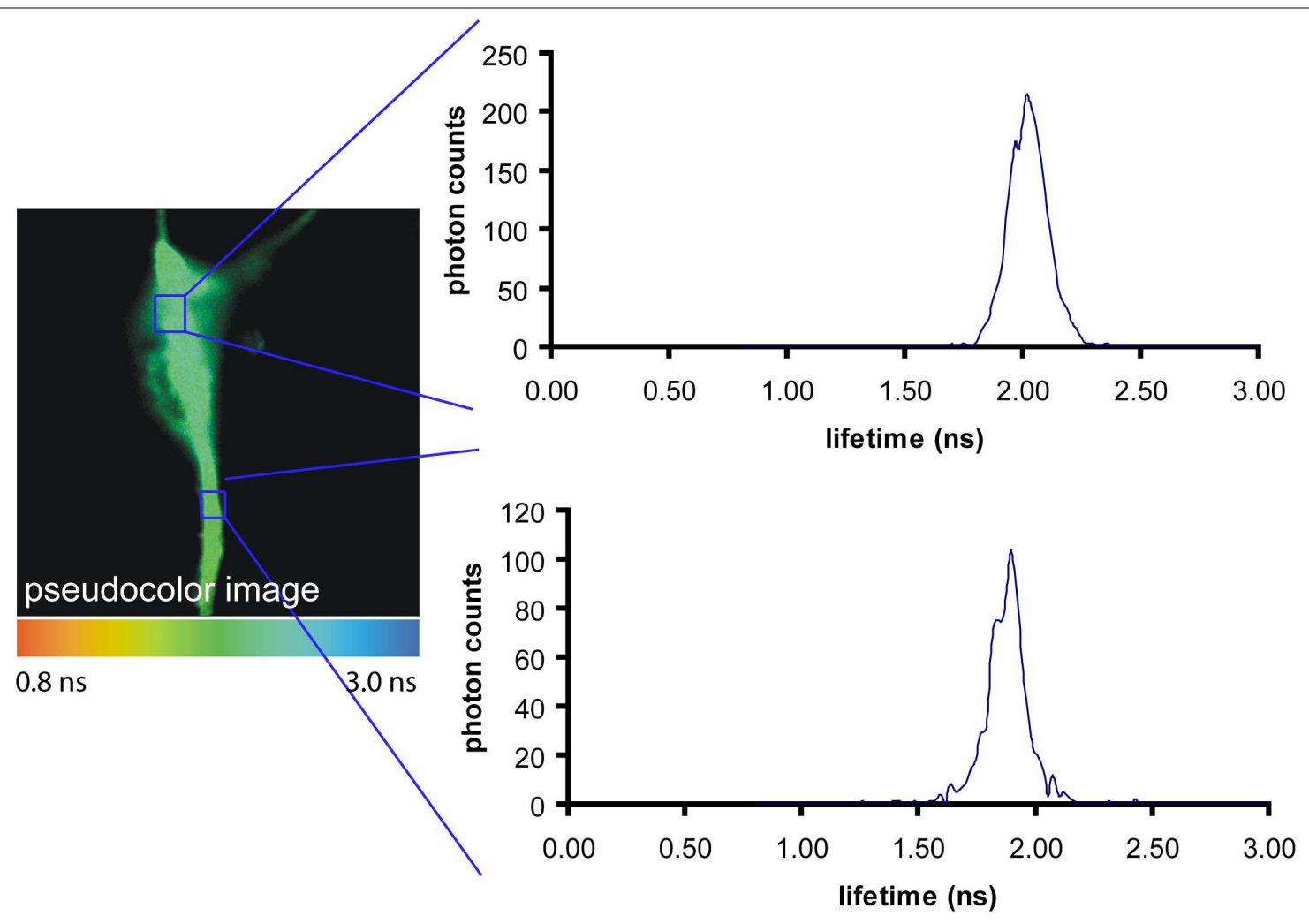

Figure 29. Primary neurons 4 days after transfection with Cerulean-tau.

Pseudocolor image and distribution of the Cerulean lifetime in the region of interest from the cell, showed lifetime with a peak between1.8 - $2.0 \mathrm{~ns}$.

TNF- $\alpha$ induced dimerization / polymerization of tau in neurites

Since inflammation was suspected to contribute to tau pathophysiology, we analyzed the effect of the inflammatory cytokine TNF- $\alpha$ on tau dimerization. Primary neurons from hippocampi were cotransfected with Cerulean-tau and Citrine-tau and on the day 3 treated with $50 \mathrm{ng} / \mathrm{ml}$ TNF- $\alpha$ for 3 hours. Confocal analysis followed by lifetime analysis was performed (Figures 30, 31). As shown in Figures 30B and 31A, B, C in treated cells, we noticed a shift in the lifetime of the Cerulean in 65 percent of neurites and 14 percent of cell bodies. Lifetime was shifted towards the lower values (about 1.5-1.6 ns) and was distributed not equally but as "points" (clusters) mostly along the neuritis. In detail, 
distribution of Cerulean lifetime in cell bodies consists of $1.78+/-0.049$ nanoseconds $($ mean $+/-$ SEM) and in axons $1.50+/-0.038$ nanoseconds (mean +/- SEM). These results showed that TNF- $\alpha$ applied to the primary neurons culture can induce dimerization / polymerization of tau, detected by shift in the lifetime of Cerulean mostly in the part of the neurites.
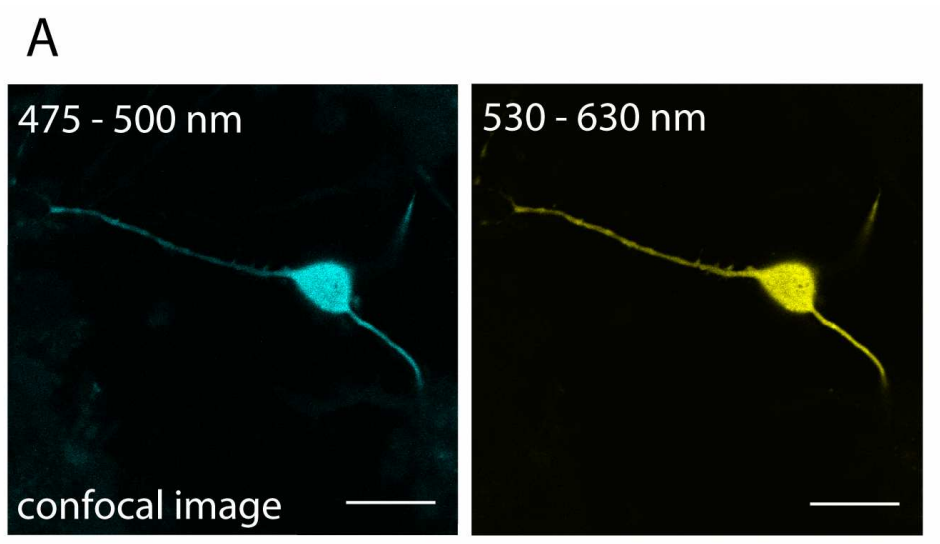

B
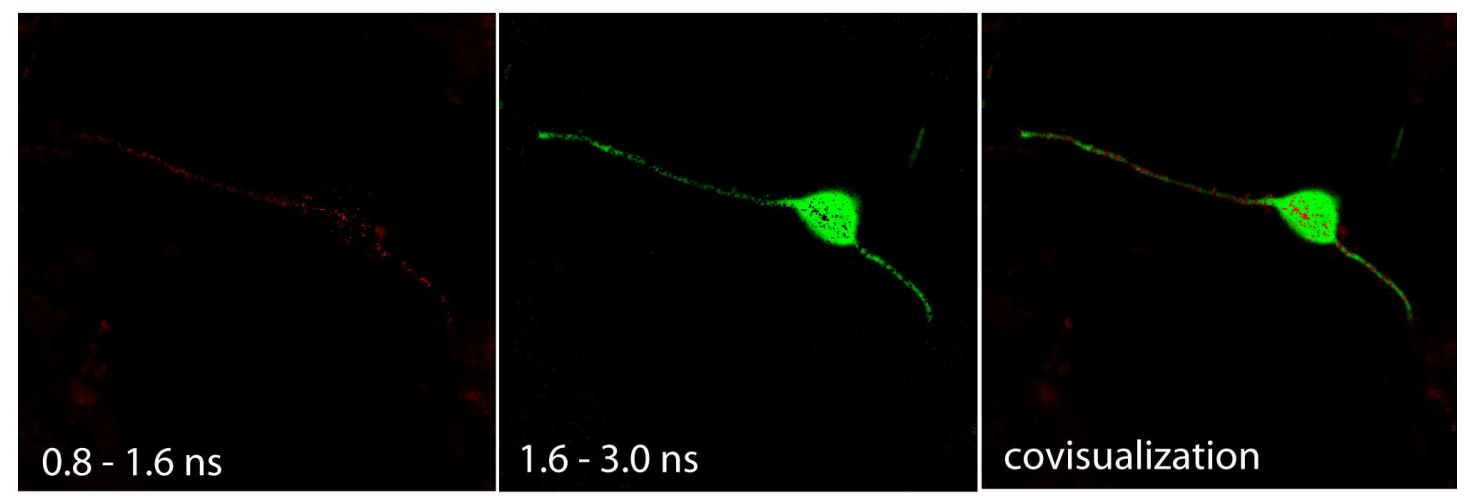

Figure 30. Primary neurons 4 days after cotransfection with Cerulean-tau and Citrinetau and treated for 3 hours with TNF- $\alpha$. A. Confocal analysis showed expression of Cerulean-tau and Citrine-tau along the cell. B. FLIM analysis of Cerulean in the same cell. Lifetimes are coded in red (0.8 to $1.6 \mathrm{~ns})$ and green (1.6 to $3.0 \mathrm{~ns})$. Scale bar: 20 $\mu m$. 

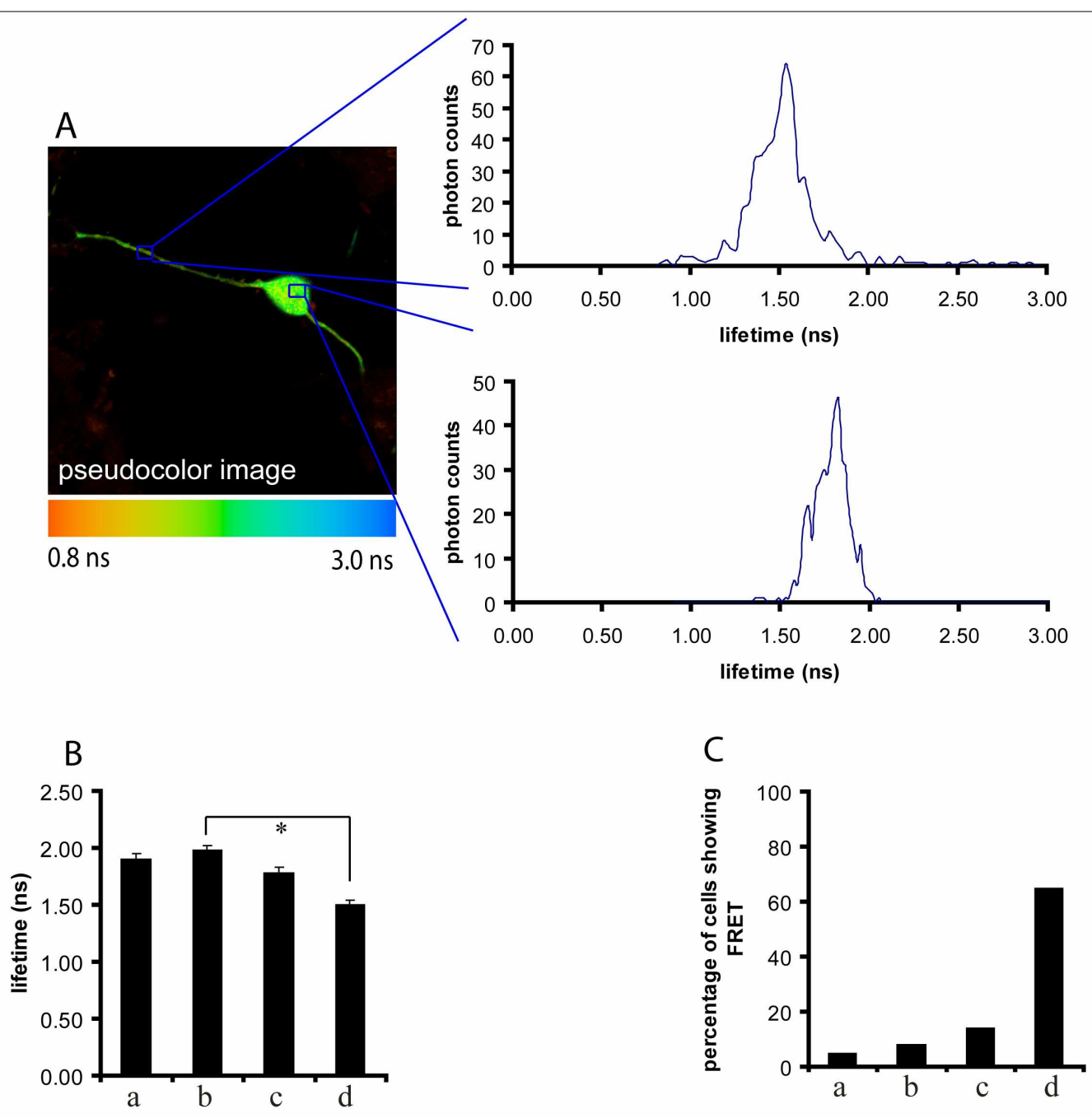
$\mathrm{a}-$ Cerulean-tau $+\quad \mathrm{b}-$ Cerulean-tau +
Citrine-tau cell body Citrine-tau $\mathrm{n}=10$ axon $\mathrm{n}=10$
c - Cerulean-tau +
Citrine-tau
+ TNF-a, cell body
$\mathrm{n}=9$
d - Cerulean-tau + Citrine-tau + TNF-a, axon $\mathrm{n}=9$

Figure 31. Primary neurons 4 days after cotransfection with Cerulean-tau and Citrinetau and treated for 3 hours with TNF- $\alpha$. A. Distribution of the Cerulean lifetime in the cell, from the regions of interest. B. Analysis of lifetime peak values. Averaged lifetime distribution in three regions of interest in several primary neurons (n), cotransfected with Cerulean-tau and Citrine-tau and treated or untreated with TNF-a. Data are presented as mean +/- SEM of independent experiments. For each experimental condition $n>5$; * $p<0.001$ (two-tailed t-student test). C. Analysis of the percentage of cells showing short lifetime as a sign of FRET in primary neurons cotransfected with Cerulean-tau and Citrine-tau and treated with TNF- $\alpha$. 
The data demonstrate that TNF- $\alpha$ that is prevalent in degenerative brain diseases, can induce dimerization / polymerization of tau and might be involved in the first steps of neurofibrillary tangle formation. 


\section{Discussion}

\section{Why FRET?}

With the onset of modern proteomics, hundreds of pairs of cellular proteins that are in vitro capable of interacting with each other have been identified. However, the extent to which this possibility of interaction reflects their behaviour in living cells is not clear. Nonetheless, it is abundantly clear that these protein-protein interactions are crucial in both maintaining the stable "resting" state of cells and in driving activation processes to eventually give cellular responses to external stimuli. Hence it becomes more and more important to be able to detect such interactions in situ inside or on the surface of the cells. Fluorescence techniques are widely used to quantify molecular parameters of various biochemical and biological processes in vivo because of their inherent sensitivity, specificity and temporal resolution. Combination of fluorescence spectroscopy with flow and image cytometry provided a solid basis of rapid and continuous improvements of these technologies. A major asset in studying molecular level interactions was the application of Förster resonance energy transfer (FRET) to cellular system.

FRET allows studying molecular interaction at the nanometre resolution. FRET is based on the phenomena, that energy from the donor molecule, without releasing a photon, can be transferred directly to an acceptor. The conditions for energy to transfer are: the donor and acceptor fluorophores should be in close proximity with distances shorter than $10 \mathrm{~nm}$; there should be certain dipole orientations of molecules; the emission spectrum of the donor has to overlap with the excitation spectrum of the acceptor. Fluorescence Lifetime Imaging Microscopy (FLIM) is a technique suitable for studying protein interactions in space and time in fixed and living samples through the detection of FRET (Wallrabe $\mathrm{H}$ et al., 2005). An important advantage of these lifetime measurements is that they are independent of changes in probe concentration, photobleaching and other factors that limit intensity-based steady-state measurements.

Since in FRET technique presence of donor and acceptor molecule is required, finding of proper fluorophore pairs were a task of many investigations. Several 
combinations of fluorescent proteins and dyes are described up to now, and the research in this field continues, resulted in appearance of new fluorophores. It is very difficult to obtain an ideal FRET pair: in theory they have to be photostable, have a high excitation coefficient, high quantum yield of emission and shouldn't have influence on the host.

Exploring possible fluorophores suitable for our experiments we first found CFP and YFP as donor and acceptor. The emission curve of CFP has a big overlap with absorbtion curve of YFP, which makes this pair of fluorophores a good candidate for the FRET experiments. The problem is that, CFP molecule has some disadvantages including low intensity, and complex lifetime resulted in two lifetime peaks detected by lifetime measurements. In 2004 a new mutant of CFP, Cerulean, was designed. Cerulean has a single exponent lifetime, better quantum yield and higher brightness, which provide an obvious benefit for FLIM experiments. Also the improved version of yellow fluorescent protein, Citrine, is characterized by improved brightness and a monomeric nature. Searching another pair, which could allow us to study interaction of the proteins, when one of them is labelled with antibodies, we made our choice for GFP (as donor) and Cy3 dye (as acceptor) found to be efficient FRET pair in several studies.

Apart the advantages of FRET technique, the limitations have to be taking into consideration. New types of fluorophores are continuously develops, but there is still not enough information about influence of them on the processes in cells. Apart of this, physical characteristics of fluorescent molecules should be improved, helping to avoid possible artefacts and other problems.

\section{Cellular model to study tau protein}

In our studies we used two types of cells, - primary neuronal cultures and N1E cell line. The N1E cell line is really easy to cultivate. In addition, the level of transfection and intensity of expression of transfected proteins are very high. This was very useful to establish our model. Nevertheless, to address our biological questions we had to analyse the expression of tau protein in primary neurons. To this end, we use lipofection. One of the disadvantages of this technique is low transfection efficiency. In this case it appears very delicate to use classical biochemical techniques (Western blot, immunoprecipitation) 
to further confirm our results. Additional methods of transfection are available: electroporation and viral transduction. The plasmids we used for expression of tau (pLent i6/V5) can also be used to produce viral particles for transduction of cells. We are currently working on this possibility in our group. Another promising alternative strategy would be to generate neurons derived from embryonic stem cells. These cells can be genetically modified in their process of differentiation more easily and efficiently than primary neurons. This protocol is currently developed in our lab.

\section{Validation of used cellular model}

Tau protein bind microtubles with its C-terminal domain, which contained repeats, representing the core of the microtubule-binding domain. Attached to the microtubules tau can provide its function of stabilization and promotion of the polymerization of microtubules, as well as regulation of the axonal transport. To confirm that our model is adequate we first verified that the overexpression of tau didn't modify significantly the neuronal physiology. To do so we had to show that tau was able to interact with its endogenous partner tubulin. We performed FLIM analysis of the primary neurons expressing GFP-tau and labelled with $\beta$-tubulin-Cy3. As a FRET pair in this experiment GFP as a donor and Cy3 as an acceptor were chosen. Analysis of the data demonstrated that interaction between tau and tubulin occurred in transfected primary neurons. Particularly, we see that part of the axon as well as low part of cell body showing FRET between GFP and Cy3. The fact that the shift of the lifetime observed only in the part of the cell, can be explained by not complete incorporation of new tau molecules with tubulin track. It is known that process of interaction between new tau molecules and tubulin involves other microtubule associated agents promoting this event. We could expect that in case of overexpressed tau not all of these molecules are able to be incorporated in tubulin track. Another possibility could be a low efficiency of FRET in those parts of the cell. 


\section{Mechanism of tau aggregation}

\section{Role of mediated TNF- $\alpha$ inflammation}

As mentioned in introduction, it was proposed that extracellular factors such as amyloid- $\beta$ aggregates favours tau polymerization in AD. Such aggregates of amyloid- $\beta$ could stimulate inflammation and innate brain immunity, particularly microglia. Microglial cells are activated and highly motile in inflammatory and degenerative brain diseases, where they directly can interact with neurons. As a consequence of microglial activation overexpression of reactive oxygen species and cytokine occurs. One of these cytokines is tumor necrosis factor alpha (TNF- $\alpha$ ). TNF- $\alpha$ stimulates inflammation by turning on gene transcription through the signalling cascades. Previous studies in our group demonstrate that TNF- $\alpha$ disrupts the interaction between the kinesin KIF5B and tubulin via phosphorylation of one of the stress kinases JNK, selectively in axons (Stagi et al. 2006). JNK is a member of the mitogen-activated protein (MAP) kinase family which can be activated within the axons. As mentioned in Introduction (Figure 2), JNK is playing an important role in TNF-induced cell death. JNK not only forms a complex with kinesin and JIP, but also appears to directly modulate the function of kinesin. Additionally, TNF- $\alpha$ inhibits anterograde and retrograde axonal movement of some organelles and vesicles via JNK phosphorylation. Some studies showed also that JNK may have downstream axoplasmic substrates and play role in cytoskeletal function. Particularly, JNK1 phosphoryated the microtubule-associated protein 2 and regulated the dendritic architecture. Moreover recent studies reported that activated phospho-JNK, as a sign of stress kinase signalling, co-localized with the neurofibrillary tangles in neurites (Mohit et al., 1995; Zhu et al., 2001). Consistent with these last information's, TNF- $\alpha$ can disrupt cytoskeleton organisation, by stimulation of tau aggregation, and consequently impair the axonal transport.

Previous studies in the lab showed that microglial-derived nitric oxide induced the phosphorylation of JNK in axons. In the present work, we study if microglial TNF- $\alpha$ can also activate JNK and stimulate the phosphorylation of JNK in neurites of primary neurons. Our data showed that treatment of primary neuronal cultures with TNF- $\alpha$ 
resulted in strong immunolabelling of phosphorylated JNK in most of the neurites, what was not the case for untreated neurons, where staining of processes was not detected. Therefore it proves the fact that TNF- $\alpha$ being upstream can activate JNK, which can play a role in the inflammatory processes in injury of the axon.

\section{Involvement of TNF- $\alpha$ in the dimerization / polymerization of tau}

As was mentioned before, extracellular aggregates of amyoid- $\beta$ could favours tau aggregation via release of inflammatory cytokines. In the present work we study involvement of cytokine $\mathrm{TNF}-\alpha$ in aggregation of tau protein in primary neurons, using FLIM technique. Since in our studies we apply overexpression of proteins in the cells, it is necessary to understand if overexpression of tau protein can lead to the spontaneous aggregation in neurons. Our data demonstrated that cotransfection of primary neurons with Cerulean-tau and Citrine-tau doesn't lead to the dimerization / polymerization of tau. In this case, no shift of the lifetime of Cerulean towards the lower values was observed nor in cell bodies not in the neuritis. These results together with results indicating interaction of transfected tau with tubulin, makes us expect, that tau protein which overexpressed in transfected primary neurons could follow its function and interact with microtubules. In the same time we would not suspect that all the tau molecules overexpressed in the primary cultures are functional and binds to microtubules. Nevertheless additional analysis would be required to validate the possible impairment and the level of function of tau.

Next, we treated primary neurons, cotransfected with Cerulean-tau and Citrine-tau with TNF- $\alpha$. Analysis showed that TNF- $\alpha$ leads to the formation of tau aggregates as the clusters along the neurites, but not in the cell bodies. Thus, our results show that TNF- $\alpha$ applied to the cells in primary neurons cultures, initiates dimerization / polymerization of tau protein and might be involved in the first steps of neurofibrillary tangle formation. Additionally, it would be necessary to analyse more the nature of these aggregates. 


\section{Pathology of tau and inflammation}

Neuronal injury accompanied with tau pathology, results in disturbance of normal functions of tau, which could be a result of action of different participants in this process. Microglia is appears to be one of the upstream factors. Microglial cells are the resident macrophages of the CNS, which form the brain's first line of defence and are in control of the immune response in the brain. Microglia form an essential link between the CNS, isolated from the rest of the immune system by the blood-brain barrier, and the general immune system. Microglia is generally inactive, or resting, playing a part in tissue repair after injury. But it was observed, that it can rapidly change their morphology upon activation. Microglial activation is controlled by a positive feedback mechanism - resting microglia can be activated by inflammatory cytokines, which are in turn produced by the microglia themselves - leading to damage of healthy tissue surrounding the site of microglial activation. Therefore it is not clear what role microglia is really playing, protective or offensive, which exact mechanisms leads it to act on neurons. The cross-talk between microglia and neurons remains also an open question in neurobiology.

TNF- $\alpha$ produced in substantial amounts by activated microglia. Disregulation of TNF- $\alpha$ has been implicated in a wide variety of inflammatory diseases. TNF- $\alpha$ however is required for proper proliferation of $\mathrm{T}$ cells, macrophages and other cells. The effect of the TNF- $\alpha$ on neurons is still under discussion. In our studies we showed that TNF- $\alpha$, can induce aggregation of tau and might be involved in the first steps of neurofibrillary tangle formation. When it so, one of the ways to prevent the effect of TNF- $\alpha$ would be to use the blockers of its activity. But, up to now the blockers which exist are not safe enough and further investigations are going on.

One of the pathways of the TNF- $\alpha$ includes recruiting by its receptor TNFR1, the secondary adaptors like TRAF2 which can activate JNK, promoting phosphorylation of JNK, making possible involvement of stress kinases in the pathology of tau. We showed also in the present studies that TNF- $\alpha$ can activate JNK and stimulate the increase of phosphorylated JNK in neurites of primary neurons. Moreover, in several studies, phosphorylated JNK was detected in neurites in Alzheimer's disease associated with senile plaques and co-localized with the neurofirbillary tangles. JNKs are rapidly 
activated within the axons following nerve injury and can be transported on microtubules along the axon via their association with motor proteins of the kinesin family. It was shown that JNK forms a complex with kinesin and appears to directly modulate the function of kinesin. Previously, in our lab was shown that TNF- $\alpha$ break apart the molecular interaction between KIF5B and tubulin via JNK, proving that TNF-JNK signalling pathway can impair the kinesin-mediated axonal transport system. Therefore involvement of tau in regulation of axonal transport makes it be a possible substrate for the activated JNK during apoptosis, taking into consideration fact that JNK known to phosphorylate proteins which regulate the microtubule cytoskeleton.

Apart the TNF- $\alpha$ other agents can be involved in axonal injury and has influence on tau. Nitric oxide (NO) is one of the components which level increased after microglial activation. It is shown that NO can inhibit axonal transport, makes it another candidate involved in pathology of tau. One of the way to elucidate if NO or other agent of activated microglia can have influence on tau protein, would be to apply the experiment of coculture of mouse primary neurons with primary microglial cells which we currently plan to establish in our lab.

In summary, we would expect that pathways including activation of JNK or possibly other stress kinases, via TNF- $\alpha$ can be involved in aggregation process of tau. But the question either such processes leads to aggregation of tau or already the aggregation of tau leads to further axonal injury, still have to be clarified. Nevertheless, tau plays an important role both in healthy cells stabilize microtubules, being involved in axonal outgrowth and transport, and, in case of injury, being a one of the agent in neuronal damage. Therefore, understanding and finding the common aggregation mechanism of different participants of damage in neurons can open new strategies to search for the appropriate therapeutic approaches. 


\section{Summary}

Intracellular aggregates of the microtubule associated protein tau in neurites are the major component of neurofibrillary tangles in Alzheimer's disease and other neurodegenerative tauopathies. The exact molecular mechanism of tau aggregation is not known. Genetic mutations of tau and extracellular deposits of amyloid- $\beta$ peptide oligomers have been shown to facilitate aggregation of tau and to be disease-causative. To analyze whether microglial inflammatory mediators such as tumor necrosis factor- $\alpha$ (TNF- $\alpha$ ) have any effects on aggregation of tau in neurons, we performed fluorescence lifetime-based Förster resonance energy transfer (FRET) analysis of cultured primary neurons transfected with the 441 amino acid long human tau (tau) fused to the green fluorescent protein variants (GFP, Cerulean and Citrine). Primary neurons cotransfected with Citrine-tau and Cerulean-tau were analyzed by FLIM to detect any FRET reflecting dimerization or polymerization of tau. Dimerization or polymerization of cotransfected Citrine-tau / Cerulean-tau was not detected in untreated neurons. Treatment of neurons with TNF- $\alpha$ for 3 hours resulted in dimerization or polymerization of Citrine-tau and Cerulean-tau preferentially in neurites.

Our data demonstrate that inflammatory mediators like TNF- $\alpha$, prevalent in degenerative brain diseases, can induce aggregation of tau and might be involved in the first steps of neurofibrillary tangle formation. The inhibition of the TNF- $\alpha$ mediated aggregation of tau could be a very promising therapeutical strategy in Alzheimer disease. 


\section{References}

Andreadis, A., W. M. Brown, et al. (1992). "Structure and novel exons of the human tau gene." Biochemistry 31(43): 10626-33.

Baudier, J. and R. D. Cole (1987). "Phosphorylation of tau proteins to a state like that in Alzheimer's brain is catalyzed by a calcium/calmodulin-dependent kinase and modulated by phospholipids." J Biol Chem 262(36): 17577-83.

Bastiaens, P. I. and A. Squire (1999). "Fluorescence lifetime imaging microscopy: spatial resolution of biochemical processes in the cell." Trends Cell Biol 9(2): 48-52.

Baumann, K., E. M. Mandelkow, et al. (1993). "Abnormal Alzheimer-like phosphorylation of tau-protein by cyclin-dependent kinases cdk2 and cdk5." FEBS Lett 336(3): 417-24.

Behl, C. (1999). "Alzheimer's disease and oxidative stress: implications for novel therapeutic approaches." Prog Neurobiol 57(3): 301-23.

Becker, W., K. Benndorf, A. Bergmann, C. Biskup, K. König, U. Tirlapur, and T. Zimmer (2001). „FRET measurements by TCSPC laser scanning microscopy.” Proc. SPIE 4431: 414-419.

Biernat, J., N. Gustke, et al. (1993). "Phosphorylation of Ser262 strongly reduces binding of tau to microtubules: distinction between PHF-like immunoreactivity and microtubule binding." Neuron 11(1): 153-63.

Billingsley, M. L. and R. L. Kincaid (1997). "Regulated phosphorylation and dephosphorylation of tau protein: effects on microtubule interaction, intracellular trafficking and neurodegeneration." Biochem J 323 (Pt 3): 577-91.

Bird, T. D., E. M. Wijsman, et al. (1997). "Chromosome 17 and hereditary dementia: linkage studies in three non-Alzheimer families and kindreds with late-onset FAD." Neurology 48(4): 949-54.

Bitsch, A., J. Schuchardt, et al. (2000). "Acute axonal injury in multiple sclerosis. Correlation with demyelination and inflammation." Brain 123 (Pt 6): 1174-83.

Bramblett, G. T., M. Goedert, et al. (1993). "Abnormal tau phosphorylation at Ser396 in Alzheimer's disease recapitulates development and contributes to reduced microtubule binding." Neuron 10(6): 1089-99.

Brück W, Sommermeier N, Bergmann M, Zettl U, Goebel HH, Kretzschmar H, et al. (1996). „Macrophages in multiple sclerosis.“ Immunobiology 195: 588-600. 
Buée, L., T. Bussiere, et al. (2000). "Tau protein isoforms, phosphorylation and role in neurodegenerative disorders." Brain Res Brain Res Rev 33(1): 95-130.

Butner KA, Kirschner MW. (1991). Tau protein binds to microtubules through a flexible array of distributed weak sites. J. Cell Biol. 115(3):717-30

Carswell, E. A., L. J. Old, et al. (1975). "An endotoxin-induced serum factor that causes necrosis of tumors." Proc Natl Acad Sci U S A 72(9): 3666-70.

Cleveland, D. W., S. Y. Hwo, et al. (1977). "Purification of tau, a microtubule-associated protein that induces assembly of microtubules from purified tubulin." J Mol Biol 116(2): 207-25.

Couchie, D., C. Mavilia, et al. (1992). "Primary structure of high molecular weight tau present in the peripheral nervous system." Proc Natl Acad Sci U S A 89(10): 4378-81.

Crowther, R. A. and M. Goedert (2000). "Abnormal tau-containing filaments in neurodegenerative diseases." J Struct Biol 130(2-3): 271-9.

Cruts and Rademakers (2006). Alzheimer Disease and Frontotemporal Dementia Mutation Database

Dawson, H. N., A. Ferreira, et al. (2001). "Inhibition of neuronal maturation in primary hippocampal neurons from tau deficient mice." J Cell Sci 114(Pt 6): 1179-87.

Dermaut, B., S. Kumar-Singh, et al. (2005). "Tau is central in the genetic Alzheimerfrontotemporal dementia spectrum." Trends Genet 21(12): 664-72.

Drechsel, D. N., A. A. Hyman, et al. (1992). "Modulation of the dynamic instability of tubulin assembly by the microtubule-associated protein tau." Mol Biol Cell 3(10): 114154.

Drewes, G., A. Ebneth, et al. (1997). "MARK, a novel family of protein kinases that phosphorylate microtubule-associated proteins and trigger microtubule disruption." Cell 89(2): 297-308.

Drewes, G., B. Lichtenberg-Kraag, et al. (1992). "Mitogen activated protein (MAP) kinase transforms tau protein into an Alzheimer-like state." Embo J 11(6): 2131-8.

Foster, N. L., K. Wilhelmsen, et al. (1997). "Frontotemporal dementia and parkinsonism linked to chromosome 17: a consensus conference. Conference Participants." Ann Neurol 41(6): 706-15.

Förster, Th. (1948). „Zwischenmolekulare Energiewanderung und Fluoreszenz." Ann. Phys. (Serie 6) 2: 55-75. 
Gentleman, S. M., M. J. Nash, et al. (1993). "Beta-amyloid precursor protein (beta APP) as a marker for axonal injury after head injury." Neurosci Lett 160(2): 139-44.

Giovannoni, G., R. F. Miller, et al. (1998). "Elevated cerebrospinal fluid and serum nitrate and nitrite levels in patients with central nervous system complications of HIV-1 infection: a correlation with blood-brain-barrier dysfunction." J Neurol Sci 156(1): 53-8.

Giulian, D., K. Vaca, et al. (1993). "Brain glia release factors with opposing actions upon neuronal survival." J Neurosci 13(1): 29-37.

Goedert, M., E. S. Cohen, et al. (1992a). "p42 MAP kinase phosphorylation sites in microtubule-associated protein tau are dephosphorylated by protein phosphatase $2 \mathrm{~A} 1$. Implications for Alzheimer's disease [corrected]." FEBS Lett 312(1): 95-9.

Goedert M, Jakes R, Crowther RA, Six J, Lübke U, et al. (1993). The abnormal phosphorylation of tau protein at Ser202 in Alzheimer disease recapitulates phosphorylation during development. Proc. Natl. Acad. Sci. USA 90(11):5066-70

Goedert M, Jakes R, Spillantini MG, Hasegawa M, Smith MJ, Crowther RA. (1996). Assembly of microtubule-associated protein tau into Alzheimer-like filaments induced by sulphated glycosaminoglycans. Nature 383(6600):550-53

Goedert, M., M. Hasegawa, et al. (1997). "Phosphorylation of microtubule-associated protein tau by stress-activated protein kinases." FEBS Lett 409(1): 57-62.

Goedert, M., M. G. Spillantini, et al. (1992). "Cloning of a big tau microtubule-associated protein characteristic of the peripheral nervous system." Proc Natl Acad Sci U S A 89(5): 1983-7.

Goedert, M., M. G. Spillantini, et al. (1995). "Molecular dissection of the paired helical filament." Neurobiol Aging 16(3): 325-34.

Goedert, M., M. G. Spillantini, et al. (1989a). "Multiple isoforms of human microtubuleassociated protein tau: sequences and localization in neurofibrillary tangles of Alzheimer's disease." Neuron 3(4): 519-26.

Goedert, M., M. G. Spillantini, et al. (1989b). "Cloning and sequencing of the cDNA encoding an isoform of microtubule-associated protein tau containing four tandem repeats: differential expression of tau protein mRNAs in human brain." Embo $\mathbf{J}$ 8(2): 393-9.

Goedert, M., C. M. Wischik, et al. (1988). "Cloning and sequencing of the cDNA encoding a core protein of the paired helical filament of Alzheimer disease: identification as the microtubule-associated protein tau." Proc Natl Acad Sci U S A 85(11): 4051-5. 
Gustke, N., B. Trinczek, et al. (1994). "Domains of tau protein and interactions with microtubules." Biochemistry 33(32): 9511-22.

Hanger, D. P., K. Hughes, et al. (1992). "Glycogen synthase kinase-3 induces Alzheimer's disease-like phosphorylation of tau: generation of paired helical filament epitopes and neuronal localisation of the kinase." Neurosci Lett 147(1): 58-62.

Hardy, J. and D. Allsop (1991). "Amyloid deposition as the central event in the aetiology of Alzheimer's disease." Trends Pharmacol Sci 12(10): 383-8.

Heutink, P., M. Stevens, et al. (1997). "Hereditary frontotemporal dementia is linked to chromosome 17q21-q22: a genetic and clinicopathological study of three Dutch families." Ann Neurol 41(2): 150-9.

Hong, M., V. Zhukareva, et al. (1998). "Mutation-specific functional impairments in distinct tau isoforms of hereditary FTDP-17." Science 282(5395): 1914-7.

Hutton, M., C. L. Lendon, et al. (1998). "Association of missense and 5'-splice-site mutations in tau with the inherited dementia FTDP-17." Nature 393(6686): 702-5.

Ishiguro, K., S. Kobayashi, et al. (1994). "Identification of the $23 \mathrm{kDa}$ subunit of tau protein kinase II as a putative activator of cdk5 in bovine brain." FEBS Lett 342(2): 2038.

Kanemaru, K., K. Takio, et al. (1992). "Fetal-type phosphorylation of the tau in paired helical filaments." J Neurochem 58(5): 1667-75.

Kobayashi, S., K. Ishiguro, et al. (1993). "A cdc2-related kinase PSSALRE/cdk5 is homologous with the $30 \mathrm{kDa}$ subunit of tau protein kinase II, a proline-directed protein kinase associated with microtubule." FEBS Lett 335(2): 171-5.

Kondo, J., T. Honda, et al. (1988). "The carboxyl third of tau is tightly bound to paired helical filaments." Neuron 1(9): 827-34.

Kosik, K. S., L. D. Orecchio, et al. (1988). "Epitopes that span the tau molecule are shared with paired helical filaments." Neuron 1(9): 817-25.

Lakowicz, J.R. (1999). "Energy transfer." In Principles of Fluorescence Spectroscopy 2nd ed. Plenum: 367-394.

Lee, V. M., B. J. Balin, et al. (1991). "A68: a major subunit of paired helical filaments and derivatized forms of normal Tau." Science 251(4994): 675-8.

Lee, V. M., M. Goedert, et al. (2001). "Neurodegenerative tauopathies." Annu Rev Neurosci 24: 1121-59. 
Lendon, C. L., T. Lynch, et al. (1998). "Hereditary dysphasic disinhibition dementia: a frontotemporal dementia linked to 17q21-22." Neurology 50(6): 1546-55.

Litersky, J. M. and G. V. Johnson (1992). "Phosphorylation by cAMP-dependent protein kinase inhibits the degradation of tau by calpain." J Biol Chem 267(3): 1563-8.

Liu, D., C. L. Smith, et al. (1999). "Astrocytic demise precedes delayed neuronal death in focal ischemic rat brain." Brain Res Mol Brain Res 68(1-2): 29-41.

Mandelkow, E. M., G. Drewes, et al. (1992). "Glycogen synthase kinase-3 and the Alzheimer-like state of microtubule-associated protein tau." FEBS Lett 314(3): 315-21.

Manning, P. T., E. M. Johnson, Jr., et al. (1987). "MHC-specific cytotoxic T lymphocyte killing of dissociated sympathetic neuronal cultures." Am J Pathol 128(3): 395-409.

Mawal-Dewan, M., J. Henley, et al. (1994). "The phosphorylation state of tau in the developing rat brain is regulated by phosphoprotein phosphatases." J Biol Chem 269(49): 30981-7.

McGlade-McCulloh, E., A. M. Morrissey, et al. (1989). "Individual microglia move rapidly and directly to nerve lesions in the leech central nervous system." Proc Natl Acad Sci U S A 86(3): 1093-7.

Medana, I., M. A. Martinic, et al. (2001). "Transection of major histocompatibility complex class I-induced neurites by cytotoxic T lymphocytes." Am J Pathol 159(3): 80915 .

Medana, I. M., N. P. Day, et al. (2002). "Axonal injury in cerebral malaria." Am J Pathol 160(2): 655-66.

Mohit, A. A., J. H. Martin, et al. (1995). "p493F12 kinase: a novel MAP kinase expressed in a subset of neurons in the human nervous system." Neuron 14(1): 67-78.

Morishima-Kawashima, M., M. Hasegawa, et al. (1995). "Hyperphosphorylation of tau in PHF." Neurobiol Aging 16(3): 365-71; discussion 371-80.

Murray, J., J. A. Barbara, et al. (1997). "Regulation of neutrophil apoptosis by tumor necrosis factor-alpha: requirement for TNFR55 and TNFR75 for induction of apoptosis in vitro." Blood 90(7): 2772-83.

Newman TA, Woolley ST, Hughes PM, Sibson NR, Anthony DC, Perry VH. (2001) Tcell- and macrophage-mediated axon damage in the absence of a CNS-specifc immune response: involvement of metalloproteinases. Brain; 124: 2203 \pm 14 . 
Neumann, H. (2003). "Molecular mechanisms of axonal damage in inflammatory central nervous system diseases." Curr Opin Neurol 16(3): 267-73.

Neumann, H., I. M. Medana, et al. (2002). "Cytotoxic T lymphocytes in autoimmune and degenerative CNS diseases." Trends Neurosci 25(6): 313-9.

Neve, R. L., P. Harris, et al. (1986). "Identification of cDNA clones for the human microtubule-associated protein tau and chromosomal localization of the genes for tau and microtubule-associated protein 2." Brain Res 387(3): 271-80.

Nunez, J. (1988). "Immature and mature variants of MAP2 and tau proteins and neuronal plasticity." Trends Neurosci 11(11): 477-9.

Patrick GN, Zukerberg L, Nikolic M, de laMonte S, Dikkes P, Tsai LH. (1999). Conversion of p35 to p 25 deregulates Cdk5 activity and promotes neurodegeneration. Nature 402(6762):615-22

Pendlebury, S. T., M. A. Lee, et al. (2000). "Correlating magnetic resonance imaging markers of axonal injury and demyelination in motor impairment secondary to stroke and multiple sclerosis." Magn Reson Imaging 18(4): 369-78.

Peterson, J. W., L. Bo, et al. (2001). "Transected neurites, apoptotic neurons, and reduced inflammation in cortical multiple sclerosis lesions." Ann Neurol 50(3): 389-400.

Poorkaj, P., T. D. Bird, et al. (1998). "Tau is a candidate gene for chromosome 17 frontotemporal dementia." Ann Neurol 43(6): 815-25.

Raja, F., F. E. Sherriff, et al. (1997). "Cerebral white matter damage in HIV infection demonstrated using beta-amyloid precursor protein immunoreactivity." Acta Neuropathol (Berl) 93(2): 184-9.

Rawes JA, Calabrese VP, Khan OA, DeVries GH. (1997). Antibodies to the axolemmaenriched fraction in the cerebrospinal ${ }^{-}$uid and serum of patients with multiple sclerosis and other neurological diseases. Mult Scler; 3: 363 \pm 9 .

Reynolds, C. H., A. R. Nebreda, et al. (1997a). "Reactivating kinase/p38 phosphorylates tau protein in vitro." J Neurochem 69(1): 191-8.

Reynolds, C. H., M. A. Utton, et al. (1997b). "Stress-activated protein kinase/c-jun Nterminal kinase phosphorylates tau protein." J Neurochem 68(4): 1736-44.

Selkoe, D. J. (2002). "Alzheimer's disease is a synaptic failure." Science 298(5594): 78991. 
Sengupta, A., Q. Wu, et al. (1997). "Potentiation of GSK-3-catalyzed Alzheimer-like phosphorylation of human tau by cdk5." Mol Cell Biochem 167(1-2): 99-105.

Singh, T. J., T. Zaidi, et al. (1995). "Modulation of GSK-3-catalyzed phosphorylation of microtubule-associated protein tau by non-proline-dependent protein kinases." FEBS Lett 358(1): 4-8.

Sloviter RS, Dean E, Sollas AL, Goodman JH (1996). "Apoptosis and necrosis induced in different hippocampal neuron populations by repetitive perforant path stimulation in the rat." J Comp Neurol 366: 516-33.

Sobue, K., A. Agarwal-Mawal, et al. (2000). "Interaction of neuronal Cdc2-like protein kinase with microtubule-associated protein tau." J Biol Chem 275(22): 16673-80.

Spillantini, M. G., T. D. Bird, et al. (1998a). "Frontotemporal dementia and Parkinsonism linked to chromosome 17: a new group of tauopathies." Brain Pathol 8(2): 387-402.

Spillantini, M. G., M. Goedert, et al. (1997). "Familial multiple system tauopathy with presenile dementia: a disease with abundant neuronal and glial tau filaments." Proc Natl Acad Sci U S A 94(8): 4113-8.

Stagi, M., P. S. Dittrich, et al. (2005). "Breakdown of axonal synaptic vesicle precursor transport by microglial nitric oxide." J Neurosci 25(2): 352-62.

Stagi, M, P.Gorlovoy, S. Larionov, K. Takahashi and H. Neumann. (2006). "Unloading kinesin transported cargoes from the tubulin track via the inflammatory c-Jun N-terminal kinase pathway”. FASEB J. 2006 Dec; 20.

Takahashi, M., K. Tomizawa, et al. (1995). "Involvement of tau protein kinase I in paired helical filament-like phosphorylation of the juvenile tau in rat brain." J Neurochem 64(4): 1759-68.

Takei, Y., J. Teng, et al. (2000). "Defects in axonal elongation and neuronal migration in mice with disrupted tau and map1b genes." J Cell Biol 150(5): 989-1000.

Thery, C., B. Chamak, et al. (1991). "Cytotoxic Effect of Brain Macrophages on Developing." Eur J Neurosci 3(11): 1155-1164.

Trapp, B. D., J. Peterson, et al. (1998). "Axonal transection in the lesions of multiple sclerosis." N Engl J Med 338(5): 278-85.

Trinczek, B., J. Biernat, et al. (1995). "Domains of tau protein, differential phosphorylation, and dynamic instability of microtubules." Mol Biol Cell 6(12): 1887902. 
Trojanowski, J. Q. and V. M. Lee (1994). "Paired helical filament tau in Alzheimer's disease. The kinase connection." Am J Pathol 144(3): 449-53.

von Bergen, M., P. Friedhoff, et al. (2000). "Assembly of tau protein into Alzheimer paired helical filaments depends on a local sequence motif ((306)VQIVYK(311)) forming beta structure." Proc Natl Acad Sci U S A 97(10): 5129-34.

Watanabe, A., M. Hasegawa, et al. (1993). "In vivo phosphorylation sites in fetal and adult rat tau." J Biol Chem 268(34): 25712-7.

Weingarten, M. D., A. H. Lockwood, et al. (1975). "A protein factor essential for microtubule assembly." Proc Natl Acad Sci U S A 72(5): 1858-62.

Wijker, M., Z. K. Wszolek, et al. (1996). "Localization of the gene for rapidly progressive autosomal dominant parkinsonism and dementia with pallido-ponto-nigral degeneration to chromosome 17q21." Hum Mol Genet 5(1): 151-4.

Wischik, C. M., M. Novak, et al. (1988). "Isolation of a fragment of tau derived from the core of the paired helical filament of Alzheimer disease." Proc Natl Acad Sci U S A 85(12): 4506-10.

Wullaert, A., K. Heyninck, et al. (2006). "Mechanisms of crosstalk between TNFinduced NF-kappaB and JNK activation in hepatocytes." Biochem Pharmacol 72(9): 1090-101.

Yamaguchi, H., K. Ishiguro, et al. (1996). "Preferential labeling of Alzheimer neurofibrillary tangles with antisera for tau protein kinase (TPK) I/glycogen synthase kinase-3 beta and cyclin-dependent kinase 5, a component of TPK II." Acta Neuropathol (Berl) 92(3): 232-41.

Yoshida, H. and Y. Ihara (1993). "Tau in paired helical filaments is functionally distinct from fetal tau: assembly incompetence of paired helical filament-tau." J Neurochem 61(3): 1183-6.

Zhu, X., A. K. Raina, et al. (2001). "Activation and redistribution of c-jun N-terminal kinase/stress activated protein kinase in degenerating neurons in Alzheimer's disease." J Neurochem 76(2): 435-41. 


\section{Curriculum vitae}

Name: $\quad$ Philipp Gorlovoy

Date of birth: 16.01 .1978

Citizenship: Russia

Professional

Address: Institute of Reconstructive Neurobiology, Bonn University, Life \& Brain Center, Sigmund-Freud-str. 25, 53127 Bonn, Germany

E-mail: $\quad$ pgorlovoy@uni-bonn.de

\section{Education}

Since 2002 PhD student - University, Goettingen (since 2005 Institute of Reconstructive Neurobiology, Bonn // 2002-2005 European Neuroscience Institute, Goettingen)

2001-2002 Employeer as Biologist - Branch of the Institute of Bioorganic Chemistry, Puschino on Oka, Russia.

1996-2001 Master of Science degree in Biochemistry - Molecular Biology Department, Moscow State University, Russia.

\section{Publications}

M. Stagi *, P.Gorlovoy *, S. Larionov, K. Takahashi and H. Neumann.

Unloading kinesin transported cargoes from the tubulin track via the inflammatory c-Jun N-terminal kinase pathway.

FASEB J. 2006 Dec;20

* the two first authors contributed equally to this work

Kalebina TS, Farkas V, Laurinavichiute DK, Gorlovoy PM, Fominov GV, Bartek P and Kulaev IS.

"Deletion of BGL2 results in an increased chitin level in the cell wall of Saccharomyces cerevisiae."

Antonie Van Leeuwenhoek 2003 84(3): 179-84. 


\section{Poster presentations}

P.Gorlovoy and H. Neumann.

Dimerization of the microtubulin associated protein tau induced by tumor necrosis factoralpha. Erstes gemeinsames wissenschaftliches Symposium der Medizinischen Fakultäten der Universitäten Koeln und Bonn, Bonn, Germany, 4 October 2006

\section{P. Gorlovoy and H. Neumann.}

Dimerization of the microtubulin associated protein tau induced by tumor necrosis factoralpha. $5^{\text {th }}$ Forum of European Neuroscience, Vienna, Austria, 8-12 July 2006

P. Gorlovoi, M. Stagi, I. Bartoszek and H. Neumann.

Dimerization of the microtubulin associated protein tau induced by inflammatory mediators. 6th Meeting of the German Neuroscience Society, 30th Göttingen Neurobiology Conference, Goettingen, Germany, 2005 


\section{Acknowledgments}

I would like to thank Prof. Dr. Harald Neumann for his support and for giving me the opportunity to work in his laboratory on an interesting project and learn many valuable, new and interesting techniques. I am also indebted to Prof. Ralf Heinrich and Prof. Erwin Neher for their support as my thesis committee and for their assistance and help whenever it was needed.

I am greatly thankful to everybody in European Neuroscience Institute in Göttingen and especially for Andreas and Christine for the great environment, help and wonderful time spent together.

I am very grateful for Dagmar Thomitzek and Wiebke Heinrich for providing me with a lot of help and for their friendship since I came to Germany. I would like also to thank Magda for her constant sunny mood.

My special great thanks goes to Neuroimmunology group in ENI: Suzan, Sarita, Sadanand, Heiko, Alex, Uli, Kazuya, Christian, Nadia, Massimiliano and Wenlin for the unforgettable time spent in Göttingen.

I would like to give my great thanks to Alexandra Bohl and Heiko Röhse for their high professional and great technical support during my work.

My great thanks goes as well to the group of Neural Regeneration in Bonn, especially to Anissa who provided me with a great support, as well as to Jessica, Olga, Levent, Yiner, Sergei, Isabella, Katrin, Vera, Jian-Guo, Jens, Mark and Christine.

Finally, I would like to thank my parents for their huge support, for everything what provided a possibility to make this work, and for putting up with me through it all. 
"The important thing in a science is not so much to obtain new facts as to discover new ways of thinking about them"

Sir William Bragg 